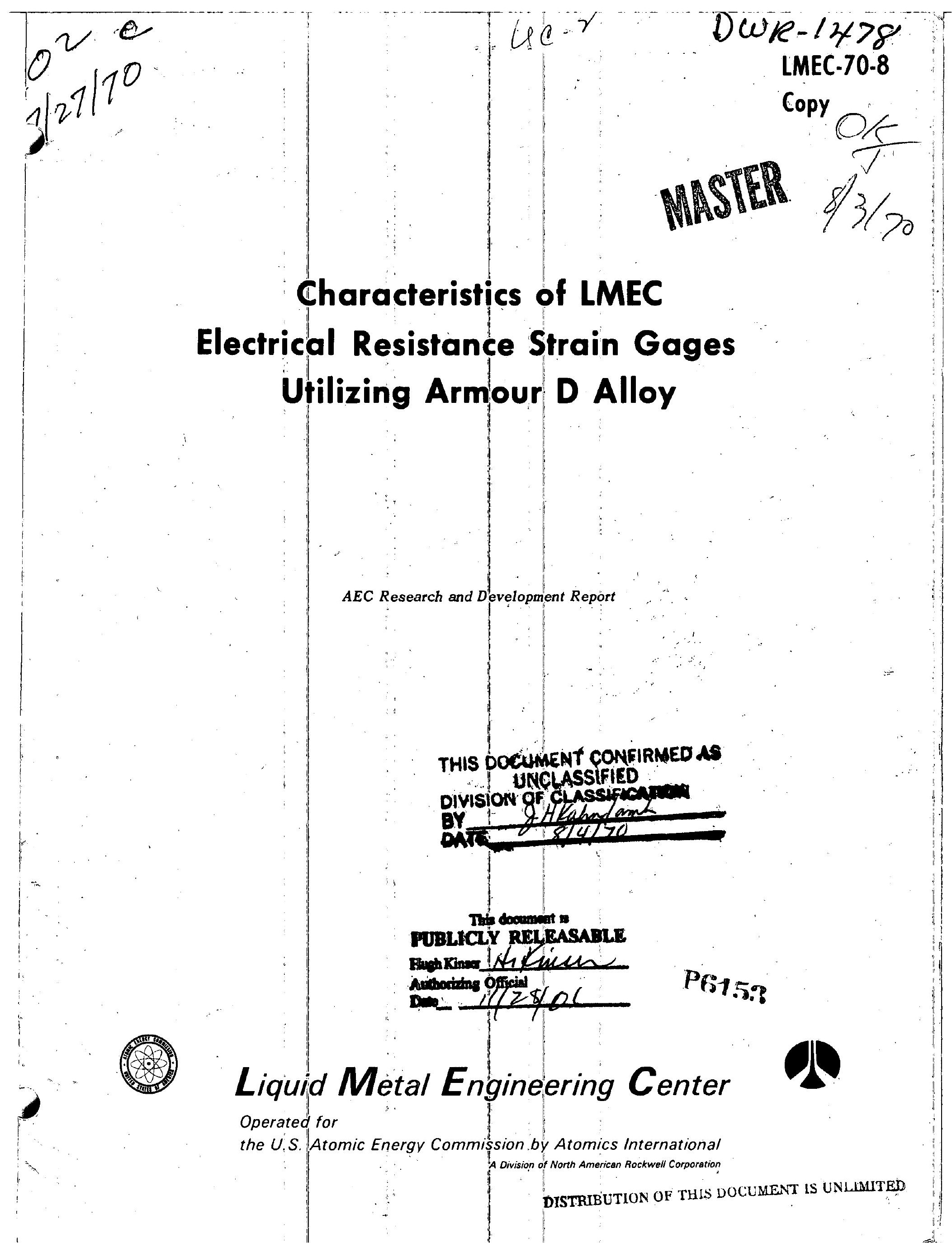




\section{DISCLAIMER}

This report was prepared as an account of work sponsored by an agency of the United States Government. Neither the United States Government nor any agency Thereof, nor any of their employees, makes any warranty, express or implied, or assumes any legal liability or responsibility for the accuracy, completeness, or usefulness of any information, apparatus, product, or process disclosed, or represents that its use would not infringe privately owned rights. Reference herein to any specific commercial product, process, or service by trade name, trademark, manufacturer, or otherwise does not necessarily constitute or imply its endorsement, recommendation, or favoring by the United States Government or any agency thereof. The views and opinions of authors expressed herein do not necessarily state or reflect those of the United States Government or any agency thereof. 


\section{DISCLAIMER}

Portions of this document may be illegible in electronic image products. Images are produced from the best available original document. 
ii.

- This report was prepored as an account of Govemment sponsored work. Neither' the United States, nor the Commission, nor any person acting on behalf of the Commission: A. Makes any warror accuracy, completeness, or usefulness of the information contained in this report, or that the use of any information, apparatus, method, or process disclosed in this report may not infringe privately owned rights; or

B. Assumes any liabilities with respect to the use of, or for damages resulting from the use of information, opparatus, method, or process disclosed in this report.

As used in the above, "person octing on beholf of the Commission" includes ony employee or contractor of the Commission, or employee of such contractor, to the extent that such employee of contractor of the Commission, or employee of such contractor pre. pares, disseminates, or provides access to, any information pursuant to his employment or contract with the Commission, or his employment with such contractor.

.

Printed in the United States of America Available from

Clearinghouse for Federal Scientific and Technical Information National Bureau of Standards, U.S. Department of Commerce

Springfield, Virginia 22151

Price: Printed Copy $\$ 3.00$; Microfiche $\$ 0.65$ 


\title{
Characteristics of LMEC \\ Electrical Resistance Strain Gages \\ Utilizing Armour D Alloy
}

\author{
By \\ M. M. Lemcoe
}

This report was prepared as an account of work
sponsored by the United States Government. Neither
the United States nor the United States Atomic Energy
Commission, nor any of their employees, nor any of
their contractors, subcontractors, or their employees,
makes any warranty, express or implied, or assumes any
legal liability or responsibility for the accuracy, com-
pleteness or usefulness of any information, apparatus,
product or process disclosed, or represents that its use
would not infringe privately owned rights.

\section{Liquid Metal Engineering Center}

Operated for

the U.S. Atomic Energy Commission by Atomics International

A Division of North American Rockwell Corporation

Contract: $\operatorname{AT}(04-3)-700$

Issued: JUN 301970 


\section{DISTRIBUTION}

This report has been distributed according to the category "General, Miscellaneous, and Progress Reports" as given in "Standard Distribution Lists for Unclassified Scientific and Technical Reports," TID-4500. 


\section{CONTENTS}

Page

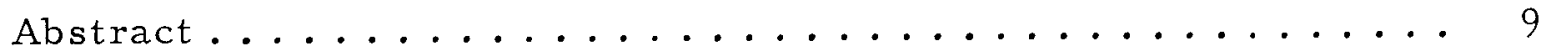

I. Introduction ....................... 11

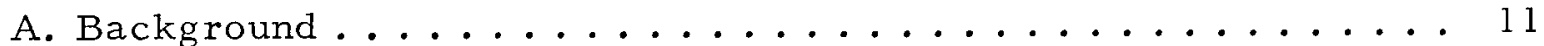

B. Performance Parameters Evaluated .............. 12

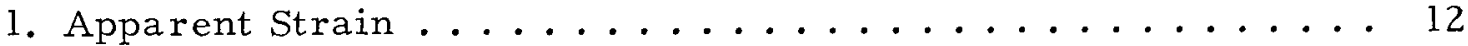

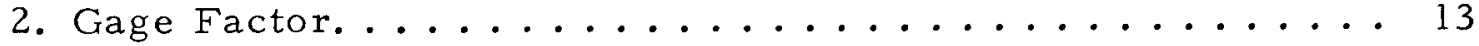

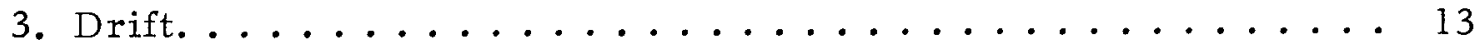

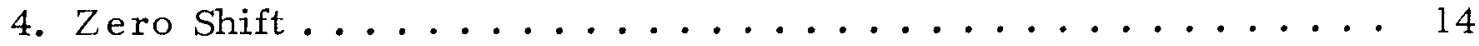

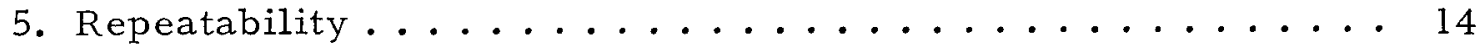

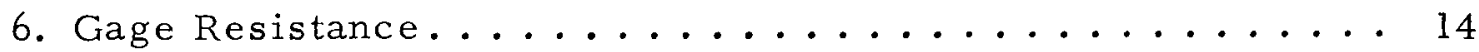

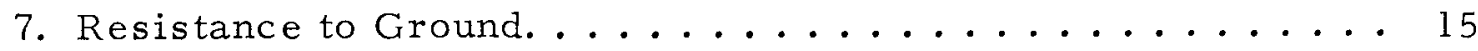

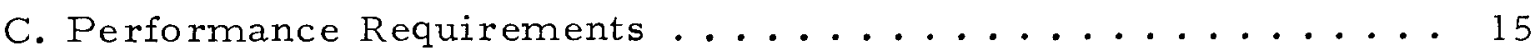

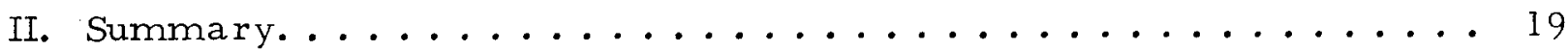

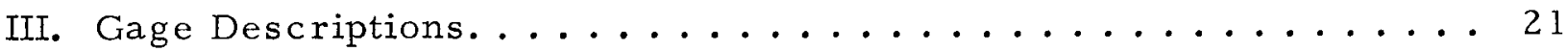

A. Standard LMEC Armour D-Platinum Strain Gage . . . . . . . 21

B. LMEC Armour D-Platinum Gage Fabricated with 2-Mil-

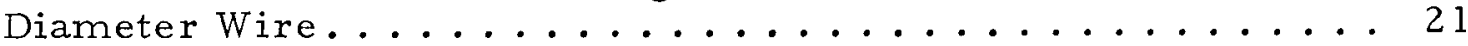

C. LMEC Armour D Gage with Platinum Lead Tabs ......... 24

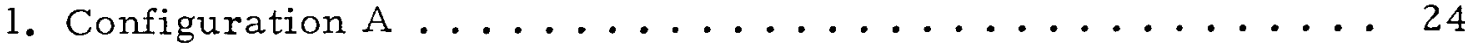

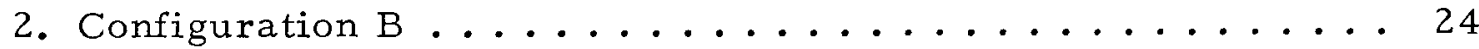

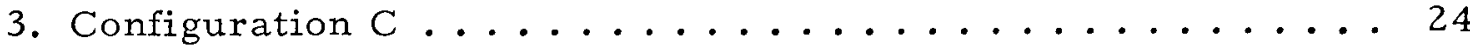

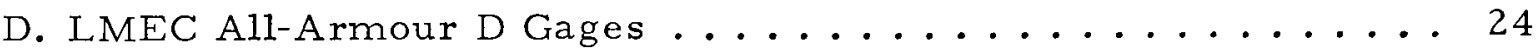

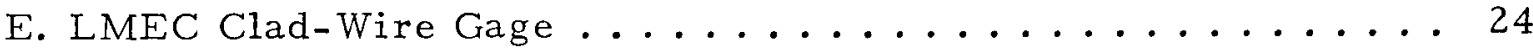

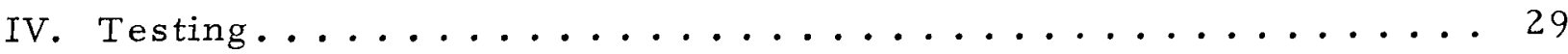

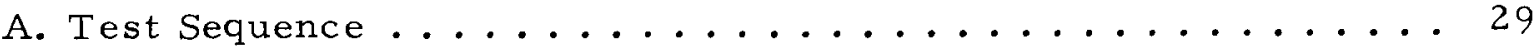

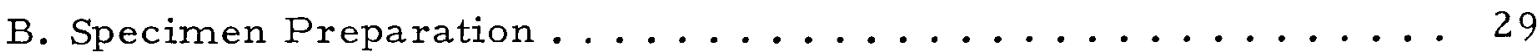

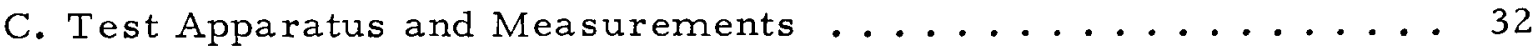

1. Gage Factor and Linearity ................. 32

2. Apparent Strain vs Temperature and Thermal Soak. ..... 35

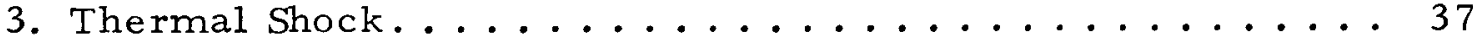

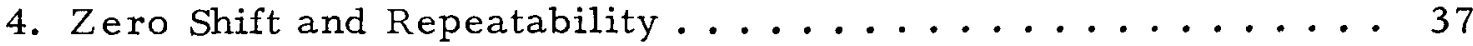

5. Gage Resistance and Resistance-to-Ground

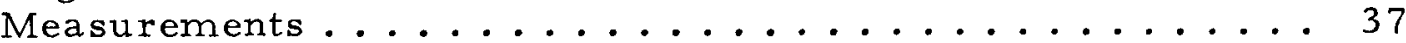

D. Special Calibration Tests, Alco IHX Gages ............440

LMEC $-70-8$ 
V. Data Reduction and Analysis .................. 41

VI. Discussion of Test Results .................... . . 45

A. Standard LMEC Armour D-Platinum Gage. . . . . . . . . 45

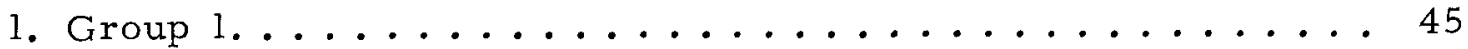

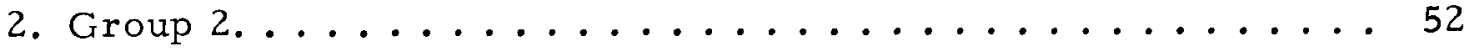

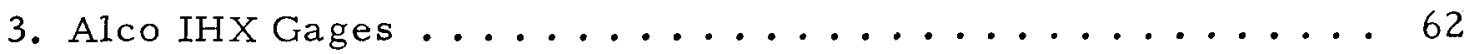

B. LMEC Armour D-Platinum Gage Fabricated with 2-Mil-

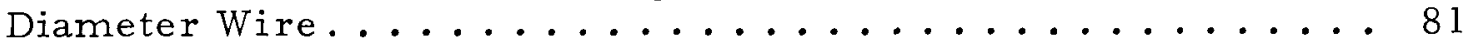

C. LMEC Armour D Gage with Platinum Lead Tabs . . . . . . . 86

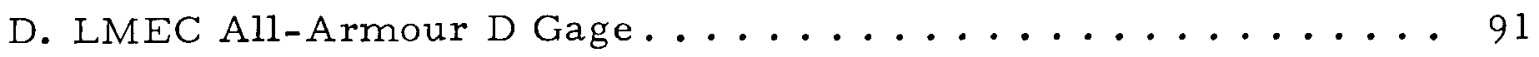

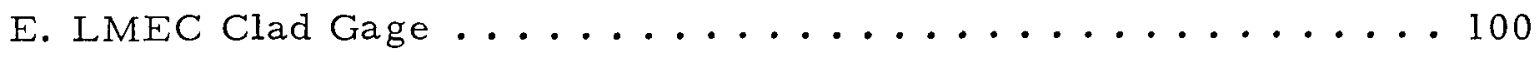

VII. Conclusions and Recommendations...................... 105

\section{TABLES}

1. Summary of Armour-D Gage Characteristics and Performance . . 46

2. Summary of Gage Characteristics and Performance for Standard Armour D-Pt Gages Calibrated for the Alco IHX . . . . . . . . 70

\section{FIGURES}

1. Schematic of Standard LMEC Armour D-Platinum Gage . . . . . 22

2. Steps Involved in Flame-Spray Bonding Armour D-Type Gage . . . 23

3. Schematic of LMEC Armour D Gage with Platinum Lead

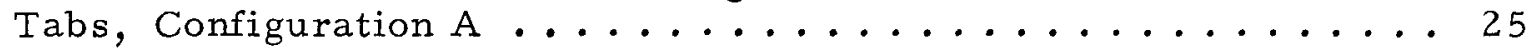

4. Schematic of LMEC Armour D Gage with Platinum Lead

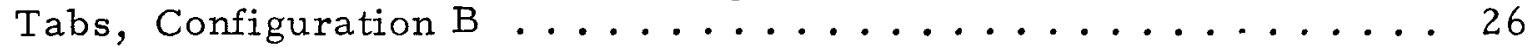

5. Schematic of LMEC Armour D Gage with Platinum Lead

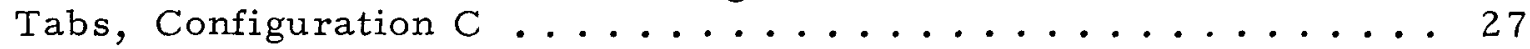

6. Schematic of LMEC Clad Armour D Gages ............. 28

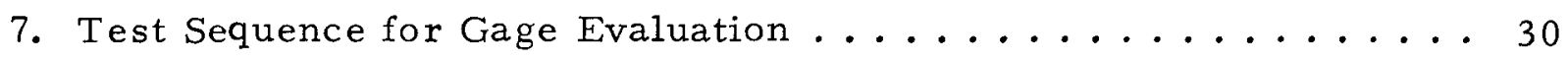

8. Rokide Flame-Spray Equipment in Operation ........... 31

9. Typical Armour D-Type Gage Installation. . . . . . . . . . . 33

10. Constant Moment Beam Calibration Fixture . . . . . . . . . 34

11. Constant Moment Beam Fixture Partially Removed from

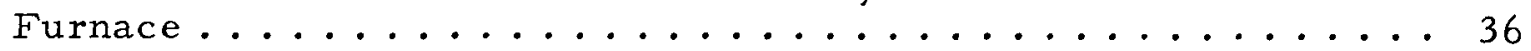




\section{FIGURES}

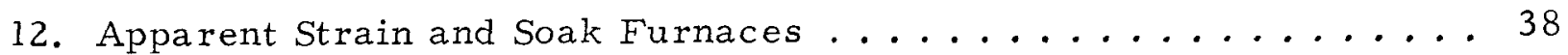

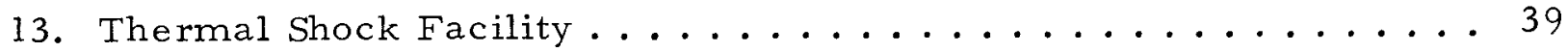

14. Gerber Digital Data Reduction System . . . . . . . . . . . . . 42

15. Apparent Strain vs Temperature, with Confidence and Tolerance Limits for Specimens D-15 and -16, 5 Gages,

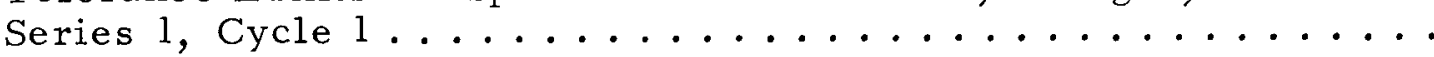

16. Apparent Strain vs Temperature, with Confidence and Tolerance Limits for Specimens D- 15 and -16, 5 Gages,

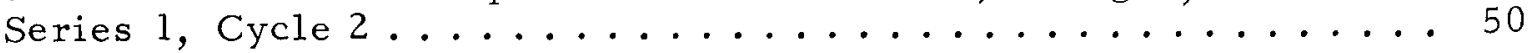

17. Apparent Strain vs Temperature, with Confidence and Tolerance Limits for Specimens D-15 and -16, 5 Gages, Series 1, Cycle $3 \ldots \ldots \ldots \ldots$

18. Gage Factor vs Temperature, with Confidence and Tolerance Limits for Specimens D-15 and - 16, 5 Gages,

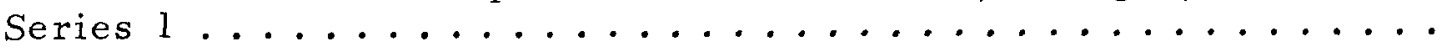

19. Average Measured Strain vs Calculated Strain for

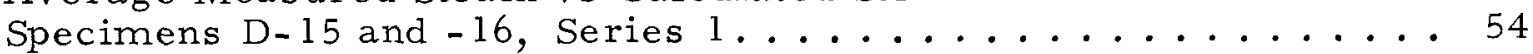

20. Drift vs Time at $1200^{\circ} \mathrm{F}$, with Confidence and Tolerance Limits for Specimens D-15 and $-16 \ldots \ldots 5$

21. Apparent Strain vs Temperature, with Confidence and Tolerance Limits for Specimens D-21 and -22, 6 Gages,

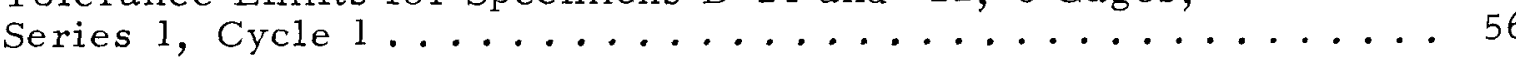

22. Apparent Strain vs Temperature, with Confidence and Tolerance Limits for Specimens D-2l and -22, 6 Gages,

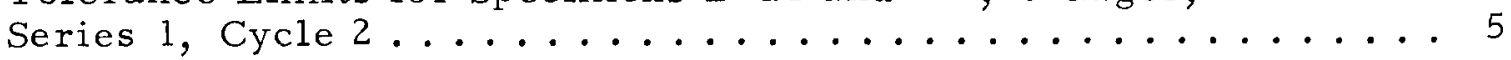

23. Apparent Strain vs Temperature, with Confidence and Tolerance Limits for Specimens D-21 and -22, 6 Gages, Series 1 , Cycle $3 \ldots \ldots \ldots \ldots \ldots$

24. Gage Factor vs Temperature, with Confidence and Tolerance Limits for Specimens D-2l and -22, 6 Gages,

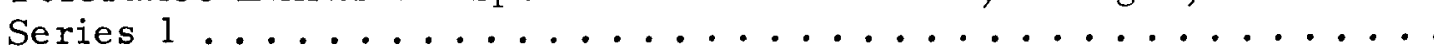

25. Average Measured Strain vs Calculated Strain for

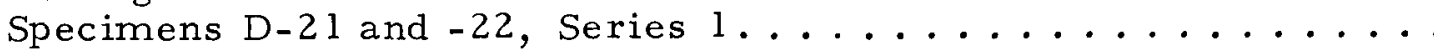

26. Drift vs Time, $1200^{\circ} \mathrm{F}$, with Confidence and Tolerance Limits for Specimens D-21 and $-22 \ldots \ldots \ldots \ldots$

27. Apparent Strain vs Temperature, with Confidence and Tolerance Limits for Specimens D-29, and -32 through

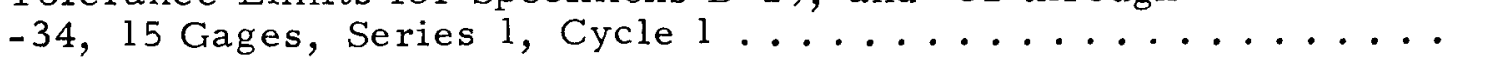

28. Apparent Strain vs Temperature, with Confidence and Tolerance Limits for Specimens D-29, and -32 through $-34,12$ Gages, Series 2 , Cycle $1 \ldots \ldots \ldots \ldots$ 


\section{FIGURES}

Page

29. Apparent Strain vs Temperature, with Confidence and Tolerance Limits for Specimens D-29, and -32 through

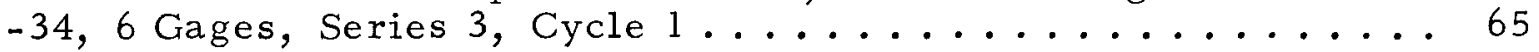

30. Gage Factor vs Temperature with Confidence and Tolerance Limits for Specimens D-29, and 32 through

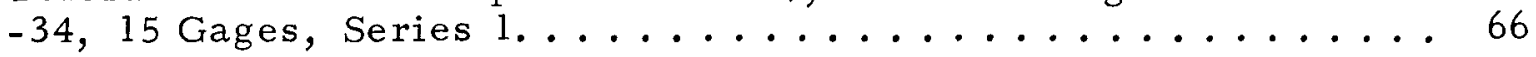

31. Gage Factor vs Temperature, with Confidence and Tolerance Limits for Specimens D-29, and 32 through

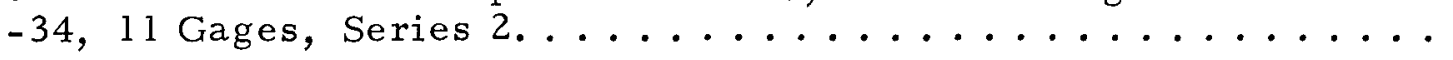

32. Average Measured Strain vs Calculated Strain for Specimens D-32 through -34 , Series 1 and $2 \ldots \ldots \ldots$

33. Drift vs Time at $1200^{\circ} \mathrm{F}$, with Confidence and Tolerance Limits for Specimens D-32 through $-34 \ldots \ldots \ldots$

34. Apparent Strain vs Temperature with Confidence and Tolerance Limits for Specimens D-35 through -37 ,

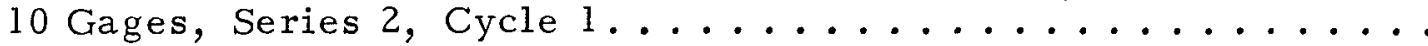

35. Apparent Strain vs Temperature, with Confidence and Tolerance Limits for Specimens D-35 through -37 ,

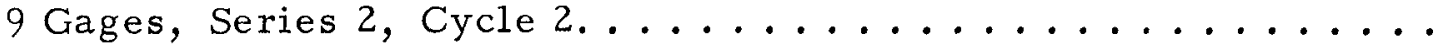

36. Apparent Strain vs Temperature, with Confidence and Tolerance Limits for Specimens D-35 through -37,

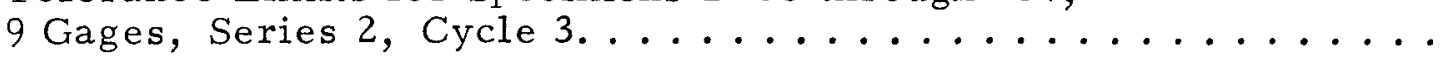

37. Gage Factor vs Temperature with Confidence and Tolerance Limits for Specimens D-35 through -37,

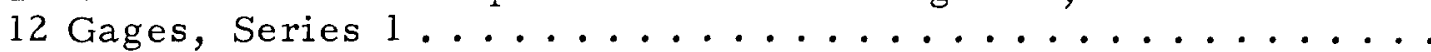

38. Average Measured Strain vs Calculated Strain for

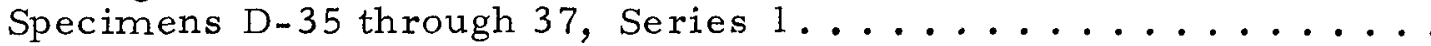

39. Apparent Strain vs Temperature, with Confidence and Tolerance Limits for Specimens AT- 1 through 6,

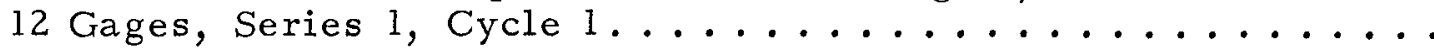

40. Apparent Strain vs Temperature, with Confidence and Tolerance Limits for Specimens AT-1 through -6,

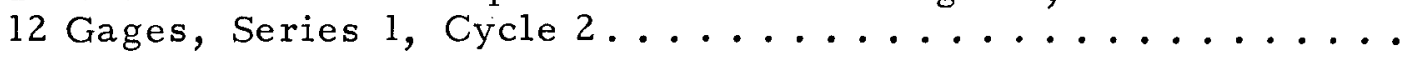

41. Apparent Strain vs Temperature, with Confidence and Tolerance Limits for Specimens AT-1 through -6,

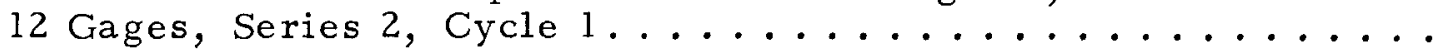

42. Apparent Strain vs Temperature, with Confidence and Tolerance Limits for Specimens AT-1 through -6,

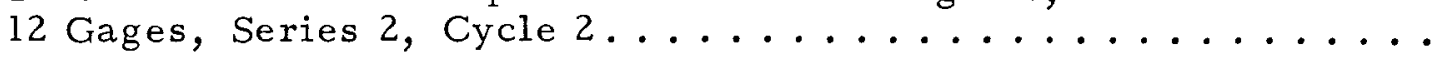

43. Gage Factor vs Temperature, with Confidence and Tolerance Limits for Specimens AT-l through -6,

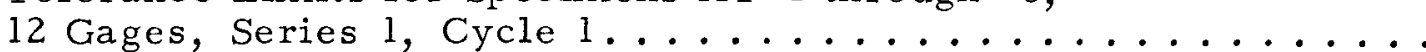


44. Gage Factor vs Temperature, with Confidence and Tolerance Limits for Specimens AT-1 through -6,

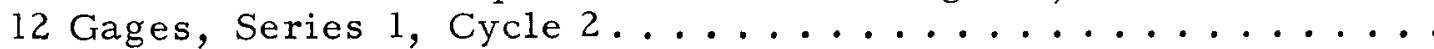

45. Gage Factor vs Temperature, with Confidence and Tolerance Limits for Specimens AT-1 through -6,

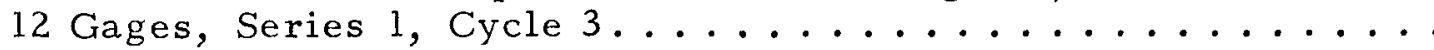

46. Average Measured Strain vs Calculated Strain for

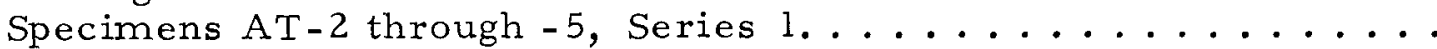

47. Average Apparent Strain vs Temperature for Specimen D-23,

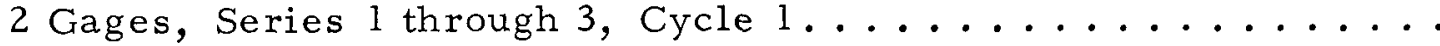

48. Gage Factor vs Temperature for Specimen D-23,

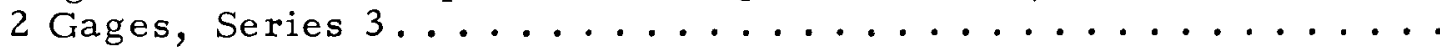

49. Average Measured Strain vs Calculated Strain, Specimen D-23, Series 1 and $2 \ldots \ldots \ldots$

50. Drift vs Time at $1200^{\circ} \mathrm{F}$ for Specimen D-23 ........... 90

51. Average Apparent Strain vs Temperature for Specimen D-25, 4 Gages, Series 1 through 3, Cycle 1.............. 92

52. Gage Factor vs Temperature for Specimen D-25, 4 Gages,

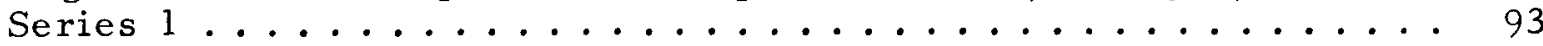

53. Average Measured Strain vs Calculated Strain,

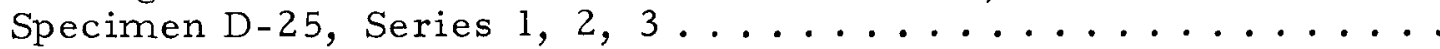

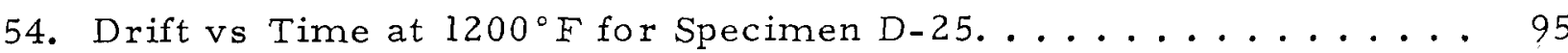

55. Apparent Strain vs Temperature, with Confidence and Tolerance Limits for Specimens D-19 and -20 ,

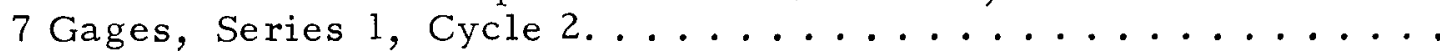

56. Apparent Strain vs Temperature, with Confidence and Tolerance Limits for All-Armour D Specimens D- 19 and -20,

6 Gages, Series 2 , Cycle $1 \ldots \ldots \ldots \ldots$

57. Apparent Strain vs Temperature, with Confidence and Tolerance Limits for Specimens D-19 and -20, 5 Gages,

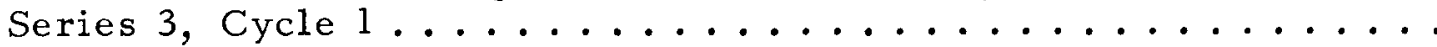

58. Gage Factor vs Temperature, with Confidence and Tolerance Limits for Specimens D-19 and -20,

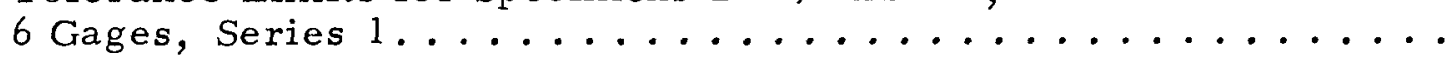

59. Average Measured Strain vs Calculated Strain for Specimens $D-19$ and -20 , Series 1 and $2 \ldots \ldots \ldots$

60. Drift vs Time, $1200^{\circ} \mathrm{F}$, with Confidence and Tolerance Limits for Specimens D-19 and $-20 \ldots \ldots \ldots$ 


\begin{abstract}
Results of a development and evaluation study are presented for several high-temperature straingage configurations which use Armour D alloy $(70 \mathrm{Fe}-20 \mathrm{Cr}-10 \mathrm{Al})$ as the primary element, and platinum as a temperature-compensating element in the composite gage configurations. The Armour D gage concepts appear promising for applications up to $1200^{\circ} \mathrm{F}$; particularly when used on austenitic stainless-steel components.
\end{abstract}




\section{INTRODUCTION}

\section{A. BACKGROUND}

The electrical resistance strain gage has been accepted and used extensively by engineers and scientists to obtain solutions, otherwise unobtainable, to stress, deformation, or instrumentation problems. These gages have been used to translate hydraulic and mechanical phenomena into electric signals which provide a reliable and relatively accurate measure of such parameters as load, pressure, torque, acceleration, flow, level, and strain. From the measured strains, stresses may be computed by means of Hooke's generalized stress-strain relations. There are literally hundreds of different sizes, shapes, and types of gages commercially available for use under a wide spectrum of environmental conditions, ranging from the cryogenic to the high-temperature regime.

If these gages are installed by competent and experienced technicians, and sound technical judgement is exercised in the selection of the gage type (in terms of the anticipated environmental conditions), good accuracy can be expected at temperatures up to $900^{\circ} \mathrm{F}$, in most situations. However, above $900^{\circ} \mathrm{F}$, reliable commercial gages are not available for testing sodium or other liquid metal components. As a consequence, other sources were investigated for gages showing promise for applications up to $1200^{\circ} \mathrm{F}$.

Under contract with the Aeronautical Structures Laboratory of the Naval Air Materiel Center, Philadelphia, Pennsylvania, the Armour Research Foundation (now called IIT Research Institute), Chicago, Illinois, developed several ironchrome-aluminum high-temperature strain gage alloys. Among those investigated, was Armour D alloy, having a nominal composition of $\mathrm{Fe}-20 \mathrm{Cr}-10 \mathrm{Al}$. Composite-wire gages were fabricated by the General Electric Co., Evendale, Ohio, utilizing this alloy and platinum. They developed a special technique for flattening the wire to make the grid retain its configuration after winding. These gages were primarily fabricated for their own use.

Because of the limited availability of the Armour D gages, the LMEC subsequently proceeded to fabricate its own Armour D-platinum gages and other gage types utilizing Armour D alloy. A technique was developed which eliminated the need for flattening the wire, and a sufficient number of the gages were

\section{LMEC - 70-8}


fabricated for evaluation and other purposes. This report contains the pertinent results from that evaluation, in addition to the procedures used to fabricate the gages.

\section{B. PERFORMANCE PARAMETERS EVALUATED}

Of the many gage parameters, the more important ones for measuring performance and accuracy of high-temperature strain gages are apparent strain, gage factor, drift, zero shift, and repeatability. An evaluation procedure was developed which permitted measurement of these parameters as a function of time and temperature. Although these parameters are frequently used to describe gage characteristics, they are defined here and discussed in the interest of clarity and completeness.

1. Apparent Strain

Apparent strain is the spurious or false signal induced by changes in gage resistivity caused by temperature and a mismatch between the coefficients of thermal expansion of the gage filament and the material to which the gage is bonded. Mathematically, it may be expressed as:

$$
\epsilon_{\text {app }}=\left[\left(\alpha_{\mathrm{m}}-\alpha_{\mathrm{g}}\right)+\frac{\mathrm{TC}}{\mathrm{GF}}\right] \Delta \mathrm{T}
$$

where

$$
\begin{aligned}
\epsilon_{\text {app }}= & \text { Apparent strain } \\
\alpha_{\mathrm{m}}= & \text { Coefficient of thermal expansion of the structure to which the gage } \\
& \text { is bonded } \\
\alpha_{\mathrm{g}} & =\text { Coefficient of thermal expansion of the gage filament } \\
\mathrm{GF} & =\text { Gage factor } \\
\mathrm{TC} & =\text { Temperature coefficient of resistance } \\
\Delta \mathrm{T} & =\text { Temperature change. }
\end{aligned}
$$

In short, it is that portion of the indicated strain which is the algebraic difference between the strain indicated by the readout equipment (hereinafter referred to as indicated strain) and the real strain being measured on the surface of the

\section{LMEC - 70-8}


test article. Like unit strain, it is a dimensionless quantity which is generally designated in units of millionths of an inch per inch $\left(\mu_{\varphi}\right.$ in./in.), or simply microstrain $(\mu \epsilon)$.

Since the apparent strain must be subtracted from the indicated strain before the real or true strain can be determined, it is desirable that the magnitude of the apparent strain of a gage be as small and predictable as possible, in the interest of accuracy. It is not within the scope of this report to discuss, in general, strain gage circuits or ways in which apparent strain may be minimized or eliminated by special resistance networks. Many references are available on this subject, and the reader is referred to the pertinent literature. The apparent strain may be substantially reduced by using a dummy gage in the adjacent leg of the bridge; or, in the case of certain gages, by using a temperature compensation resistor of a specified value in series with the active gage. Where it is not feasible to use a dummy gage or a temperature compensation resistor, one must then have available the apparent strain vs temperature curve for the gage.

\section{Gage Factor}

Gage factor is the ratio of the unit change in gage resistance to the unit change in strain in the metal to which the gage is bonded. It is dimensionless, and is a measure of the gage's sensitivity. It varies with temperature and with environmental and life exposure. To take quantitative strain measurements, the gage factor must be known.

\section{Drift}

Drift is the change in indicated strain of a gage, with time, in a stressfree condition, under constant temperature. It is generally expressed as a total drift (in units of microstrain per a given time interval), or as a drift rate (in units of microstrain per unit time). Like apparent strain, drift introduces an error which must be accounted for. The error is of particular significance where measurements over extended periods of time at temperature a re involved. Its effect may be minimized by using a dummy gage, or by prestabilizing the gage for a minimum of $16 \mathrm{hr}$ at a temperature above the maximum test temperature. If it is not feasible to do this on the test article, the gage (in many instances) can be stabilized in a laboratory furnace. Drift may also be accounted

\section{LMEC-70-8}


for by applying a correction obtained from the drift vs time curve for the gage at the temperature in question.

\section{Zero Shift}

This is a general term, often related to hysteresis effects, associated with mechanical or thermal cycling.

\section{a. Mechanical Zero Shift}

Mechanical zero shift is the difference in the indicated strain reading between an increasing and a decreasing mechanical strain cycle (generally taken at zero mechanical strain) under constant temperature conditions.

b. Thermal Zero Shift

Thermal zero shift is the difference in the indicated strain reading between an increasing and a dec reasing thermal cycle (generally referred to ambient temperature) under constant (including zero) mechanical strain conditions. This gage parameter is of particular importance where repeated transient strain measurements are made, since the errors arising from zero shift can be cumulative. Zero shift may be minimized by strain and/or temperature cycling the gage slightly above the maximum temperature or strain level it will "see"during testing. Generally, three cycles are sufficient to stabilize a good gage. Where it is feasible to accomplish this on the test article, the gage may often by cycled in a laboratory furnace.

\section{Repeatability}

Repeatability is the ability of the gage to faithfully reproduce the same indicated strain vs temperature curves, or indicated strain vs applied mechanical strain curves, when repeatedly subjected to the same set(s) of conditions. Without good repeatability, precalibration of a gage may not be meaningful, since the gage characteristics then become time dependent and also dependent upon the number of cycles to which the gage is subjected. Good gage repeatability and small zero shift go hand in hand. Errors stemming from lack of repeatability may be minimized by prestabilization, cycling, and the use of a dummy or temperature compensation resistor. Good repeatability is essential where accurate strain measurements must be made under repeated transient conditions.

\section{Gage Resistance}

This is the resistance of the gage, as determined by an accurate ohmmeter or a Wheatstone bridge, and is usually measured at room temperature. The manufacturer generally provides such information, and guarantees the resistance of each gage to be within a given tolerance. The exact resistance of a 
gage is generally not important, provided the gage factor is known. However, uniformity of gage resistance is of concern, where multichannel signal conditioning and readout equipment is involved.

7. Resistance to Ground

This characteristic is sometimes referred to as the leakage resistance. It is the resistance between the strain gage lead wires and the material to which the gage is bonded. For room-temperature measurements, this parameter is of little or no consequence for gages that have been properly installed. However, at elevated temperatures, the ceramic cement or Rokide (used to bond the gage to the structure) becomes conductive, electrically, and introduces a shunting effect, which in turn results in a spurious strain indication. Fortunately, for a good gage that has been properly installed, the magnitude of this error is small. Mathematically, it can be shown that the change in gage factor due to this shunting effect is negligible, and that the resistance to ground at temperature would have to drop to $1 \mathrm{M} \Omega$ to produce an error of $\sim 30 \mu \epsilon$, assuming a gage factor of 4 and a gage having a resistance of $120 \Omega$. For a $10 \mathrm{M} \Omega$ resistance to ground, the error would be only $3 \mu \epsilon$.

\section{PERFORMANCE REQUIREMENTS}

Ideally, gages used for steady-state and transient testing of Liquid Metal Fast Breeder Reactor (LMFBR) components at elevated temperatures should meet the following requirements:

1) Be available commercially at a reasonable price with reasonable delivery schedules.

2) Be self-temperature compensating.

3) Show little variation in gage factor with temperature changes.

4) Be stable, driftwise, at temperatures up to the maximum test temperature.

5) Exhibit a minimum amount of apparent strain over the operating temperature range.

6) Be uniform, from gage to gage, within close limits.

7) Exhibit little hysteresis or zero shift with temperature or strain cycling.

\section{LMEC-70-8}


8) Be linear, over a large strain range.

9) Exhibit good repeatability when subjected to the same time-temperature strain history.

10) Have good mechanical and thermal fatigue or shock resistance.

11) Be fabricated from materials having the same, or nearly the same, coefficient of thermal expansion as the test article.

12) Be available in gage lengths down to at least $1 / 8 \mathrm{in.}$

13) Have a protective covering, to avoid damage due to handling or the effects of moisture or corrosion.

14) Be capable of being installed in the field, in such a manner that a reliable bond is assured for the duration of the test.

15) Be of such a design that the strain sensing element "sees" the same temperature as the test article material to which it is attached, with little or no time lag.

The ideal requirements are enumerated to describe an ultimate goal for strain gage evaluation and development, even though all items are not achievable. The specific performance requirements which were the criteria for the gages described in this report are:

1) They must be capable of withstanding temperatures in the field as high as 900 to $1200^{\circ} \mathrm{F}$, for periods of hundreds of hours, without marked deterioration from oxidation, moisture, or temperature. In other engineering applications, such as those involving the measurement of strains in rocket engines, turbine blades, supersonic aircraft, or space vehicles, the temperatures are either lower than $1200^{\circ} \mathrm{F}$ or, if greater, the strain measurements are of relatively short duration, sometimes of the order of a few seconds or less. Also, in many instances only the dynamic peak-to-peak strain amplitudes are of primary interest; the steady-state component being of little or no concern. This simplifies matters considerably, in that the effects of drift or zero shift cause little or no error in the peak-to-peak values. In loop testing, where both the steady-state and transient strain magnitude are of interest, the effects of drift or zero shift cannot, in general, be ignored. 
2) They must be capable of withstanding repeated transient cycles. During loop transient operations, including startups, shutdowns, simulated "scrams," or emergency conditions, the gages are subjected to low cycle mechanical and thermal fatigue and subsequent cumulative damage which may ultimately lead to failure of the gage.

3) They must be capable of accommodating large thermal stresses, including the thermal stress generated within the gage itself. A majority of the sodium components are fabricated from austenitic stainless steel which, unfortunately, has a coefficient of thermal expansion which differs substantially from many of the alloys common to commercial high-temperature gages. This mismatch produces high thermal stresses in the strain-sensing element of the gage at temperatures in the neighborhood of 1000 to $1200^{\circ} \mathrm{F}$; these stresses, upon repeated cycling, can result in early failure of the gage.

4) They must be resistant to corrosion. Occasions may arise where gages are installed, then covered with thermal insulation, and left at ambient temperature for prolonged periods of time. Unless the gage is sealed or otherwise protected against moisture infiltration, corrosion may occur.

5) They must be amenable to field installation on curved surfaces. Most sodium components are of such large size and mass that it is not feasible to cure cement-bonded foil gages, rated for use up to $1200^{\circ} \mathrm{F}$, because they require curing at $600^{\circ} \mathrm{F}$ for at least $1 \mathrm{hr}$. On laboratory specimens, this is done with little difficulty with the use of infrared heating lamps or by curing the specimen in a laboratory oven.

6) They must be capable of measuring strain with sufficient accuracy that stresses computed from the strains are at least as accurate as those predicted by theory. 


\section{SUMMARY}

This report contains the results of a development and evaluation effort pertaining to several high-temperature strain gage configurations utilizing Armour D alloy $(70 \mathrm{Fe}-20 \mathrm{Cr}-10 \mathrm{Al})$ as the primary element, and platinum as a temperature-compensating element in the composite gage configurations.

It was the objective of this effort to develop a strain gage capable of operating in air for extended periods of time at temperatures as high as $1200^{\circ} \mathrm{F}$, under steady-state and transient conditions imposed during the loop testing of LMFBR sodium components. This effort was initiated after it was clearly established by laboratory evaluation of commercial gages that the re were no commercial gages available which were satisfactory for operations above $900^{\circ} \mathrm{F}$.

Since there is no feasible way of precalibrating each gage, the gage characteristics (apparent strain vs temperature, gage factor vs temperature, and drift vs time) must be determined on the basis of statistical sampling techniques. The 95\% confidence limits and 95\%-90\% tolerance limits for the gages evaluated in this study, including the calibration gages (D-35 through -37 , and $\mathrm{AT}-1$ through -6), indicate gage variations which are larger than permissible for accurate strain measurements on LMFBR components. This is evident from mere inspection of the confidence and tolerance limits and percent deviations for apparent strain, gage factor, and drift; a detailed error analysis is unnecessary.

On the basis of the results obtained during this study, it is believed that the Armour D-type gage concepts herein described show promise for applications up to $1200^{\circ} \mathrm{F}$; particularly when used on austenitic stainless-steel components, because of the closer match in coefficients of thermal expansion than for the platinum-tungsten alloys used in some commercial gages. However, before the full potential of the Armour D alloy can be realized, the additional development work now in progress will have to be completed, and the end products of this work carefully evaluated. 


\section{GAGE DESCRIPTIONS}

A. STANDARD LMEC ARMOUR D-PLATINUM STRAIN GAGE (Specimens D-15, $-16,-21,-22,-29,-32$ through -37 , and AT-1 through -6)

This gage type is comprised of three elements as shown in Figure 1. The two outer elements are l-mil-diameter platinum wire. The central element is 1-mil-diameter Armour D wire. The elements are electrically in series. Armour D alloy has a negative temperature coefficient of resistivity (TC); platinum has a positive $\mathrm{TC}$. By varying the ratio of the number of turns of the Armour D wire to the platinum wire, one can temperature compensate or modify the apparent strain vs temperature characteristics of the gage. The gages are wound with a nominal gage length of 5/32 in., although gages of any desired length, within reason, can be wound with the fixture used to fabricate these gages. The nominal room temperature resistance of the gage varies from 148 to $164 \mathrm{ohms}$. The lead tabs are made from Nichrome V ribbon ( $1 / 64 \times 0.002$ in.) cut to a $1 \mathrm{in.}$ length. The tabs are spot-welded to the end of each platinum element. The carrier for the wire grid is $3 \mathrm{M}$ Tape No. 1132 , which has three "windows" to permit flame-spray bonding of the gage to the substrate during the tackcoating operation (see Figure 2).

It should be noted that the gages on specimens D-35 through -37 represented statistical samples for obtaining calibration data for similar gages installed on the Alco intermediate heat exchanger (IHX), which is being tested at the SCTI facility of the LMEC. These gages were fabricated by LMEC technicians. The gages on specimens AT-1 through -6 were fabricated by Dentronics, Inc., Hackensack, N. J., in accordance with LMEC specifications.

\section{B. LMEC ARMOUR D-PLATINUM GAGE FABRICATED WITH 2-MIL-DIAMETER WIRE (D-23)}

The gage is similar in construction to the gage described above except that the Armour $D$ and platinum elements are made from 2-mil rather than 1 -mildiameter wire. The heavier 2-mil wire was used to determine whether it would result in a superior gage to that produced from l-mil-diameter wire. 


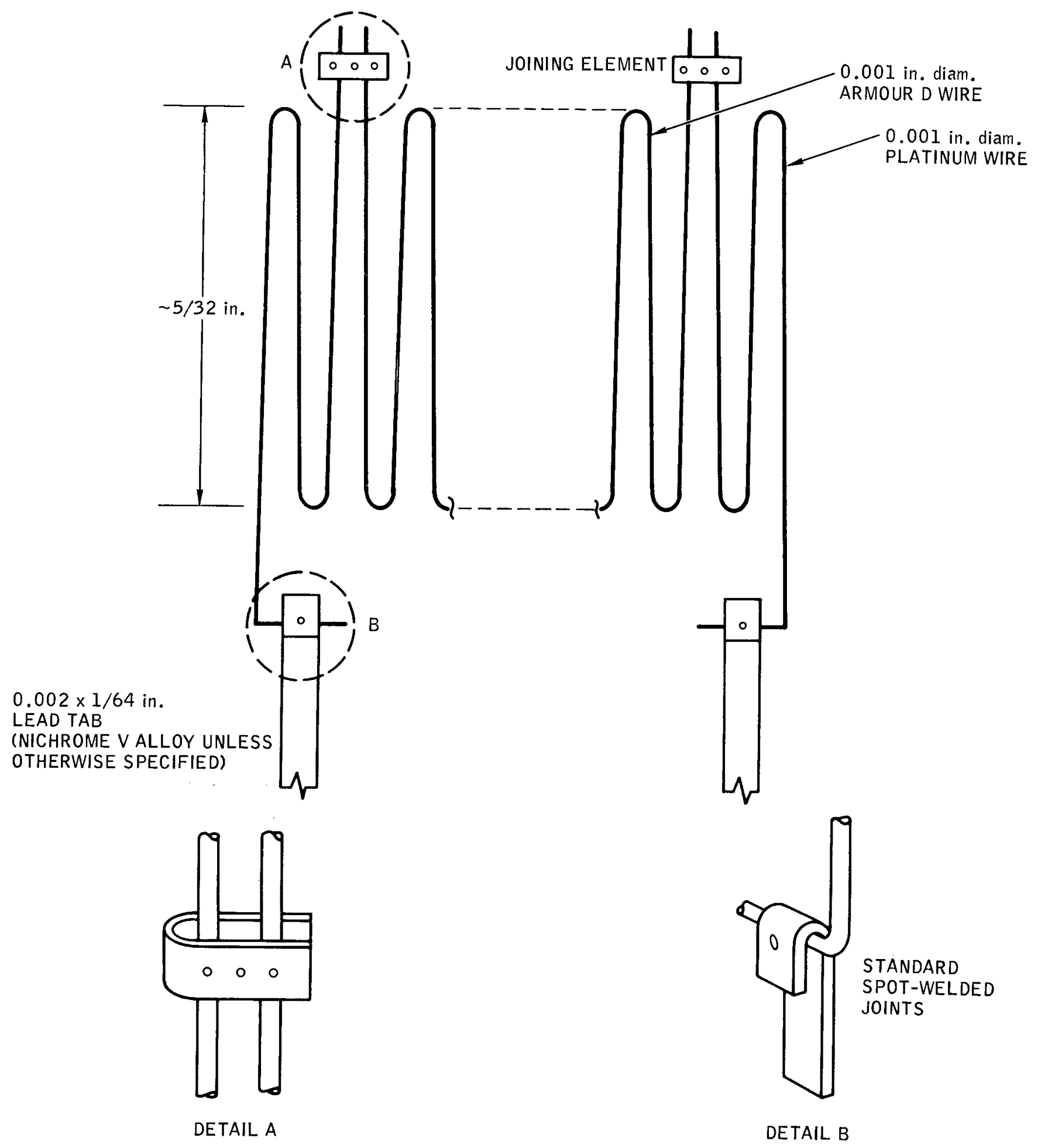

7693-55121

Figure 1. Schematic of Standard LMEC Armour D-Platinum Gage 


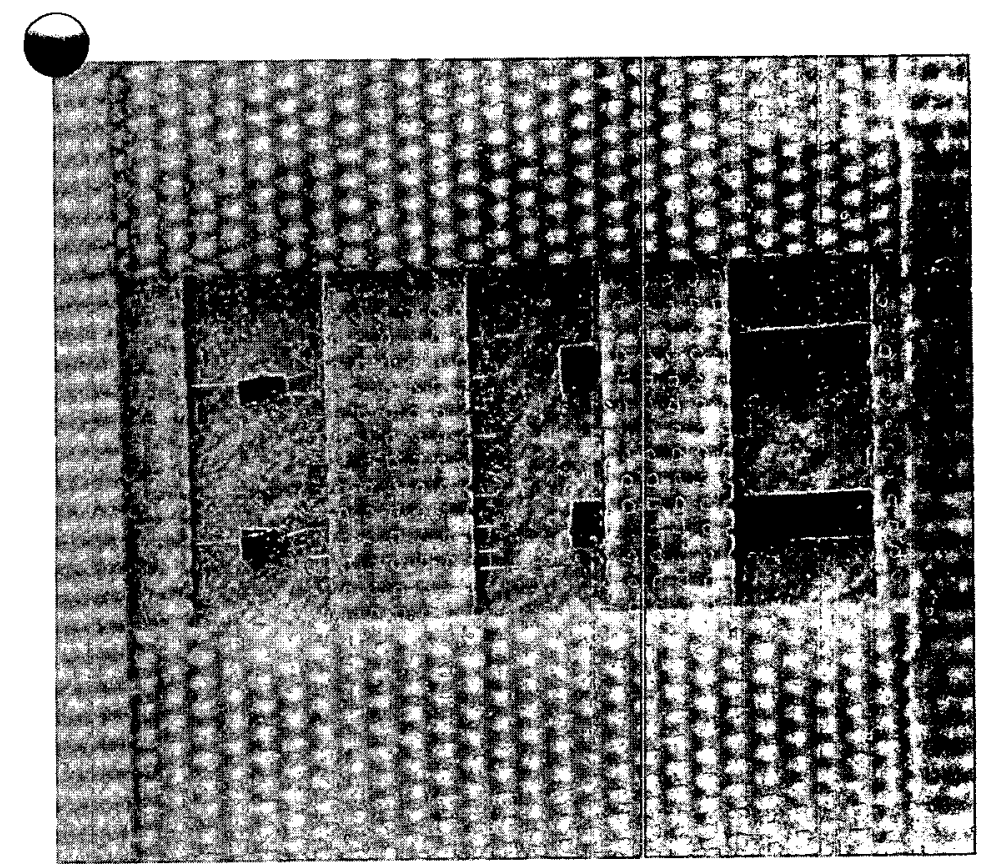

(a) Gage Taped in Position

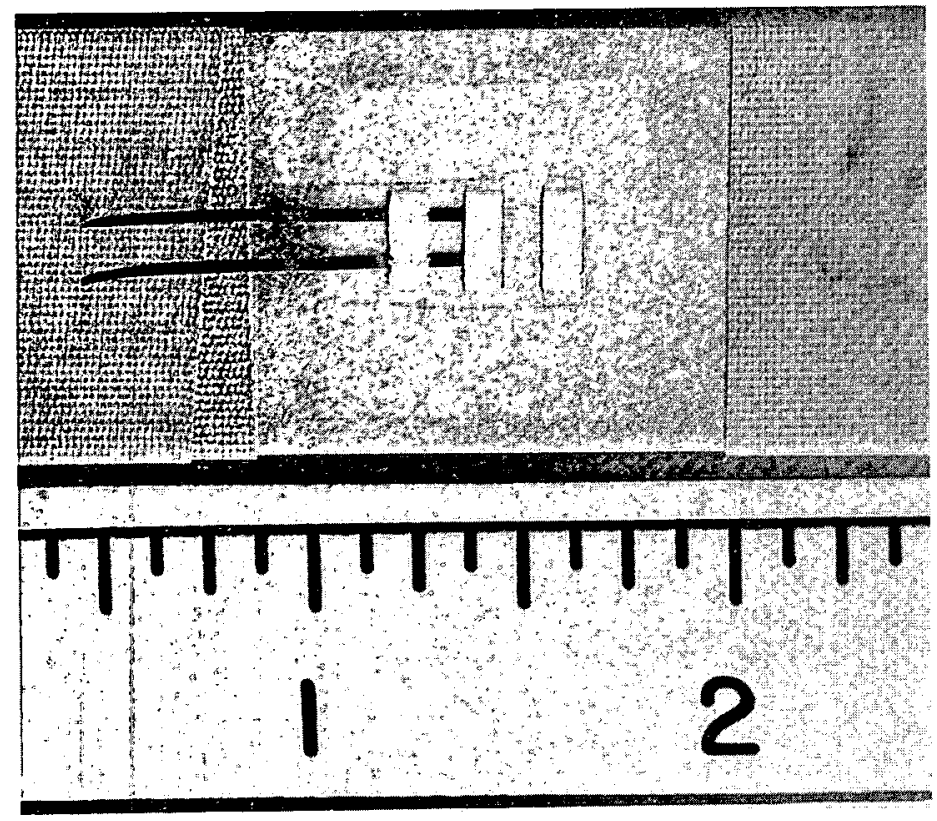

(b) After Application of "Tack Coat"

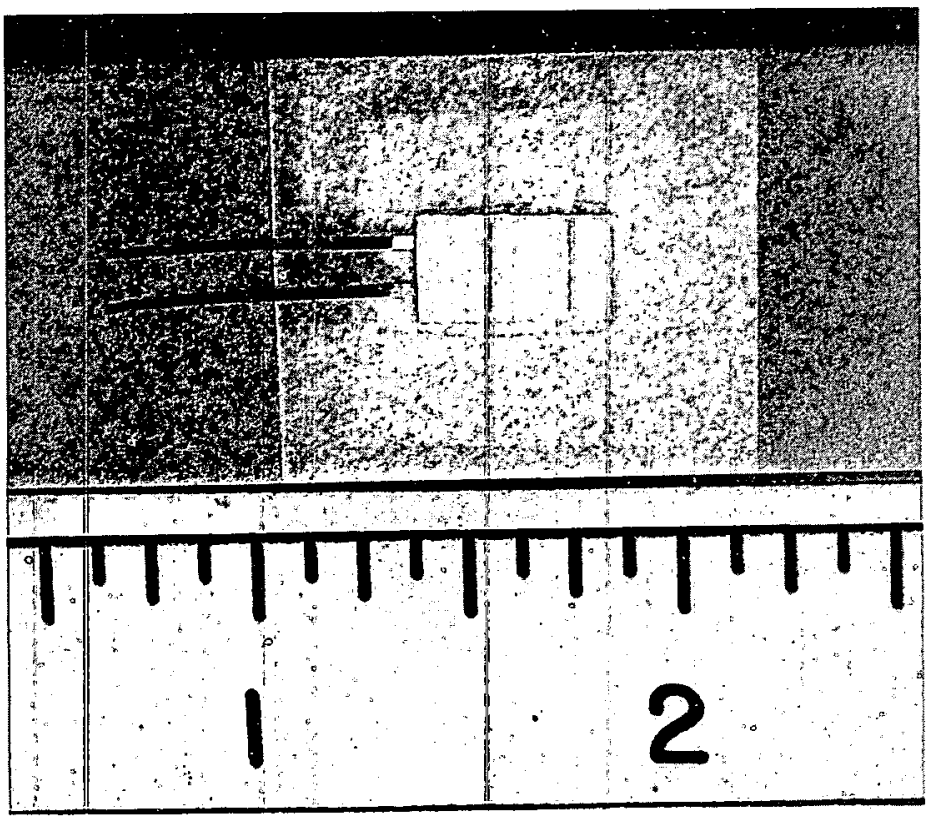

(c) After Application of Final Coat

Figure 2. Steps Involved in Flame-Spray Bonding Armour D-Type Gages

\section{LMEC-70-8}


C. LMEC ARMOUR D GAGE WITH PLATINUM LEAD TABS (D-25 through -27)

1. Configuration $A(D-26)$

This gage is comprised of a 1-mil-diameter Armour D wire grid, and two platinum elements which serve the dual purpose of lead tabs and temperaturecompensating elements (see Figure 3). The platinum elements are die cut from 1/2-mil-thick platinum foil and are spot-welded to the ends of the Armour D element. This gage design eliminates the joints between the Armour $D$ and platinum elements, as well as the two platinum wire elements, while retaining the characteristics of a temperature-compensating gage. The temperaturecompensation characteristics may be altered by varying the number of wire loops, or size of the tab. The gage length is nominally 5/32 in., and the nominal room temperature gage resistance is approximately $132 \mathrm{ohms}$.

\section{Configuration $\mathrm{B}(\mathrm{D}-27)$}

This gage has a configuration similar to configuration $A$, except that the tabs are in the "mirror image" position to produce a more compact gage configuration (see Figure 4).

\section{Configuration $\mathrm{C}(\mathrm{D}-25)$}

This gage has a configuration similar to configuration $\mathrm{A}$, except that the die-cut platinum tabs are replaced with $1 / 64 \times 0.002-i n$. platinum ribbon (see Figure 5).

\section{LMEC ALL-ARMOUR D GAGES (D-13, - 19, -20)}

This gage has a configuration similar to configuration $C$ above, except that $1 / 64 \times 0.002-i n$. Nichrome V or Hoskins Alloy 875 ribbon tabs are used instead of platinum. The gage is essentially nontemperature compensated. The gage length is nominally 5/32 in., and the nominal room temperature gage resistance, except for D-13, is 128 to 156 ohms.

E. LMEC CLAD-WIRE GAGE (D-24, -30)

These are single-element gages made from nickel-or platinum-clad Armour $D$ wire, with $1 / 64 \times 0.002-i n$. Nichrome V lead tabs. The clad wire was made by Englehard Industries, of Carteret, N. J., the Armour D rod furnished by the 


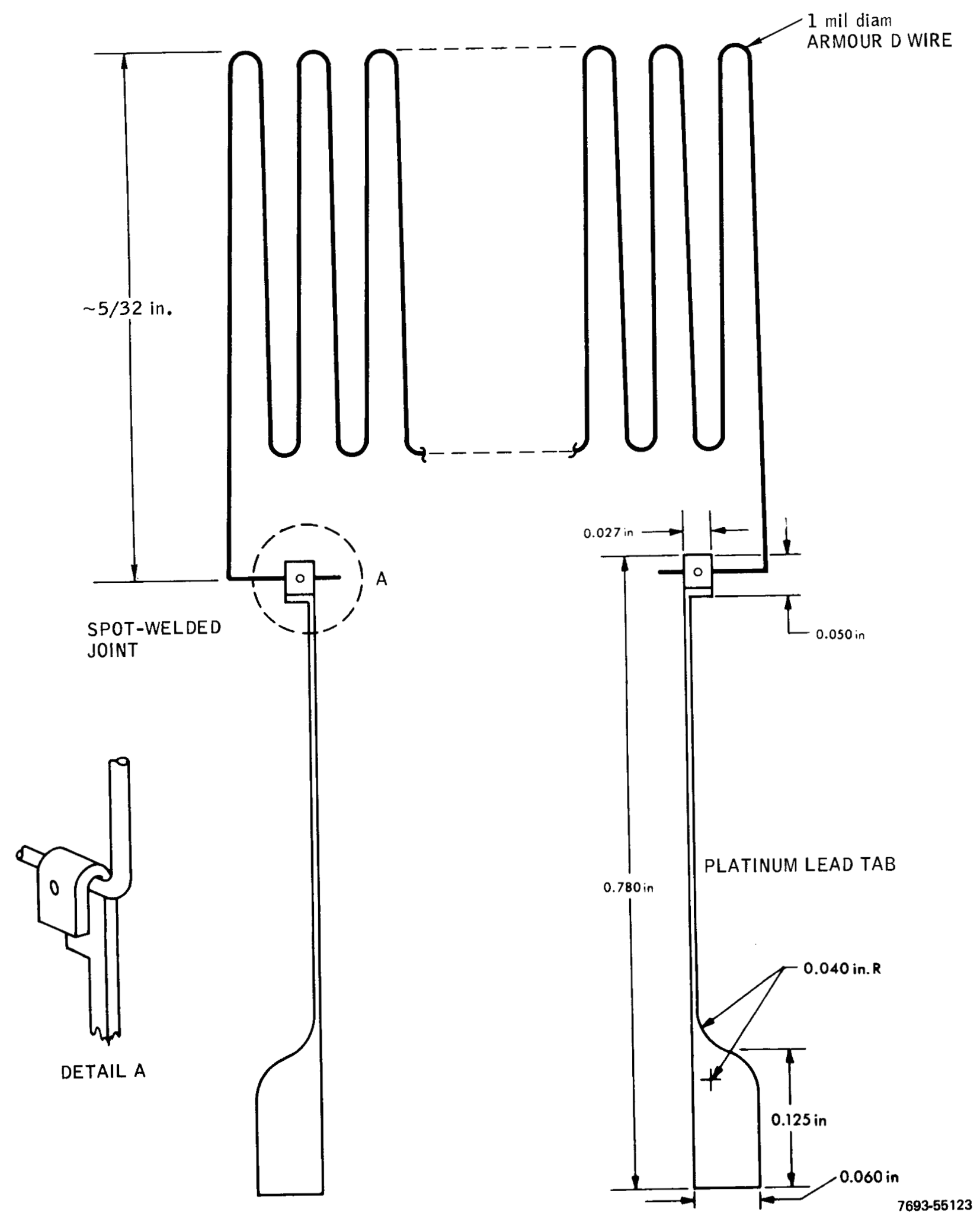

Figure 3. Schematic of LMEC Armour D Gage with Platinum Lead Tabs, Configuration A

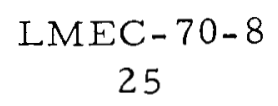




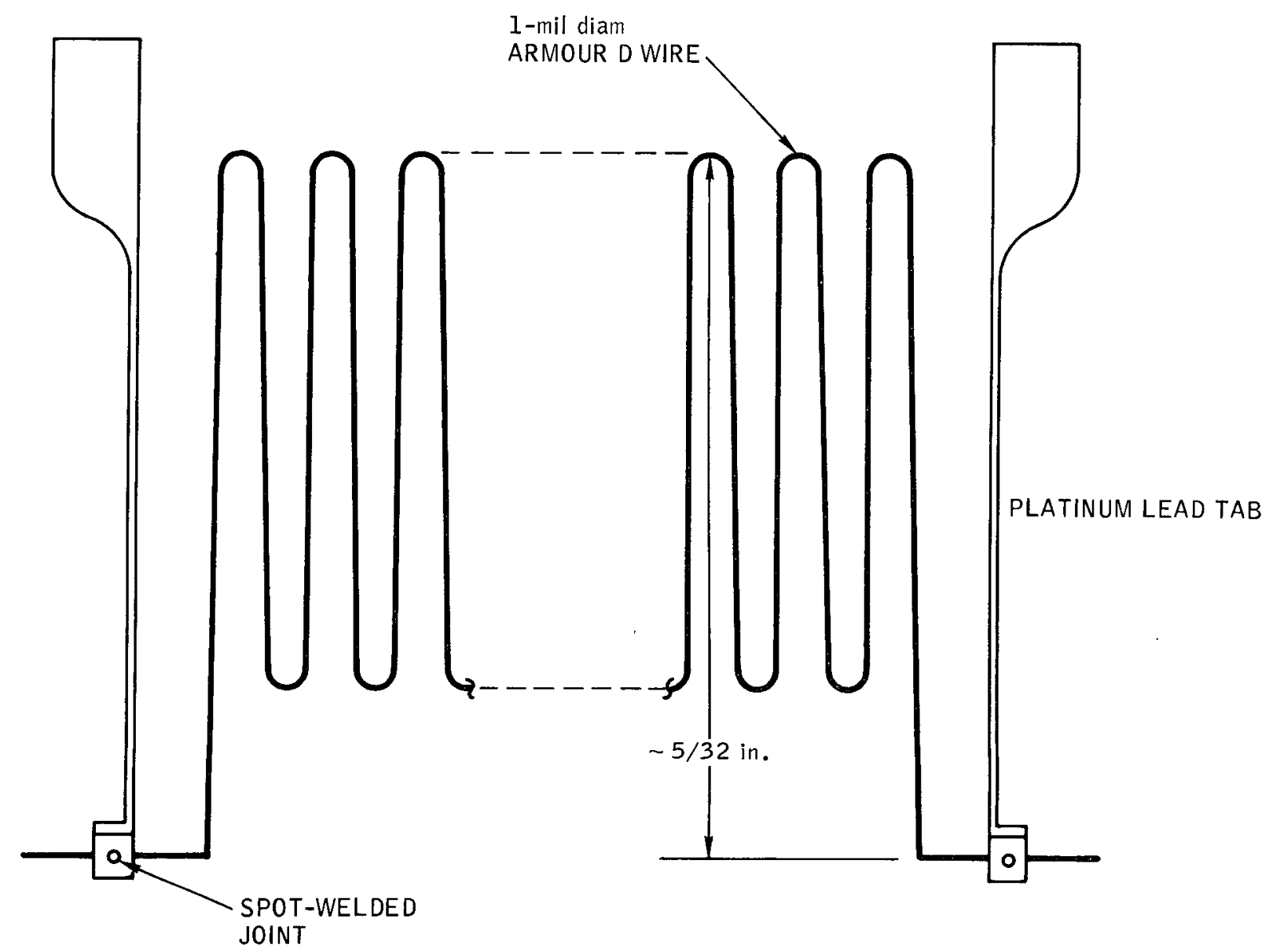

$7693-55124$

Figure 4. Schematic of LMEC Armour D Gage with Platinum Lead Tabs, Configuration B

LMEC. Rod size was approximately 3/16-in. diameter x 14 in. in length. In the case of the nickel-clad wire a nickel tube of approximately 5-mil wall thickness was slipped over the Armour D rod and the assembly swaged and drawn into the 1-mil-diameter wire. A similar procedure was used for the platinumclad wire, except that the wire was drawn to a final diameter of 2 mils, instead of 1 mil (see Figure 6).

It was intended that the cladding serve two purposes: a protective layer for the Armour D core; and a means of achieving temperature compensation by varying the ratio of cladding thickness to core diameter. 


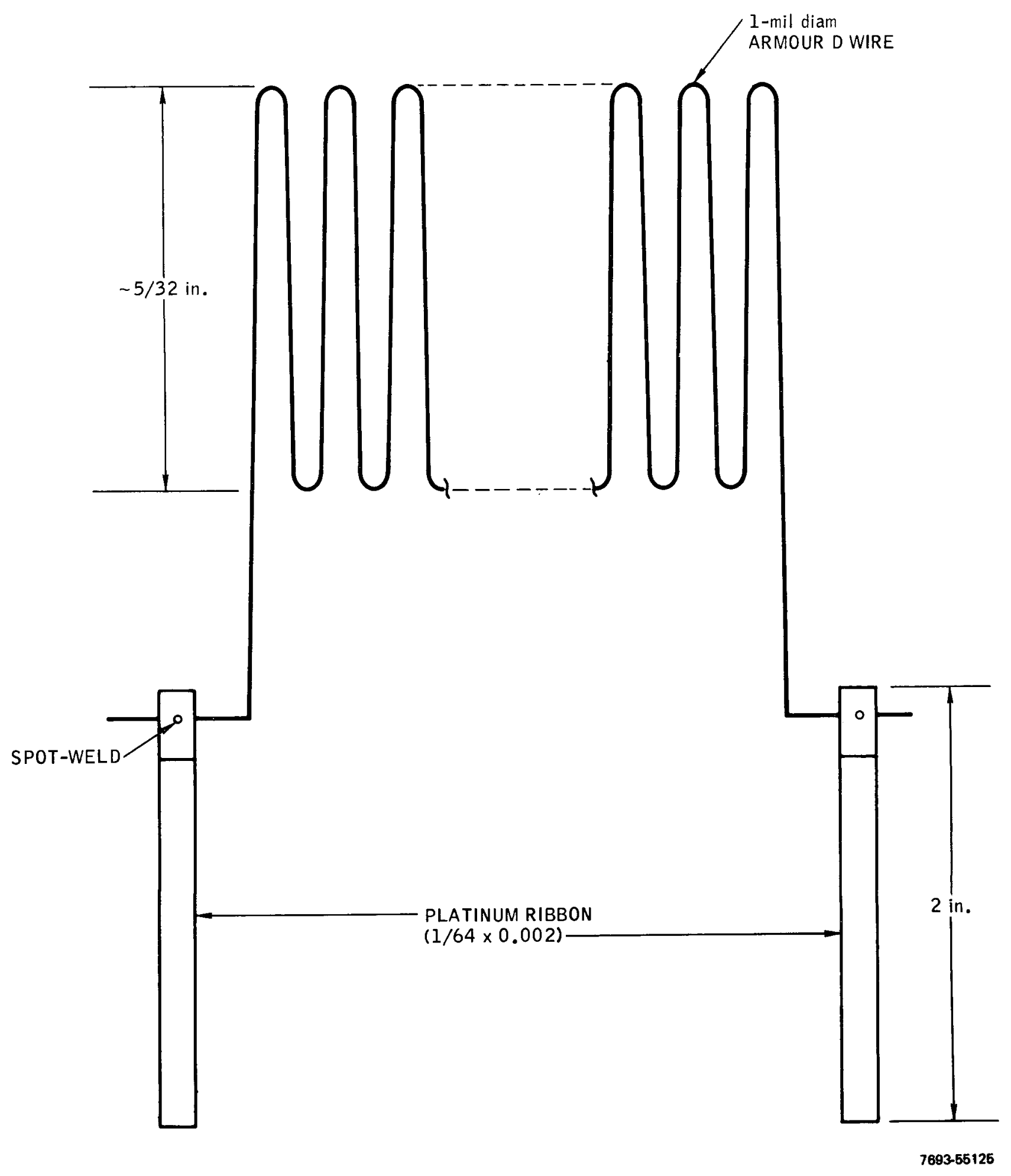

Figure 5. Schematic of LMEC Armour D Gage with Platinum Lead Tabs, Configuration $\mathrm{C}$

LMEC-70-8 

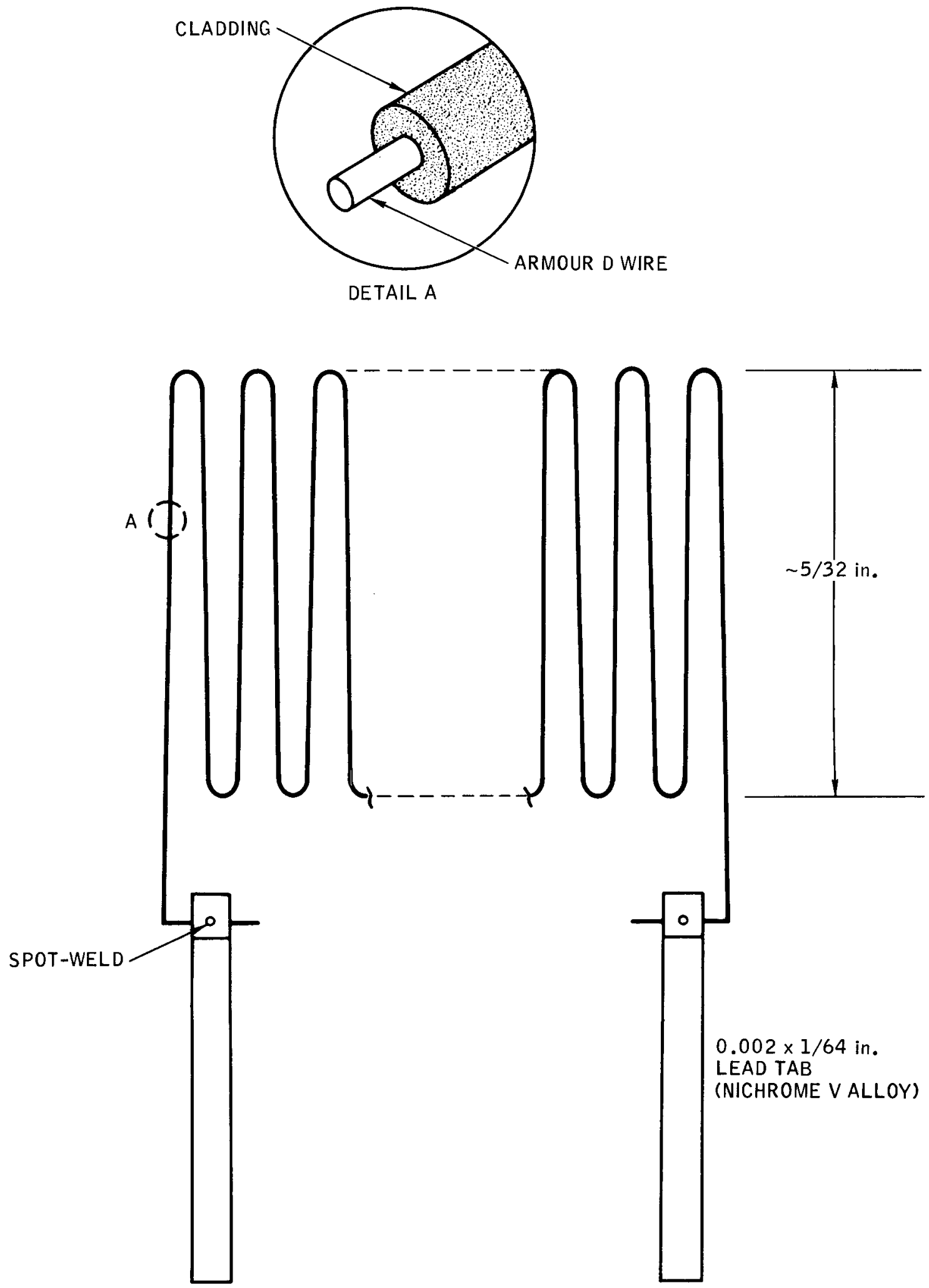

$7693-55127$

Figure 6. Schematic of LMEC Clad Armour D Gages 


\section{TESTING}

The test sequence, specimen preparation, test apparatus, and test procedures used were, in general, similar to those used to evaluate the Baldwin Lima Hamilton (BLH) and Microdot gages earlier at the LMEC. However, improvements have been made and, for the sake of completness, they are described herein.

\section{A. TEST SEQUENCE}

A test sequence was formulated which bracketed the range in time, temperature, and heating rates that could be anticipated in sodium component loop tests. This sequence is depicted in Figure 7, and consisted essentially of an as-received checkout (Event 1), a temperature stabilization procedure (Event 2), and a test series, each consisting of a sequence of events (Events 4, 3, 5, and 6), which was repeated until gage failure or until the accumulated high-temperature test time exceeded $4000 \mathrm{hr}$. For the first series, the sequence of events was Events 3, 4, 5 , and 6. Each series consisted of measurements of the more important parameters discussed in Section I. B, a thermal soak period, and a thermal shocking period. All testing was done in an air environment.

The above test sequence was used on all of the gages for which a full evaluation was required. However, the statistical gage samples, representative of gages to be installed on the Alco steam generator IHX, were not subjected to the full evaluation, since only apparent strain and gage factor calibration data were required. These gages are designated herein by specimen numbers D- 35 through - 37 and AT-1 through - 6. Their test sequence consisted of gage checkout and prestabilization, which was followed by the determination of apparent strain before and after determination of gage factor characteristics.

\section{B. SPECIMEN PREPARATION}

Molten high-purity aluminum oxide was deposited in the form of a substrate about 4 to 5 mils thick (Figure 8). A substrate of this thickness is necessary to provide at least $1 \mathrm{M} \Omega$ resistance to ground at $1200^{\circ} \mathrm{F}$. The substrate is used to provide an insulating layer between the gage and the material to which the gage 


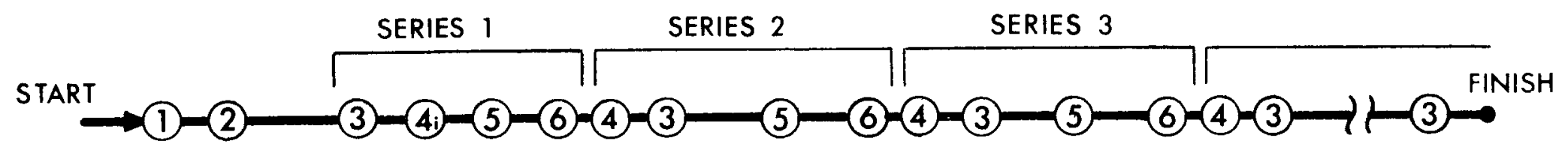

\section{EVENT}

1. Room-Temperature (RT) Checkout as "As-Received" Gages

2. Stabilization, at Constant Temperature, to or Slightly above Maximum Operating Temperature (MOT)

3. Room-Temperature and Elevated-Temperature Gage Factor and Linearity Tests

$4_{i}$. Initial Apparent Strain vs Temperature Tests, Consisting of 3 Cycles from RT to MOT

4. Same as $4_{i}$, except for Series 2 , 3, 4, etc.

5. Thermal Soak (Drift) Tests, Soak Intervals $\sim 300 \mathrm{hr}$

6. Thermal Shock Tests, 30 Cycles Between 350 and MOT, Consisting of 10 Cycles at $10^{\circ} \mathrm{F} / \mathrm{sec}, 10 \mathrm{Cycles}$ at $20^{\circ} \mathrm{F} / \mathrm{sec}$, and 10 Cycles at $\sim 30^{\circ} \mathrm{F} / \mathrm{sec}$

Figure 7. Test Sequence for Gage Evaluation 


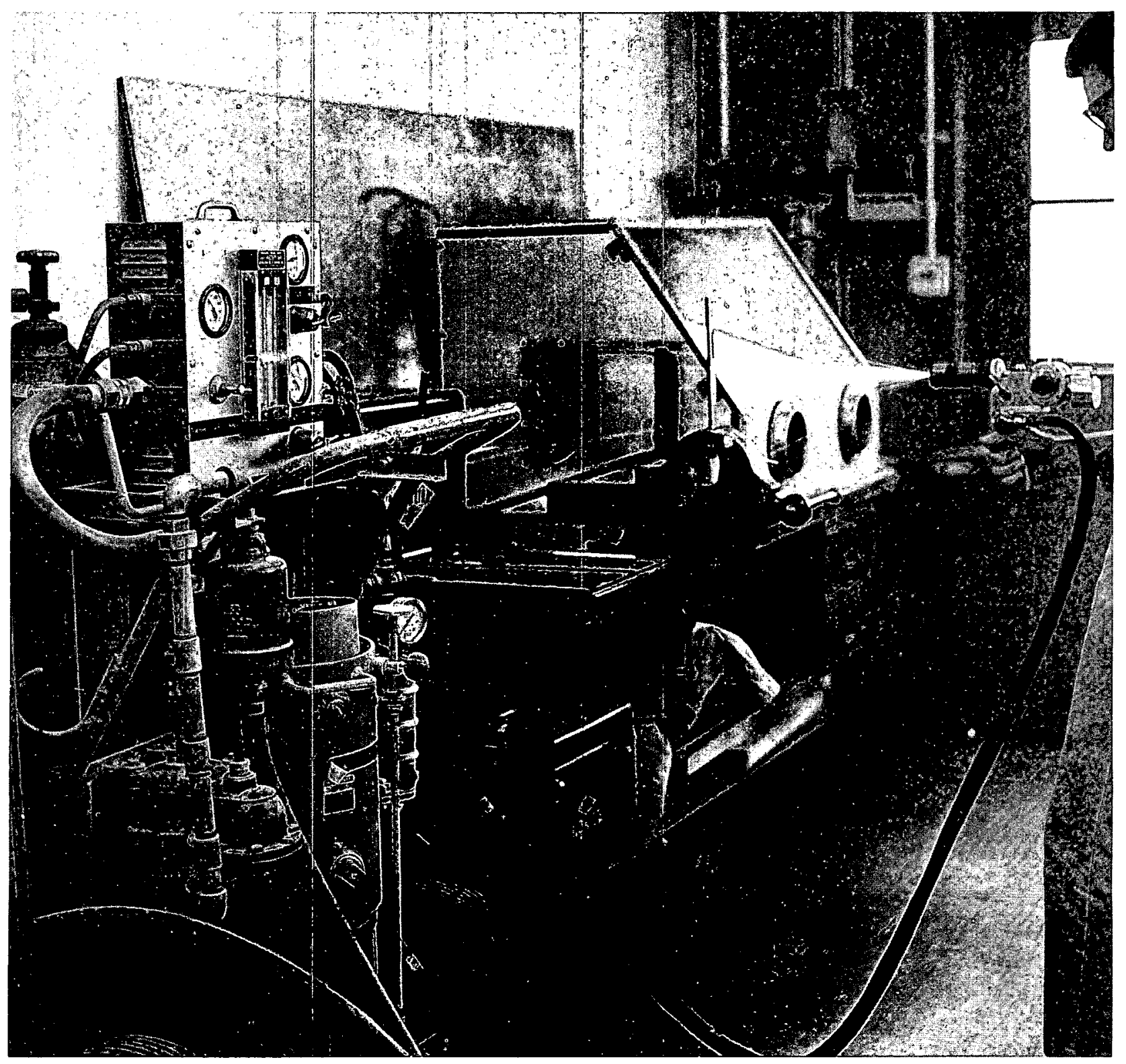

$7698-1820$

Figure 8. Rokide Flame-Spray Equipment in Operation

\section{LMEC-70-8}


is bonded. The gage was then positioned on the substrate and held in place temporarily by means of a special tape carrier. The gage was tack-coated to the substrate by spraying aluminum oxide through the slots in the carrier. The carrier was then removed and the final coat applied. Lead wires were spotwelded to the gage lead tabs. The lead wires consisted of 3-conductor, 26-gage, stainless-steel-clad copper wire, with impregnated glass fiber insulation, which can be used at temperatures up to $1200^{\circ} \mathrm{F}$. A 3-conductor lead wire system was used to eliminate lead wire errors. With this system, changes in lead wire resistance due to temperature are nulled out electrically. Figure 9 shows a typical installation, complete with lead wires and chromel-alumel thermocouple. All specimens, except those for the special calibration tests (see Section IV-D), were prestabilized for $16 \mathrm{hr}$ at $1200^{\circ} \mathrm{F}$.

In general, four gages were flame-spray-bonded to each calibration bar. The calibration bars were Type 304 SS, $1 / 8$ in. thick $x 1$ in. wide $x 12$ in. long, except those for specimens D-30 through D-37 and AT-1 through -6 , which were Type 316 SS, $1 / 4$ in. thick $\times 1$ in. wide $\times 12$ in. long.

The test sequence was not intended to duplicate a specific sodium loop operating sequence, as such a sequence would involve a multiplicity of test condition variations. The test sequence did, however, provide a basis for comparing gages subjected to sodium loop conditions, the heating rates being representative of the more severe rates expected in actual operation.

\section{TEST APPARATUS AND MEASUREMENTS}

After room temperature checkout and prestabilization of the gages at $1200^{\circ} \mathrm{F}$ for $16 \mathrm{hr}$, the gages were subjected to the test sequence shown in Figure 7, or the special sequence described in Section IV-A for specimens D-35 through -37 and specimens AT- 1 through AT-6. All tests were conducted in an air environment. The following is a description of the apparatus and procedures used to evaluate the gages.

1. Gage Factor and Linearity

The gage factor and linearity tests, which correspond to Event 3 in Figure 7, were conducted in special fixtures inserted in furnaces and operated by controls external to the furnaces. To expedite evaluation, two identical fixtures and furnaces were used. Figure 10 is a photograph of the fixture. In essence, the 


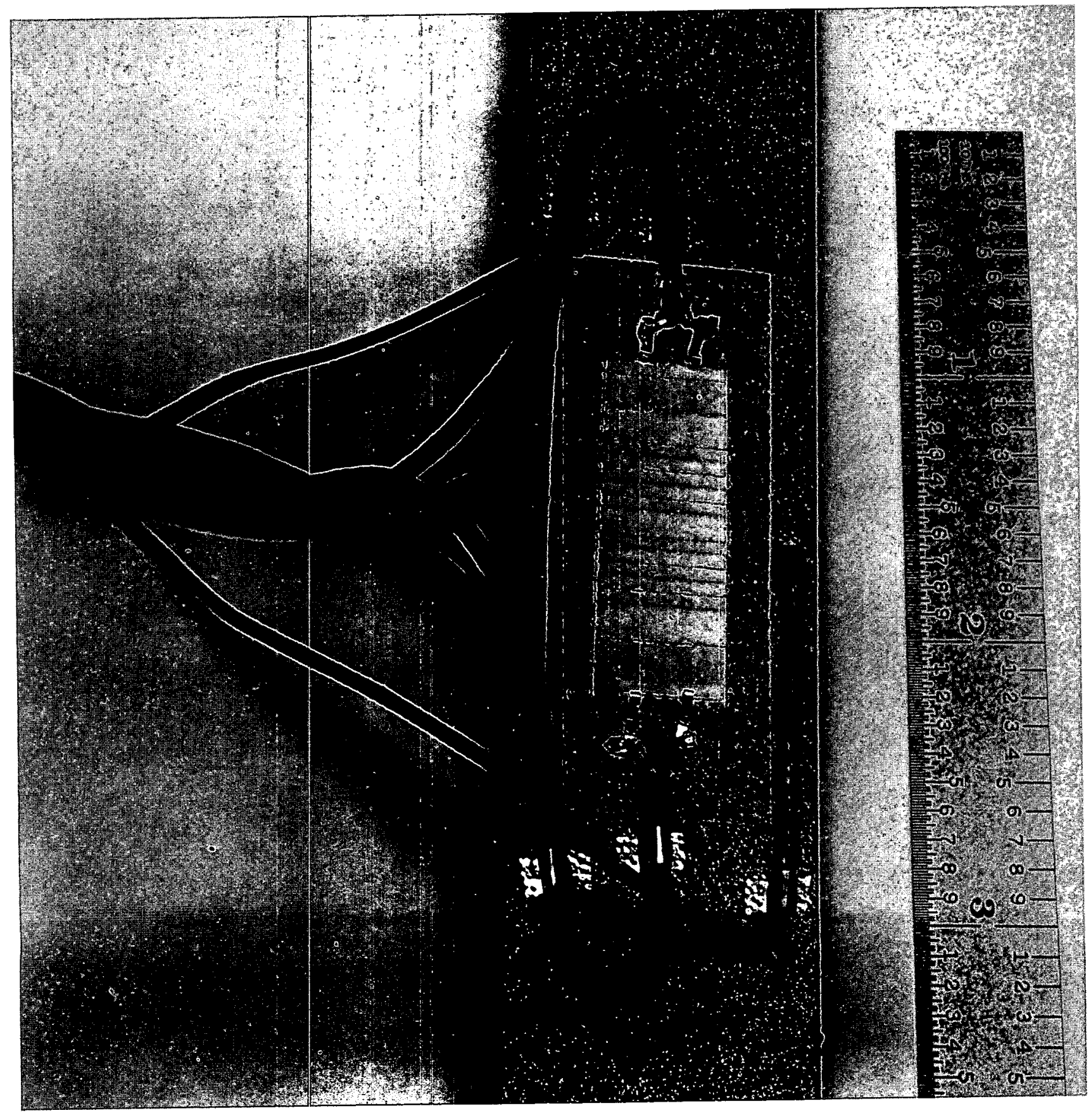

$7682-4005$

Figure 9. Typical Armour D-Type Gage Installation 

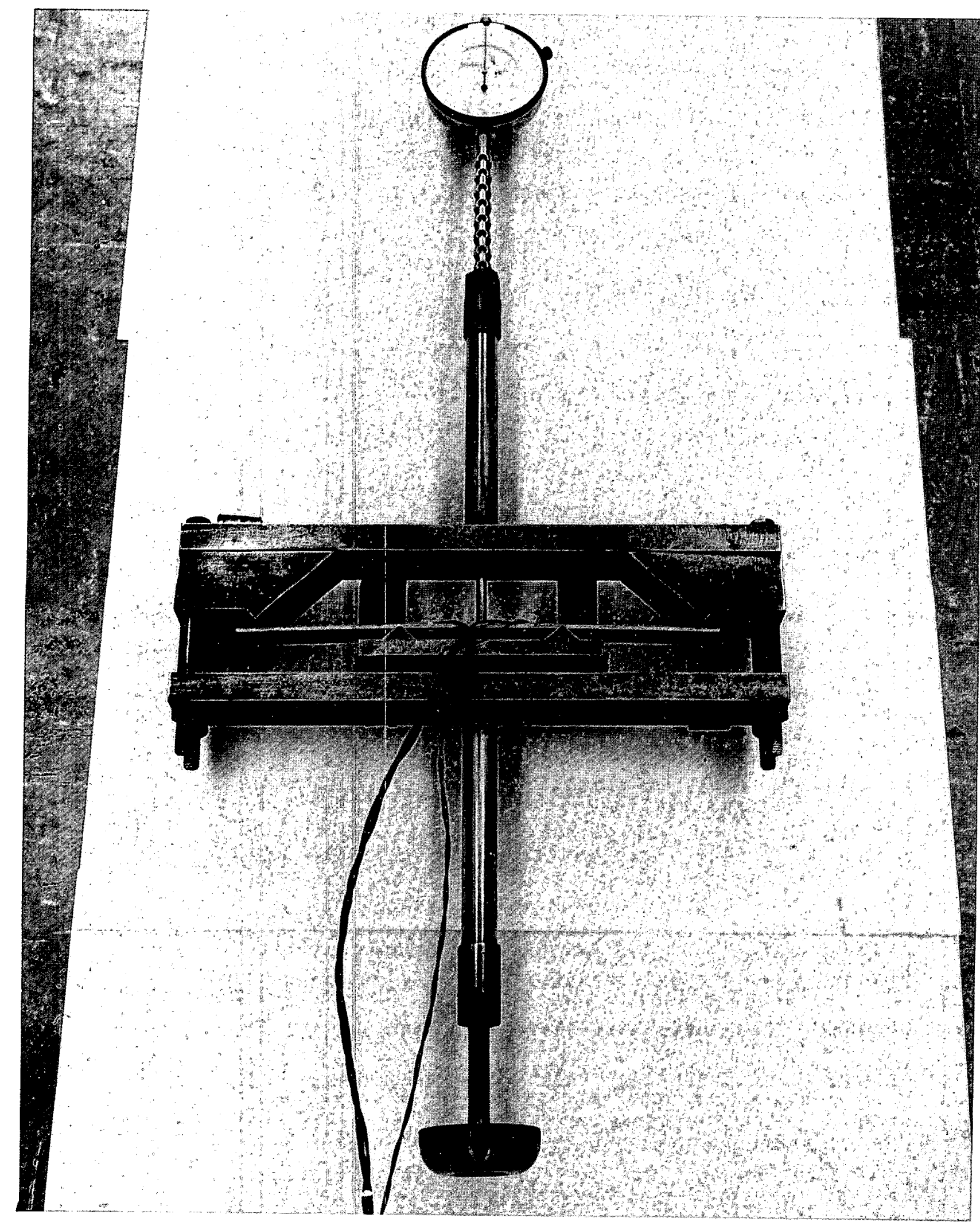

Figure 10. Constant Moment Beam Calibration Fixture 
fixture is a simply supported constant-moment beam, the bending moment of which is constant along the middle portion of the beam. By dialing in a given central deflection, a uniform strain is produced over the middle portion. With this arrangement, it was possible to determine the gage factor and linearity characteristics of several gages simultaneously by observing the strain output of the gages on a BLH Strain Indicator, having a resolution of $10 \mu \epsilon$, used in conjunction with a multichannel switch and balance unit. Before testing started, the fixture was calibrated by applying increments of deflection to a calibration bar which was instrumented with gages of known gage factor and accuracy. This calibration was checked by calculating the strain from the elementary beam equations, and comparing it with the measured strain. In actual use, it was merely necessary to dial in a given number of mils of deflection to produce a strain of a given value in the test specimen. The measured strains were corrected to account for the thin layer of material between the surface of the beam and the sensing element. Figure 11 is an overall view of the test setup, with the fixture partially removed from one of the furnaces.

The gage factors are determined from the linearity plots by use of the following equation:

$$
G F=\left(\frac{\epsilon_{m}}{\epsilon_{c}}\right) G F S
$$

where:

$$
\begin{aligned}
G F= & \text { Gage factor } \\
\text { GFS = } & \text { Gage factor setting } \\
\epsilon_{\mathrm{m}}= & \text { Measured strain in calibration fixture for GFS on the strain indicator } \\
\epsilon_{\mathrm{c}}= & \text { Calculated or known strain imposed by calibration fixture on gage, } \\
& \text { corrected for filament standoff from surface of calibration bar. }
\end{aligned}
$$

By conducting deflection vs strain tests at various temperatures, data were generated from which gage factor vs temperature plots and linearity plots were made.

\section{Apparent Strain vs Temperature and Thermal Soak (Drift)}

The apparent strain vs temperature tests, which correspond to Events 4 and $4_{i}$ in Figure 7 , were performed by slowly heating the specimens in two resistance

\section{LMEC-70-8}




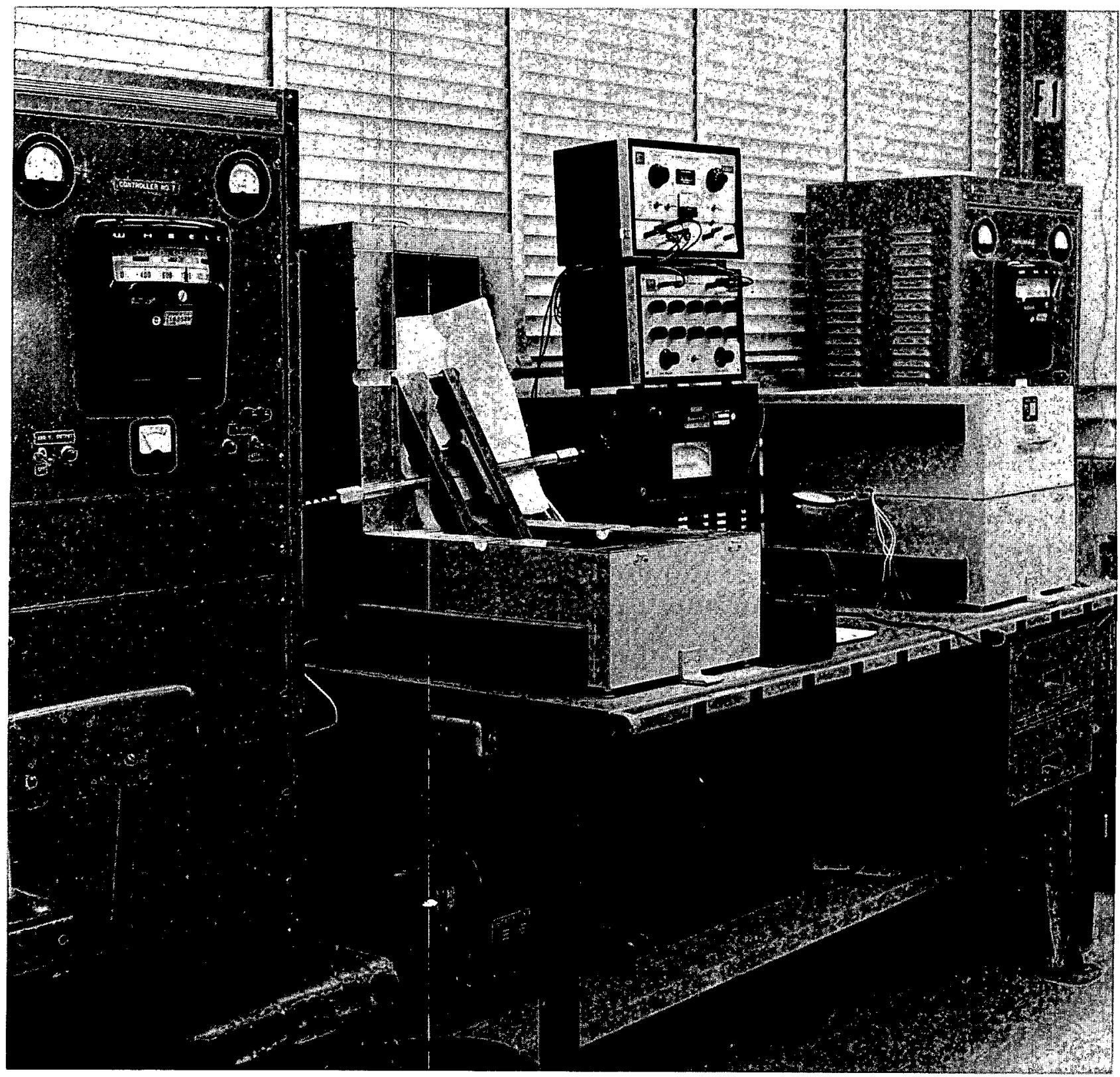

7698-1817

Figure 11. Constant Moment Beam Fixture Partially Removed from Furnace

LMEC - 70-8 
heating furnaces, in a stress-free condition, and measuring the strain produced at various temperatures during heating and cooling with a BLH Strain Indicator. The temperature of the specimen was sensed by means of the chromel-alumel thermocouple spotwelded to the calibration bar in the vicinity of the gage, and it was controlled within $\pm 10^{\circ} \mathrm{F}$ by means of two saturable reactors. To expedite evaluation, four sets of furnace-temperature/power controllers were used. Figure 12 shows two of the furnaces and related equipment.

Thermal soak (drift) tests, (which correspond to Event 5 in Figure 7), were conducted in the same furnaces. The unstressed specimens were heated to $1200^{\circ} \mathrm{F}$, and the output of the gage monitored with a BLH Strain Indicator over each soak period of approximately $300 \mathrm{hr}$, the temperature held constant within $\pm 10^{\circ} \mathrm{F}$. The strain indicators were zeroed at the beginning of each soak test; total drift was determined from a summation of the drifts for each series. Average drift rates were computed by dividing the total drift in microstrain by the elapsed time in hours.

\section{Thermal Shock}

The thermal shock tests, which correspond to Event 6 in Figure 7, were conducted in a direct resistance heating facility (Figure 13). The specimen was heated by passing current directly through it to provide heating rates of $10^{\circ} \mathrm{F} /$ $\mathrm{sec}, 20^{\circ} \mathrm{F} / \mathrm{sec}$, and 25 to $30^{\circ} \mathrm{F} / \mathrm{sec}$. These rates were controlled and programmed by means of a Research, Inc., temperature programmer, which is comprised of a Datatrak, Thermac power controller, and power supply. Temperature feedback to the recorder was provided by means of the specimen thermocouple.

Cooling was provided by means of a blower whose delivery was funneled through a duct which concentrated the air on the specimen.

Strains and temperatures were recorded on a Heiland Model 1108 Visicorder.

4. Zero Shift and Repeatability

Zero shift and repeatability characteristics were determined from the measurements of the other gage parameters.

5. Gage Resistance and Resistance-to-Ground Measurements

Gage resistance was monitored during testing with a Leeds and Northrup Model 5305 Wheatstone bridge. Resistance-to-ground was monitored with a General Radio Megger, Model 1862C, using the 50-vdc potential. 


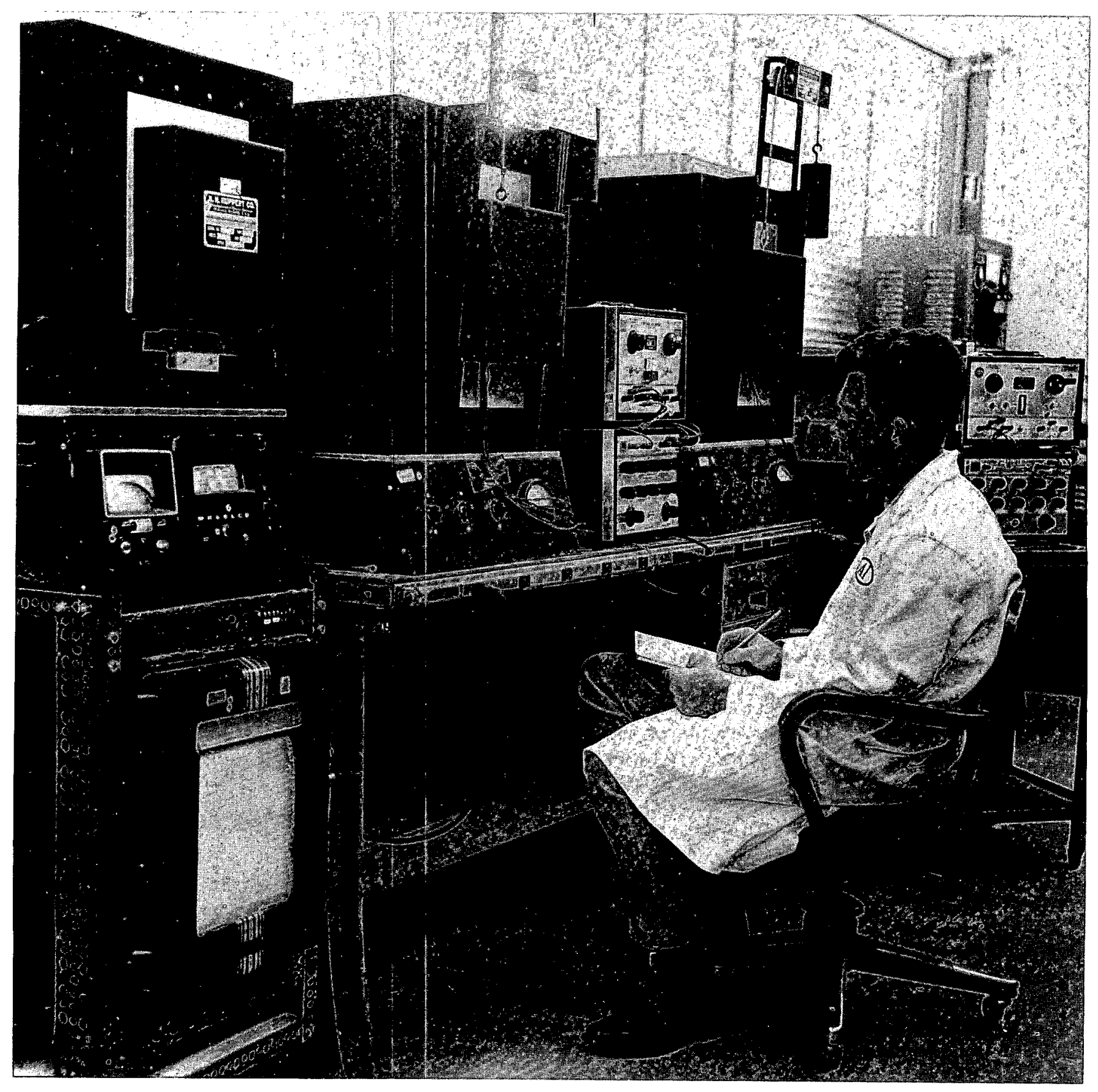

7694-1095

Figure 12. Apparent Strain and Soak Furnaces

LMEC-70-8 


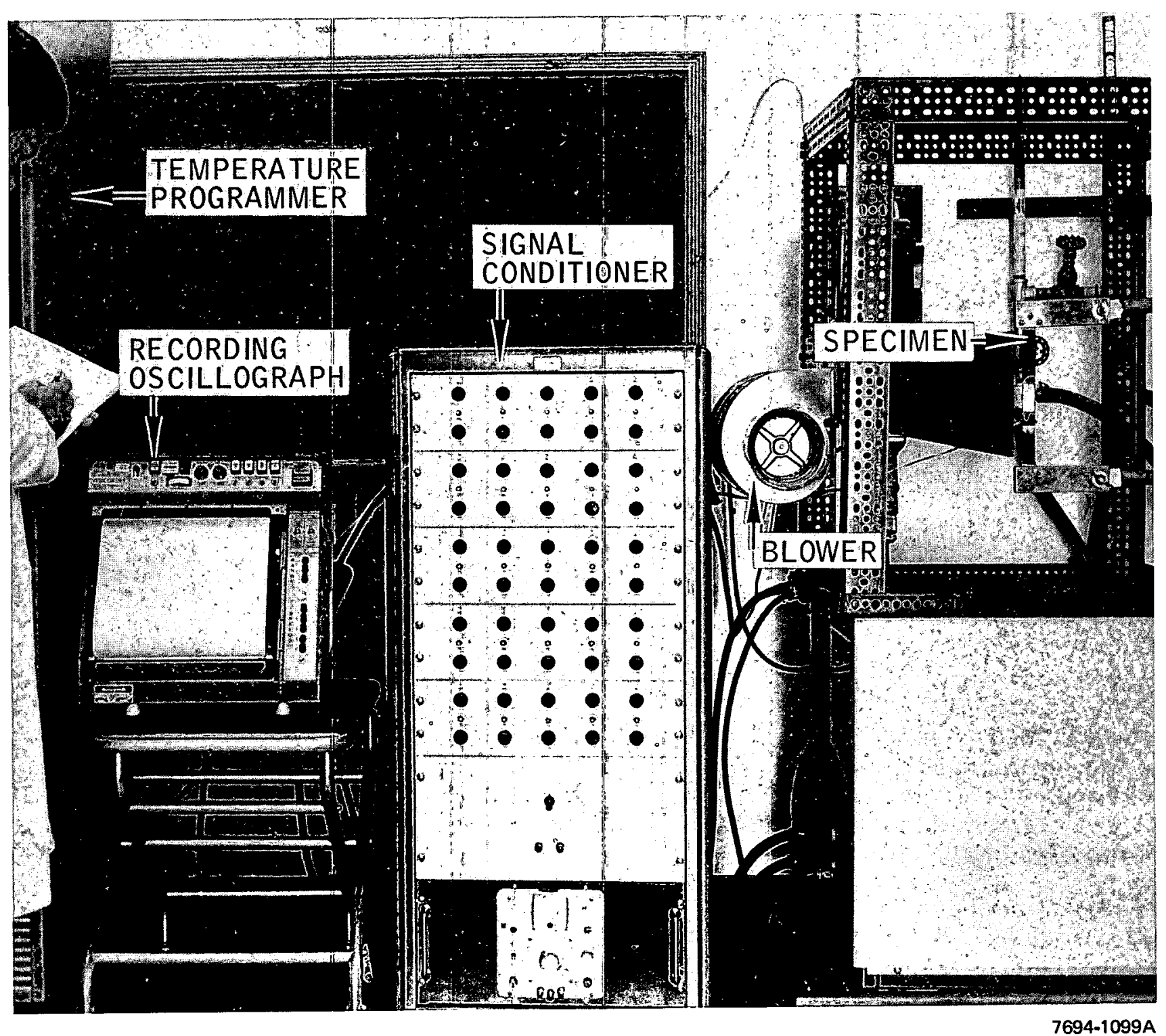

Figure 13. Thermal Shock Facility 


\section{SPECIAL CALIBRATION TESTS, ALCO IHX GAGES}

To obtain statistical values of apparent strain and gage factor for similar standard LMEC Armour D-platinum gages installed on the Alco IHX, special calibration tests were performed on the gages on specimens. These tests were conducted in the same fixtures described in preceding Sections C. 1 and C.2. The gages were stabilized at $1100^{\circ} \mathrm{F}$ for $16 \mathrm{hr}$ and the apparent strain and gage factor characteristics were then determined. The gages, therefore, were not subjected to the full test sequence depicted in Figure 7, since these were calibration rather than evaluation tests. 


\section{DATA REDUCTION AND ANALYSIS}

To facilitate data reduction of the many oscillograms generated during the transient apparent strain (thermal shock) measurements, a Gerber Digital Data Reduction System, Model GDDRS-38, was used (Figure 14). From these data, the apparent strains corresponding to given temperatures were determined. The remainder of the data were taken and reduced manually.

The raw data for gage factor determination were corrected to account for the gage factor setting on the strain indicator, for substrate thickness, and for the variation in calibration bar thickness. After the data from the oscillograms and other records were reduced, the data was fed into the IBM 360, 7090, or 7094 digital computers, whose output was converted directly into CRT's, which hereinafter will be referred to as plots. The plots were not faired in any manner; consequently, any abrupt changes in the slopes of the plots do not necessarily imply erratic gage behavior.

The plots of apparent strain vs temperature, average measured strain vs calculated strain, and drift vs time were obtained for the gage factor setting values specified with each plot. To calculate these gage characteristics for the actual gage factor and temperature in question, the values obtained from these plots should be corrected by use of the following equation:

$$
C=C^{\prime} \frac{G F S}{G F}
$$

where

$C=$ Value of the characteristic for the actual gage factor and temperature in question

$C^{\prime}=$ Value of the characteristic obtained from the plot.

GFS = Gage factor setting specified with plot

$\mathrm{GF}=$ Value of gage factor for the temperature in question obtained from the gage factor plot.

To extract the maximum amount of information from the limited number (from a statistical standpoint) of gages of each type tested, a statistical analysis,

\section{LMEC-70-8}




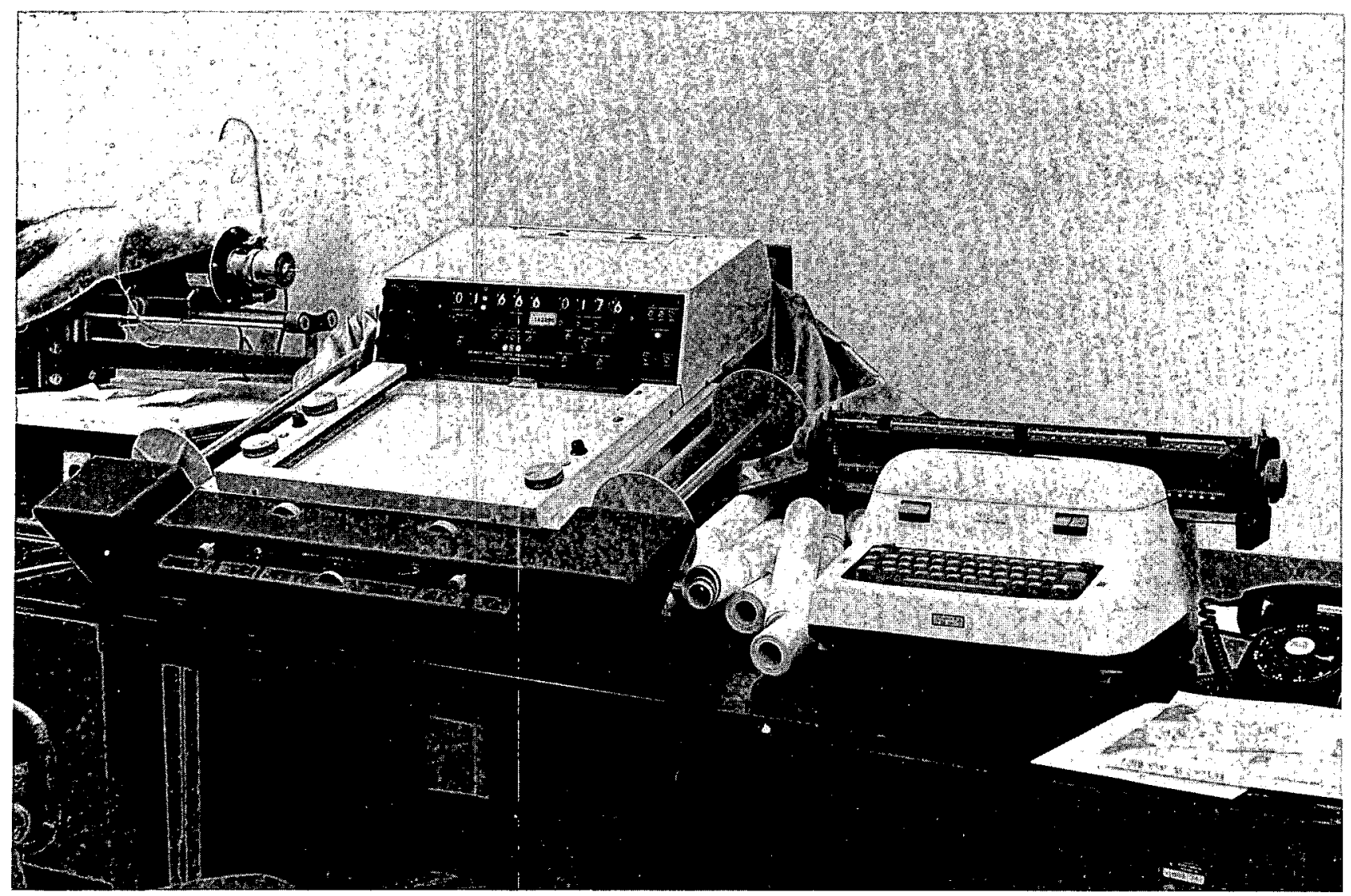

Figure 14. Gerber Digital Data Reduction System

7698-1801

based on small sampling theory and normal distributions, was performed. Specifically, the mean values, the $95 \%$ confidence limits, and the $95 \%-90 \%$ tolerance limits were determined for apparent strain, gage factor, and drift. These three gage characteristics are by far the most important to be used in connection with the determination of stresses from the measured strains. Without them, it is not possible to properly correct the raw strain data. With a knowledge of the statistical variations in these gage characteristics, one can determine the extent of the errors caused by such variations in the calculation of stresses.

The $95 \%$ confidence limits, as used in this report, represent the upper and lower limits of an interval or band, within which we may be $95 \%$ confident that the mean value of any subsequent groups of gages tested would fall. This, of course, assumes no change in the procedures or materials used in fabrication of the gages. In engineering work, the mean value of a set of measurements or 
properties is the most important statistic. Hence, the mean value curves contained in the CRT plots should be used to obtain values for apparent strain, drift, gage factor, etc. However, one is also interested in how much variation might be expected in any one sample from the population. In other words, what is the probability that a given percentage of individual samples taken from the population will lie within certain limits? To answer this question in a quantitative manner, the tolerance limits must be compiled for a specified probability and percentage. For this particular study, it was decided that the tolerance limits should be $95 \%-90 \%$ [i. e., that there be a $95 \%$ probability that $90 \%$ of the gages (gage characteristic in question) will fall within these limits]. If the percentages chosen had been higher, the tolerance interval or scatter band would be too broad to be meaningful, in terms of the gage-to-gage variations found in present day commercial gages.

To compute the confidence limits, the following equations were used:

$$
\begin{aligned}
& \text { Upper Confidence Limit }=\bar{x}+t_{c} \sqrt{\frac{\overline{x^{2}}-(\bar{x})^{2}}{N-1}}, \\
& \text { Lower Confidence Limit }=\bar{x}-t_{c} \sqrt{\frac{\bar{x}^{2}-(\bar{x})^{2}}{N-1}},
\end{aligned}
$$

where

$$
\begin{aligned}
\frac{N}{=} & \text { Number of gage samples } \\
\mathrm{x}^{2}= & \text { Mean of the sum of the squares of the numerical value of the gage } \\
& \text { characteristic of each of the gage samples } \\
\bar{x}= & \text { Arithmetic mean of the sum of the numerical value of the gage } \\
& \text { characteristic of each of the gage samples } \\
t_{c}= & \text { Confidence coefficient for } 95 \% \text { confidence level and number of gage } \\
& \text { samples. }
\end{aligned}
$$


The tolerance limits were computed from the equations:

$$
\begin{aligned}
& \text { Upper Tolerance Limit }=\bar{x}+K S, \\
& \text { Lower Tolerance Limit }=\bar{x}-K S,
\end{aligned}
$$

where

$$
\begin{aligned}
& \bar{x}=\text { (Same as for confidence limits above) } \\
& K=\text { Tolerance factor for } 95 \%-90 \% \text { limits } \\
& S=\text { Standard Deviation }
\end{aligned}
$$

$$
S=\sqrt{\frac{\sum_{i=1}^{N}\left(x_{i}-\bar{x}\right)^{2}}{N-1}}
$$

where

$$
\begin{aligned}
& x_{i}=\text { numerical value of the gage characteristic of the } i^{\text {th }} \text { gage sample } \\
& N=\text { (same as for confidence limits above). }
\end{aligned}
$$

These formulas, as well as tables for the numerical values of the confidence coefficients and tolerance factors, may be found in most references on statistical analysis. 


\section{DISCUSSION OF TEST RESULTS}

The pertinent information pertaining to gage characteristics and performance, which were determined during this study, are summarized in Tables 1 and 2, and Figures 15 through 60. The following is a discussion of these results for each gage type.

A. STANDARD LMEC ARMOUR D-PLATINUM GAGE (Specimens D-15, - 16, $-21,-22,-29$, and -32 through -34 )

These specimens represent two distinct groups: a group comprised of specimens D-15, $-16,-21$, and -22 (hereinafter referred to as Group 1); and a group comprised of D-29, and -32 through -34 (hereinafter referred to as Group 2). This separation is made to account for the fact that the gages for each group were made by different technicians, the former group representing early pilot gages, with minor variation from gage to gage.

1. Group 1 (D-15,-16,-21, and -22)

Specimen D-15 was prepared with gloves to determine whether it was possible to fabricate gages from 1-mil-diameter wire while wearing gloves. It is known that contamination of gages may result from handling due to oil or acid present in the skin. It was demonstrated that it could be done, with some sacrifice in ease of fabrication. Referring again to Table 1, it appears that some improvement resulted from the use of gloves, although more statistical data would be required to verify the observation with certainty. For example, the 4 gages on D-15 had a total life-to-failure of $2448 \mathrm{hr}$ compared to 1214,1220 , and $1834 \mathrm{hr}$ for specimens $\mathrm{D}-16,-21$, and -22 , respectively. The ability of the gages on specimen D- 15 to withstand thermal shock also appears greater; specimen D-15 gages withstood a total of 207 shocks-to-failure, while specimens D-16, -21 , and -22 gages withstood 91, 65, and 160 shocks, respectively. Referring again to Table 1, it is also evident that the gages on specimen D- 15 have more uniform apparent strain characteristics, as noted by comparing the data for cycles 2 and 3 of series 1, and the data obtained during thermal shocking. It should be noted that not too much significance can be attached to the first cycle of series 1 , since it is essentially a thermal stabilization cycle. 
TABLE 1

SUMMARY OF ARMOUR-D GAGE CHARACTERISTICS AND PERFORMANCE (Sheet 1 of 2)

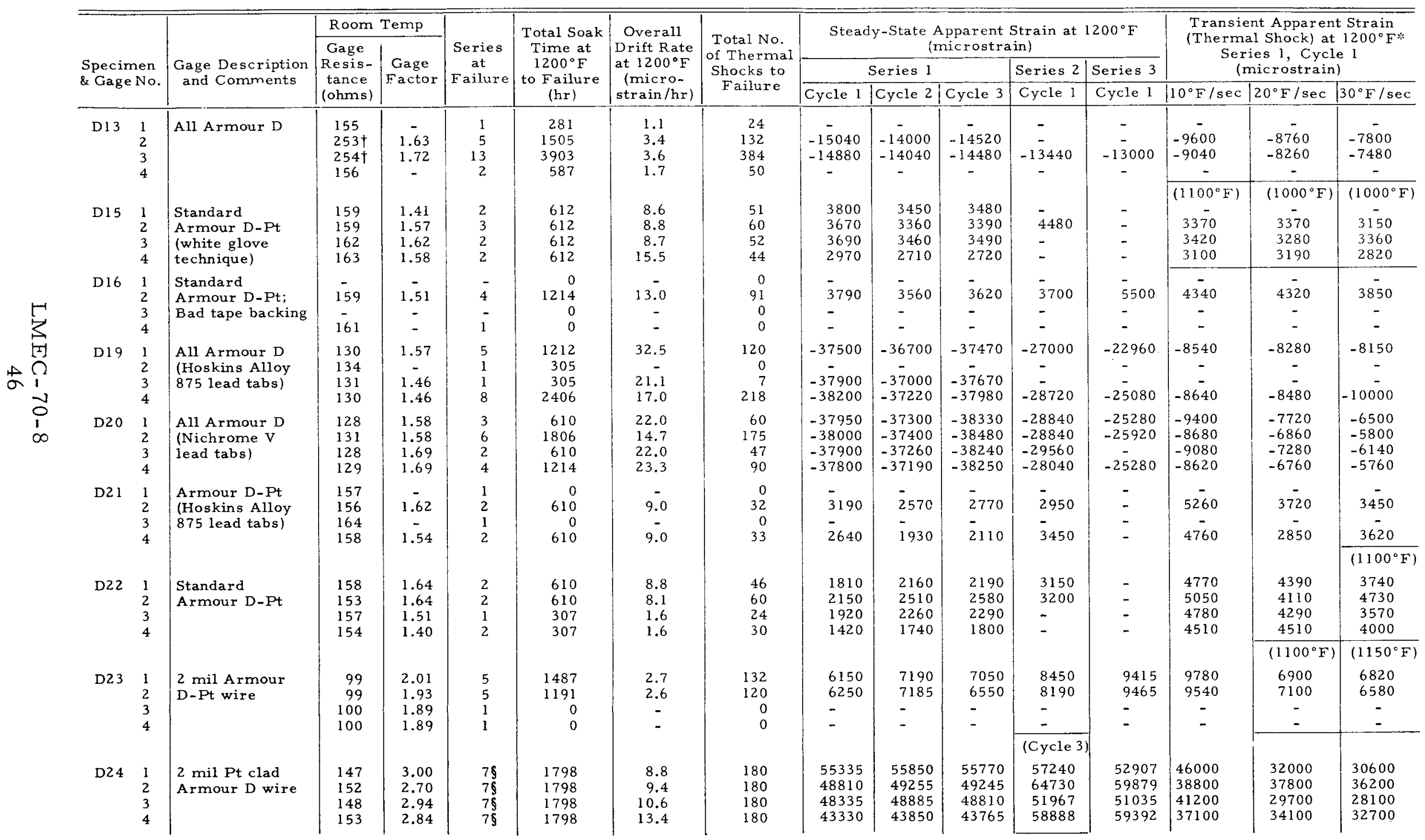


TABLE 1

SUMMARY OF ARMOUR-D GAGE CHARACTERISTICS AND PERFORMANCE (Sheet 2 of 2 )

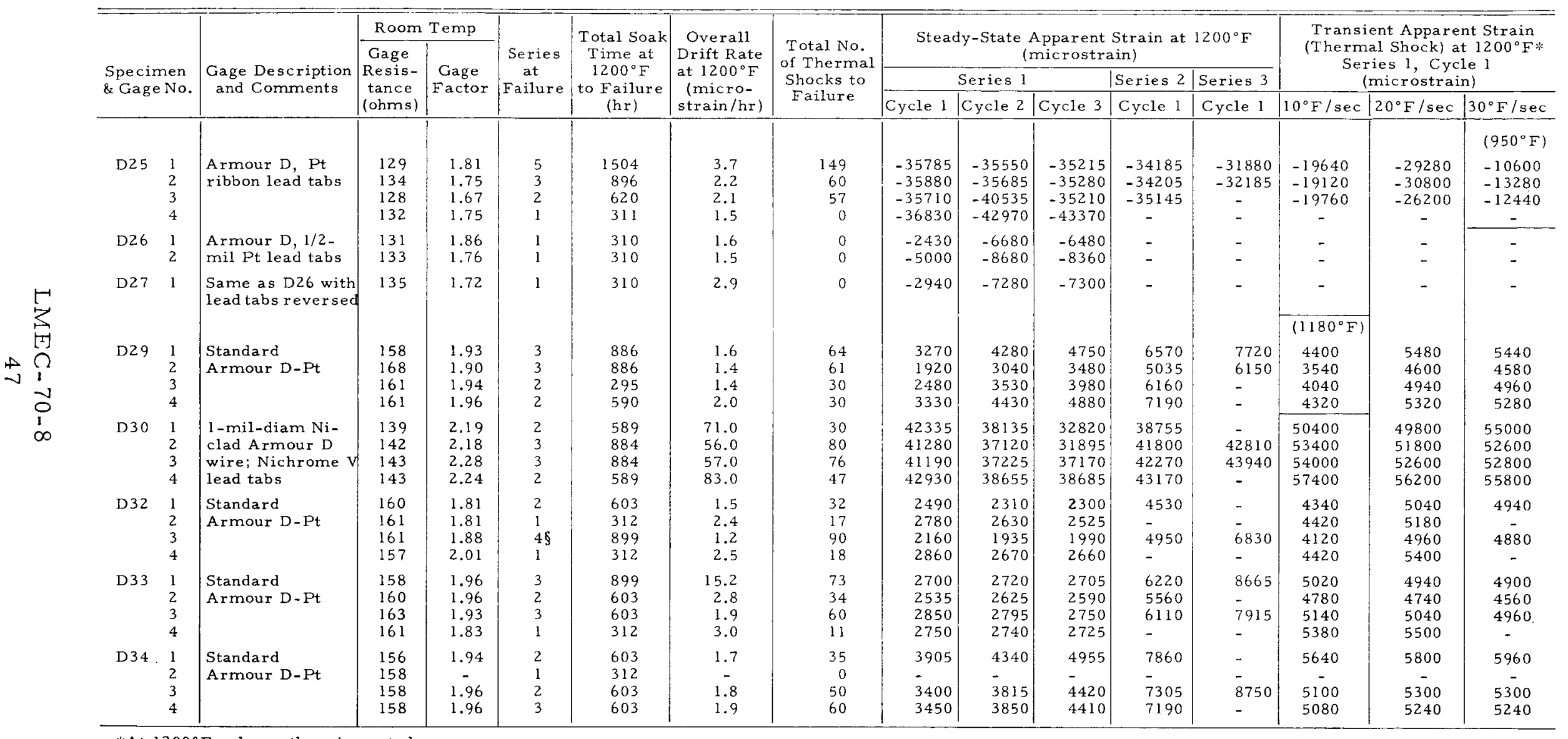

*At $1200^{\circ} \mathrm{F}$ unless otherwise noted.

$\dagger$ These are 3 -element gages.

Still in test.

NOTE: For above gages, minimum resistance to ground was $50 \mathrm{k}$ megohms at room temperature and $7 \mathrm{megohms} \mathrm{at} 1200^{\circ} \mathrm{F}$. 
On specimen D-16, three of four gages failed at the outset because of bad carrier tape, whose shelf life was more limited than supposed. During all subsequent gage fabrication, fresh carrier tape was used.

Specimen D-21 was fabricated with Hoskins Alloy 875 ribbon lead tabs and joining elements to determine if this ribbon would result in spot-welded joints that were superior, as regards fatigue, to those utilizing Nichrome $V$ ribbon. It should be noted that Armour D alloy and Hoskins Alloy 875 are both Fe-CrAl alloys and hence should be more compatible than a combination involving Nichrome V which is a Ni-Cr alloy. Whether there was an overall improvement in gage performance remained to be seen, since the Hoskins Alloy 875 was also in combination with the platinum element of the gage. Referring again to Table 1 , it is evident that there was no overall improvement in gage performance resulting from the materials substitution.

Specimen D-22 gages are similar to those on specimen D-15, except that gage fabrication was done without gloves. It is noted from Table 1 that both the total time and number of thermal shocks to failure are less than for specimen D-15. This may be due to not using gloves during fabrication. However, not enough gages were tested to substantiate this fact.

Figures 15 through 17 are plots of apparent strain vs temperature for 5 gages on specimens D-15 and -16, for series 1 , cycles 1 through 3 . The asterisks represent the actual data points. The mean value curve, $95 \%$ confidence limits, and 95\%-90\% tolerance limits are also plotted. Note that the heating and cooling portions of these curves are reasonable mirror images of one another. Because of a small amount of zero-shift and slight differences between filament and bar temperatures (leading or lagging), some dissymmetry is introduced. To expedite testing, readings were taken while the temperature was changing at the rate of about $35^{\circ} \mathrm{F} / \mathrm{min}$. Had time been taken to reach true isothermal conditions * at each temperature, it is believed that most of the dissymmetry would have been eliminated. The zero shifts of the mean value lines are about $350 \mu \epsilon, 0$, 0 , for cycles 1 through 3 . It is evident that the thermal

\footnotetext{
*Where gages are to be used for quantitative stress measurements, rather than evaluation of gage characteristics, it is LMEC practice to reach isothermal conditions, before readings are taken.
} 


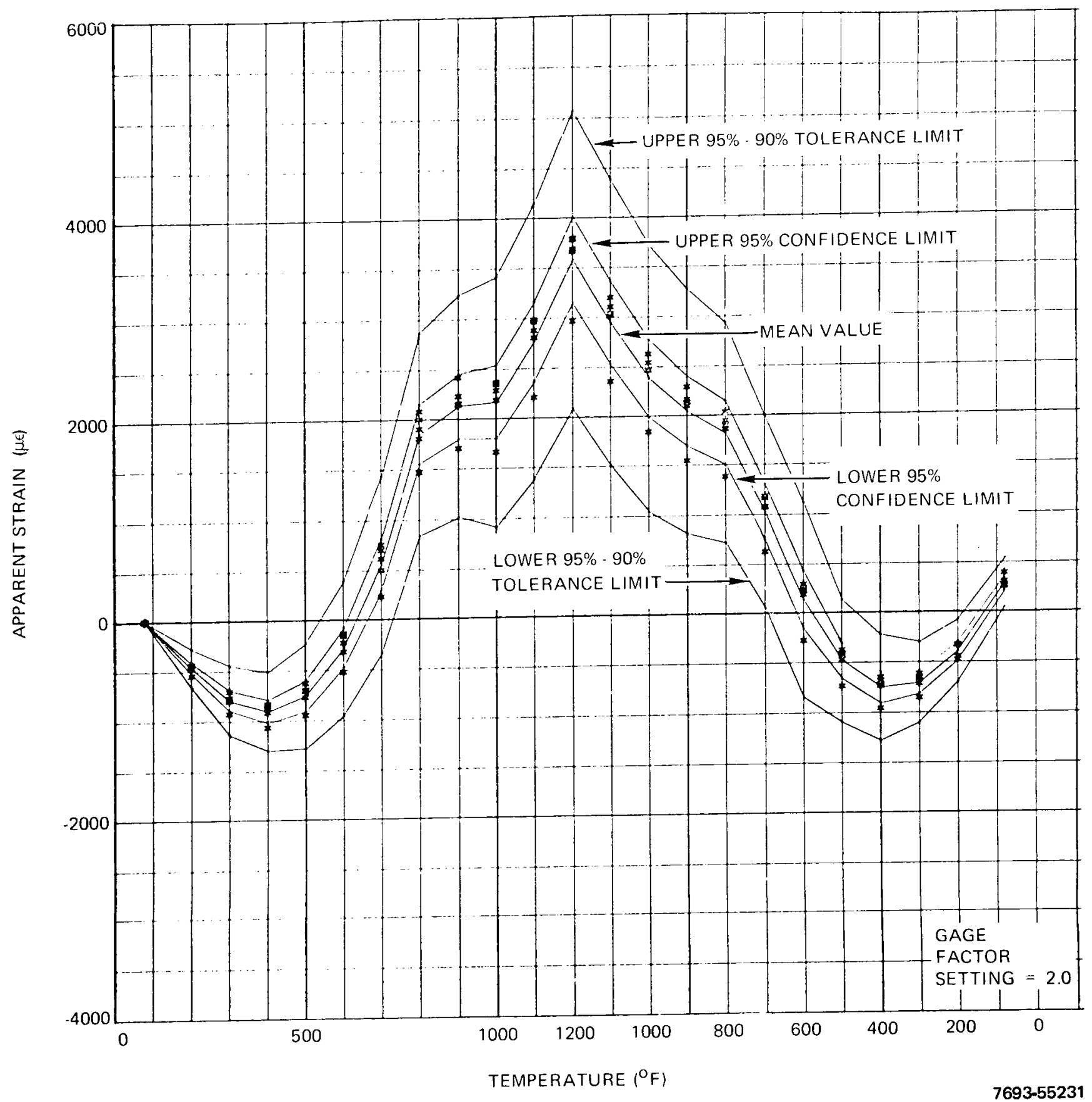

Figure 15. Apparent Strain vs Temperature, with Confidence and Tolerance Limits for Specimens D-15 and -16, 5 Gages, Series 1 , Cycle 1 


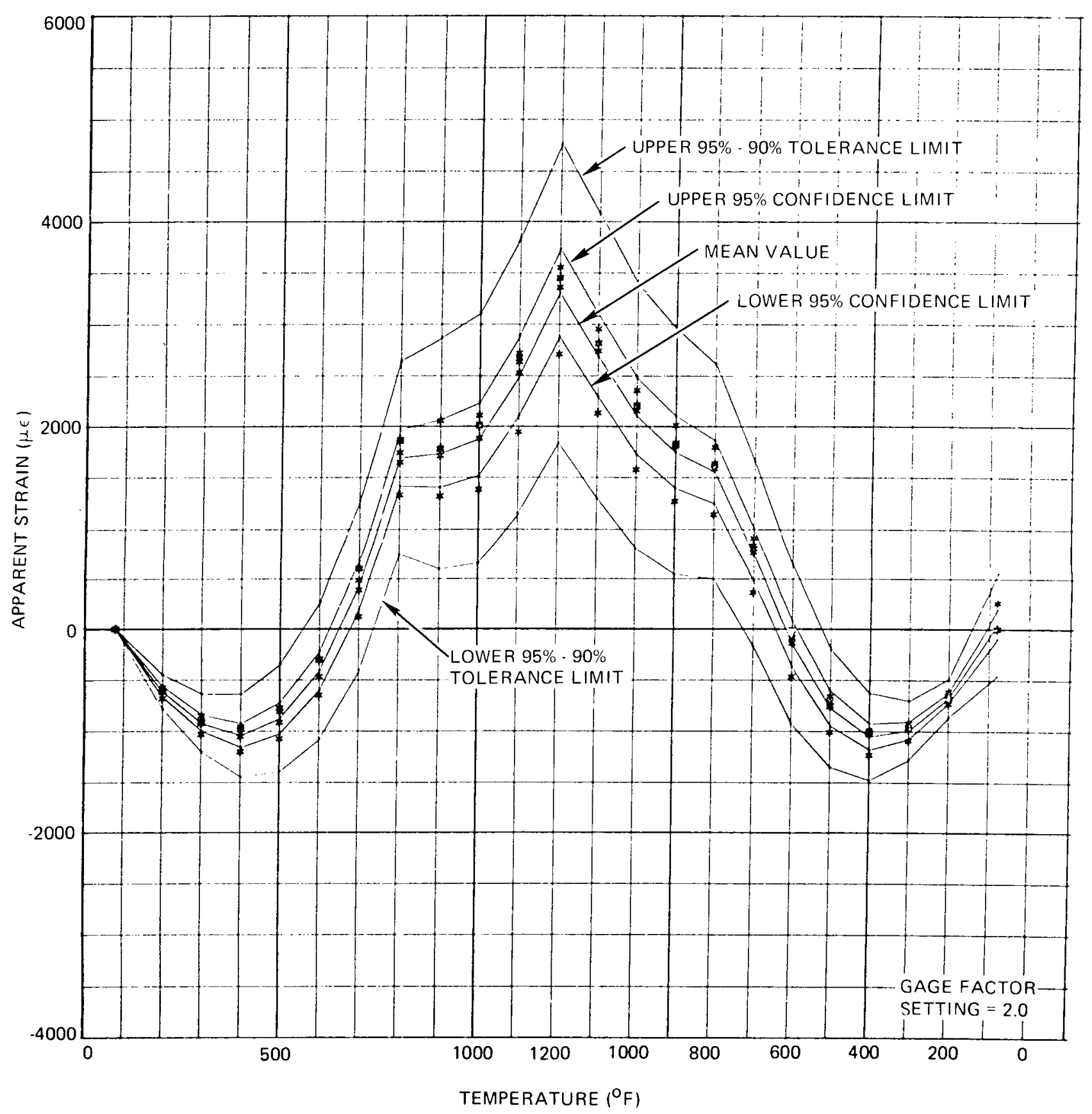

Figure 16. Apparent Strain vs Temperature, with Confidence and Tolerance Limits for Specimens D-15 and -16, 5 Gages, Series 1, Cycle 2 


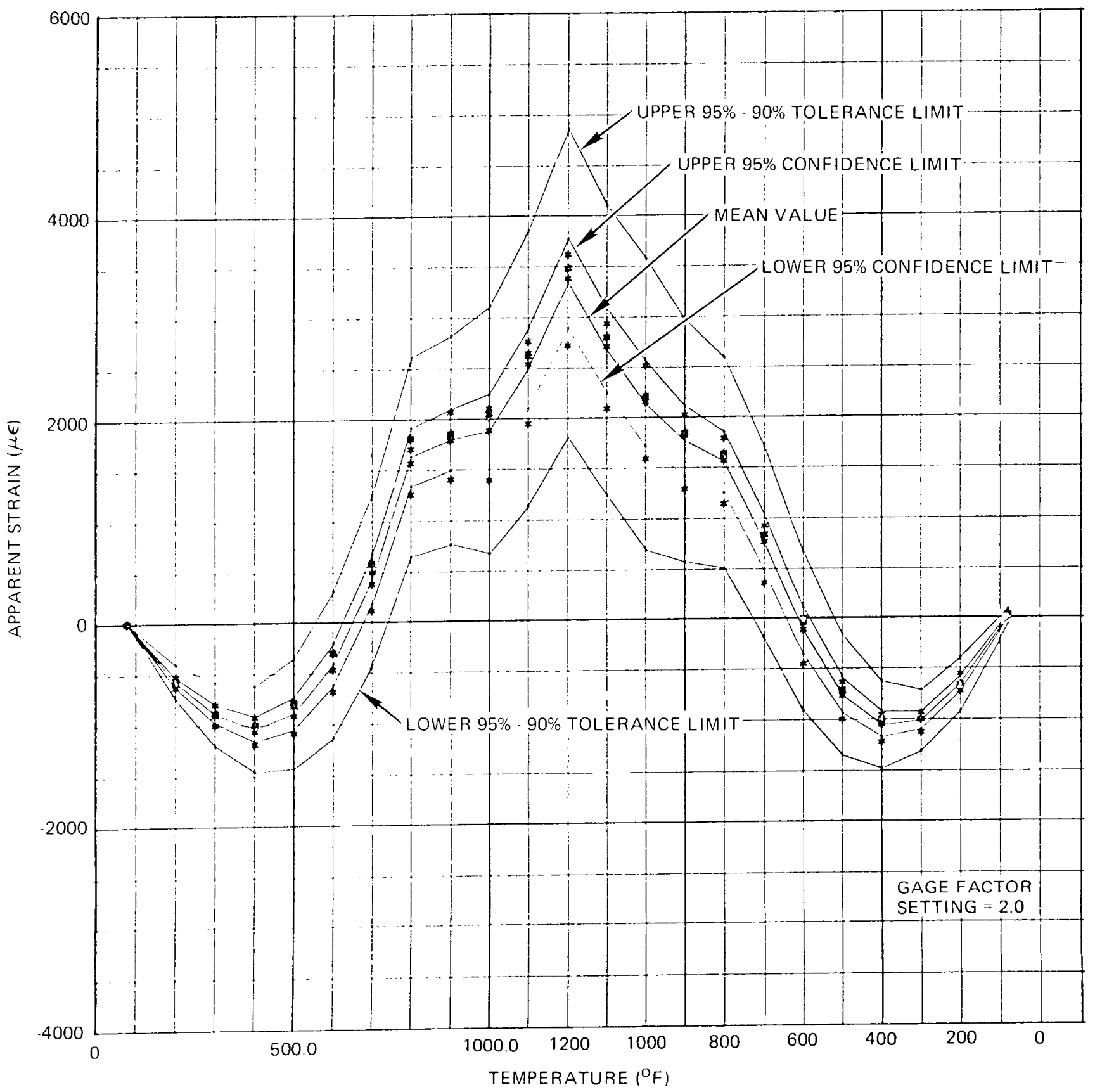

$7693-55233$

Figure 17. Apparent Strain vs Temperature, with Confidence and Tolerance Limits for Specimens D-15 and -16, 5 Gages, Series 1, Cycle 3 
cycling reduced the thermal hysteresis to essentially zero after the first apparent strain cycle. The confidence limits at $1200^{\circ} \mathrm{F}$ for the three cycles are \pm 433 , \pm 425 , and $\pm 443 \mu \epsilon$; the corresponding tolerance limits are $\pm 1488, \pm 1461$, and $\pm 1523 \mu \epsilon$, indicating little change with cycling.

Figures 18 and 19 are plots of gage factor vs temperature and average measured vs calculated strain, based on data taken at ambient and $1200^{\circ} \mathrm{F}$. Note that there is no change in the mean gage factor between ambient and $1200^{\circ} \mathrm{F}$. At $1200^{\circ} \mathrm{F}$, the confidence limits and tolerance limits are \pm 0.17 and \pm 0.60 , respectively. Inspection of Figure 19 shows good linearity over the entire range, although the measured strains are about $10 \%$ less in compression than in tension.

Figure 20 shows the drift characteristics for the same specimens. The drift rate over the first 300 to $400 \mathrm{hr}$ is only $\mathrm{l}$ to $3 \mu \mathrm{\epsilon} / \mathrm{hr}$. Beyond $400 \mathrm{hr}$, the drift rate increases rapidly.

Figures 21 through 23 are plots of apparent strain vs temperature for six gages on specimens $D-21$ and -22 for series 1, cycles 1 through 3. Again, it is noted that the thermal cycling reduces the thermal hysteresis to essentially zero after one cycle. The confidence and tolerance limits are also substantially reduced as a result of the thermal cycling. For example, the $1200^{\circ} \mathrm{F}$ confidence and tolerance limits a re reduced from \pm 666 and $\pm 2356 \mu \epsilon$ (cycle 1 ) to \pm 363 and $1283 \mu \epsilon$ (cycle 3).

Figures 24 and 25 are plots of gage factor vs temperature and average measured vs calculated strain, based on data taken at ambient and $1200^{\circ} \mathrm{F}$. The rise in gage factor with temperature is noted as well as the good linearity over the entire range. At $1200^{\circ} \mathrm{F}$, the confidence and tolerance limits are \pm 0.19 and $\pm 0.67 \mu \epsilon$, respectively.

Figure 26 is a plot of the $1200^{\circ} \mathrm{F}$ drift characteristics for the same gages. The drift rate over the first 300 to $400 \mathrm{hr}$ is very small, amounting to 1 to $2 \mu \epsilon /$ $\mathrm{hr}$. Beyond $400 \mathrm{hr}$, the drift becomes excessive. At the end of $300 \mathrm{hr}$, the confidence and tolerance limits are \pm 284 and $\pm 1004 \mu \epsilon$, respectively, indicating reasonably good uniformity from gage to gage.

2. Group 2 (D-29, and -32 through -34 )

This group of gages was fabricated with full utilization of the knowledge gained from the Group 1 pilot gages. Nichrome V ribbon was us ed for all gages, 


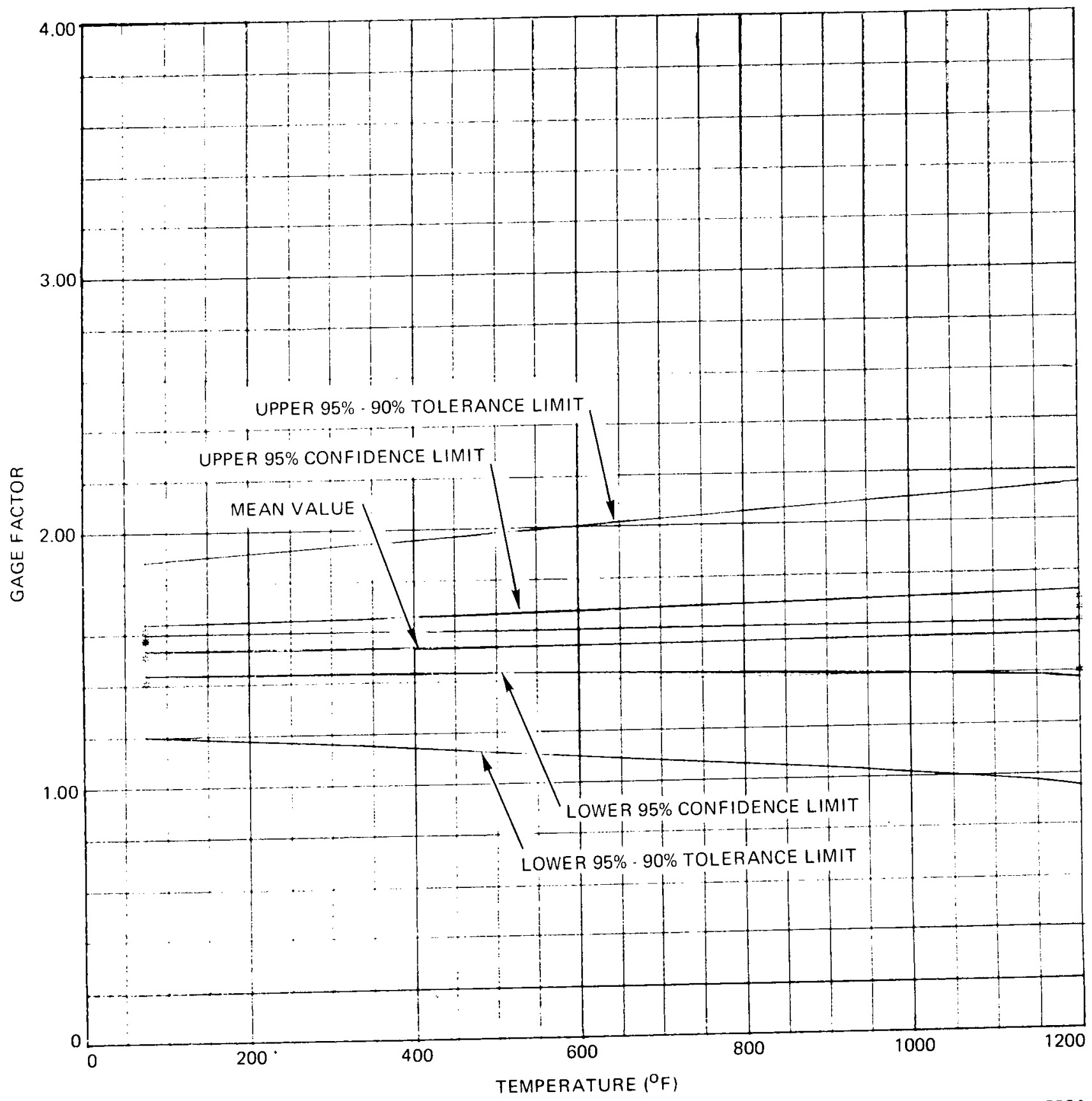

Figure 18. Gage Factor vs Temperature, with Confidence and Tolerance Limits for Specimens D- 15 and -16 , 5 Gages, Series 1 


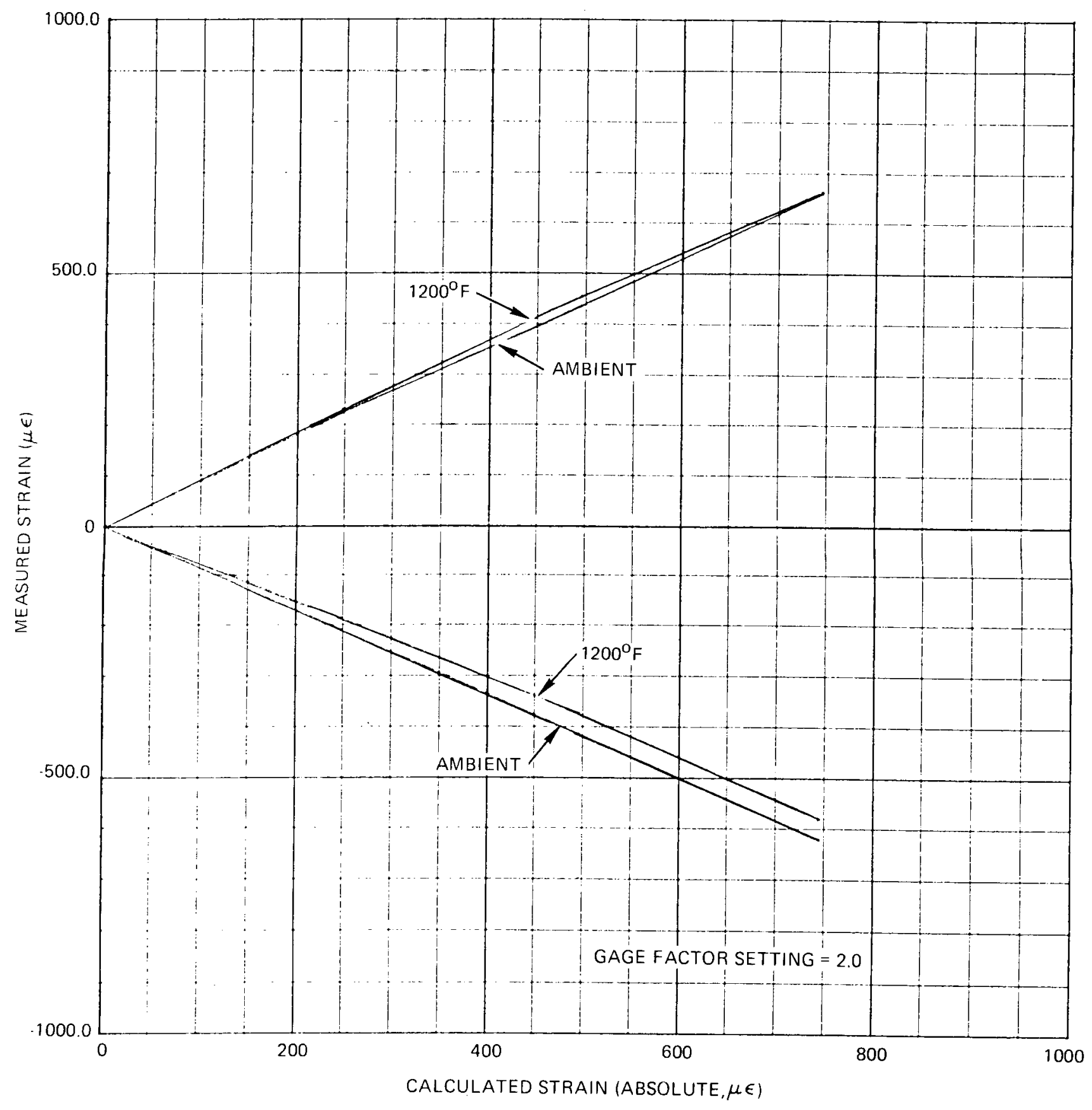

Figure 19. Average Measured Strain vs Calculated Strain for

$7693-55235$ Specimens D- 15 and -16 , Series 1 


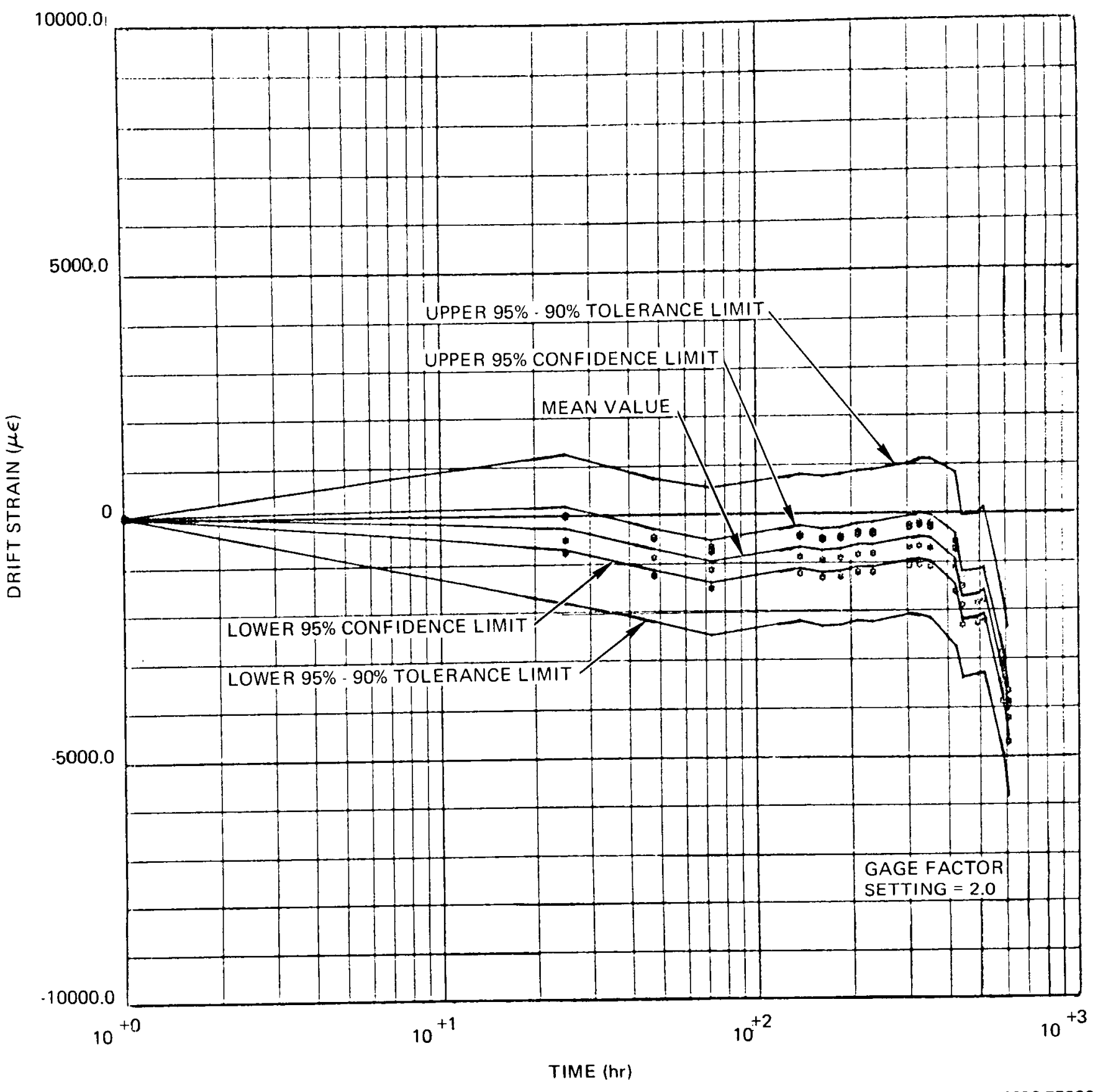

Figure 20. Drift vs Time at $1200^{\circ} \mathrm{F}$, with Confidence and Tolerance Limits for Specimens D-15 and -16 


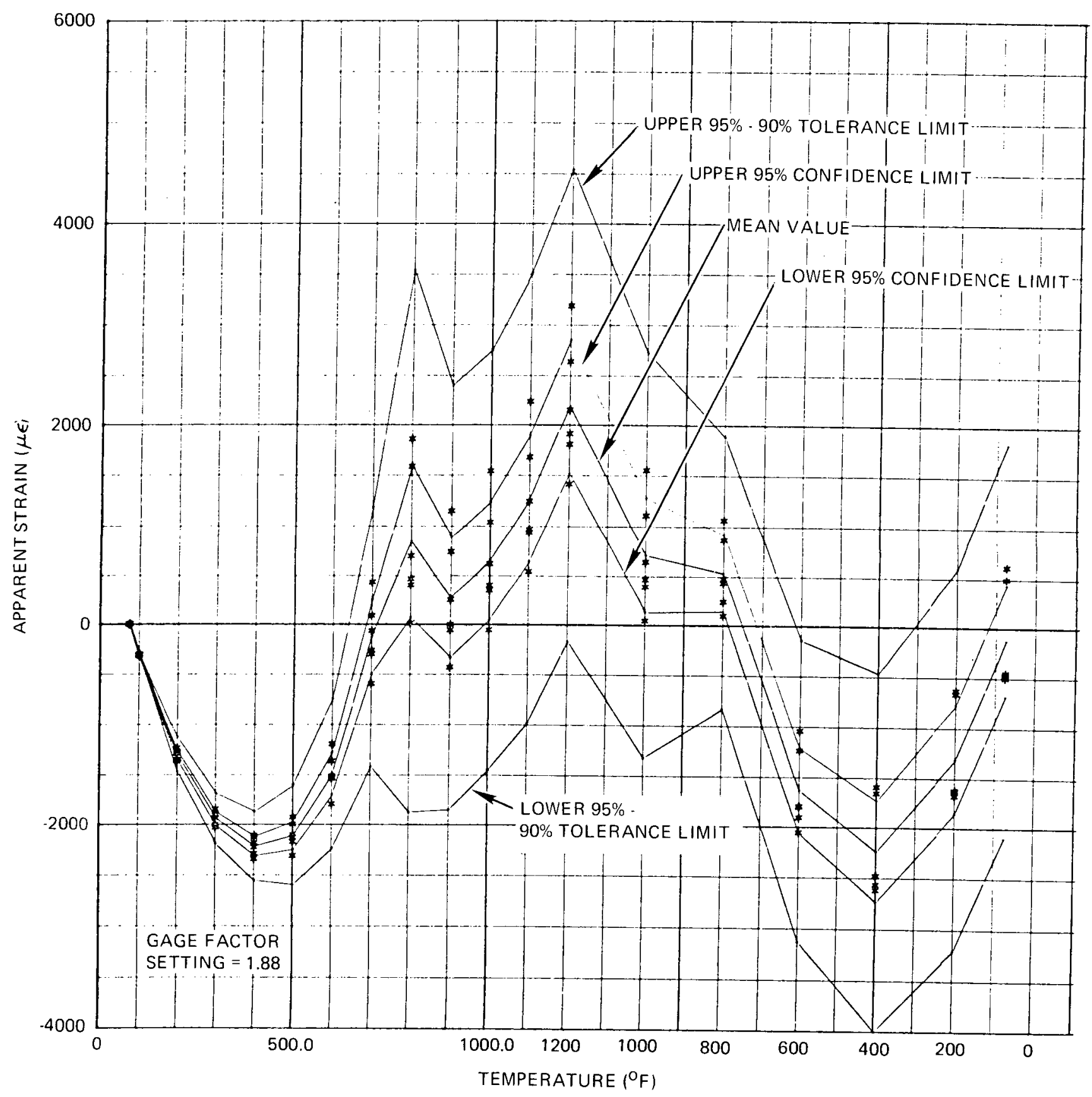

Figure 21. Apparent Strain vs Temperature, with Confidence

7693-55237 and Tolerance Limits for Specimens D-21 and -22 , 6 Gages, Series 1, Cycle 1 


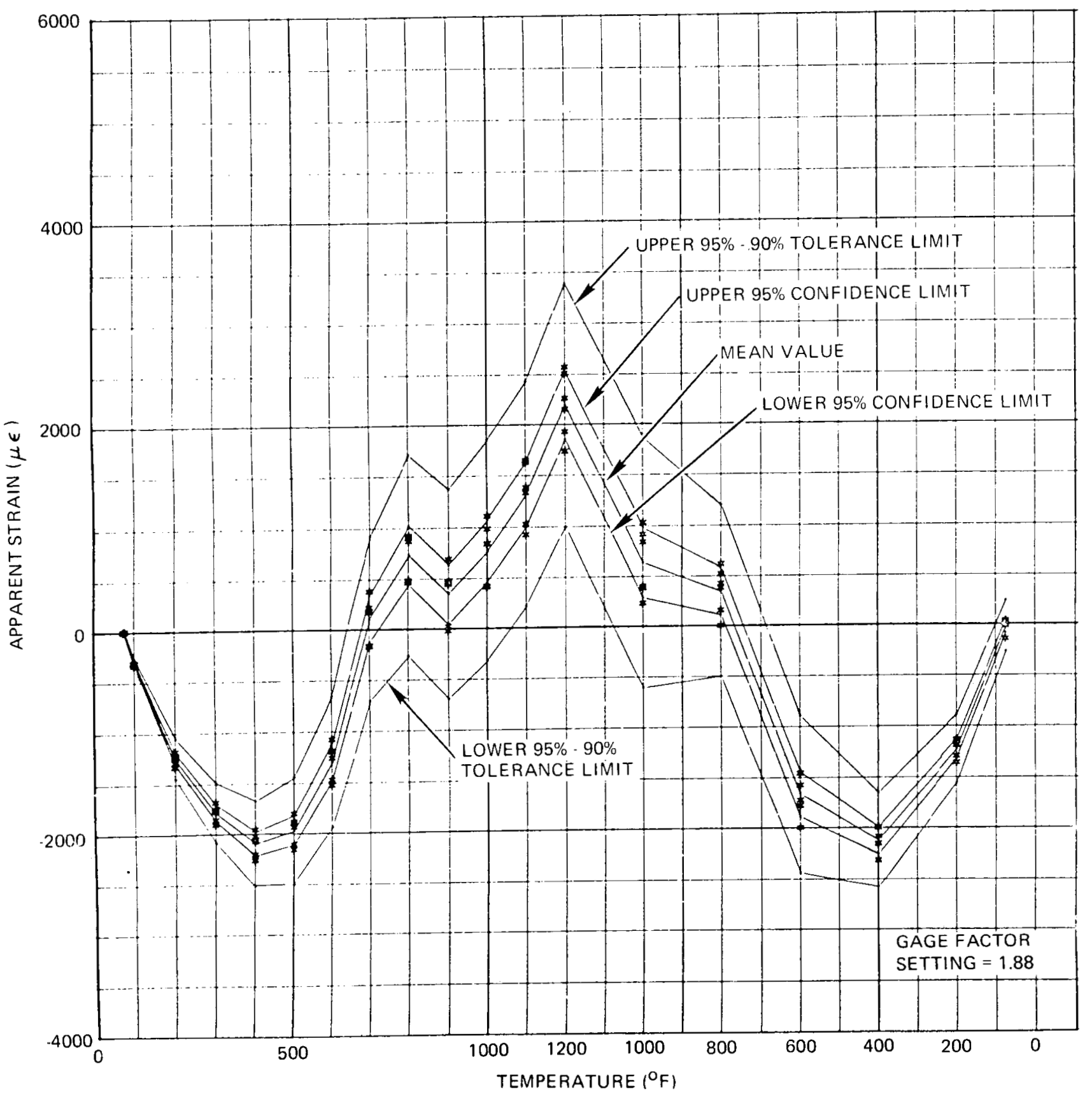

Figure 22. Apparent Strain vs Temperature, with Confidence and Tolerance Limits for Specimens D-21, and -22

6 Gages, Series 1, Cycle 2

LMEC $-70-8$ 


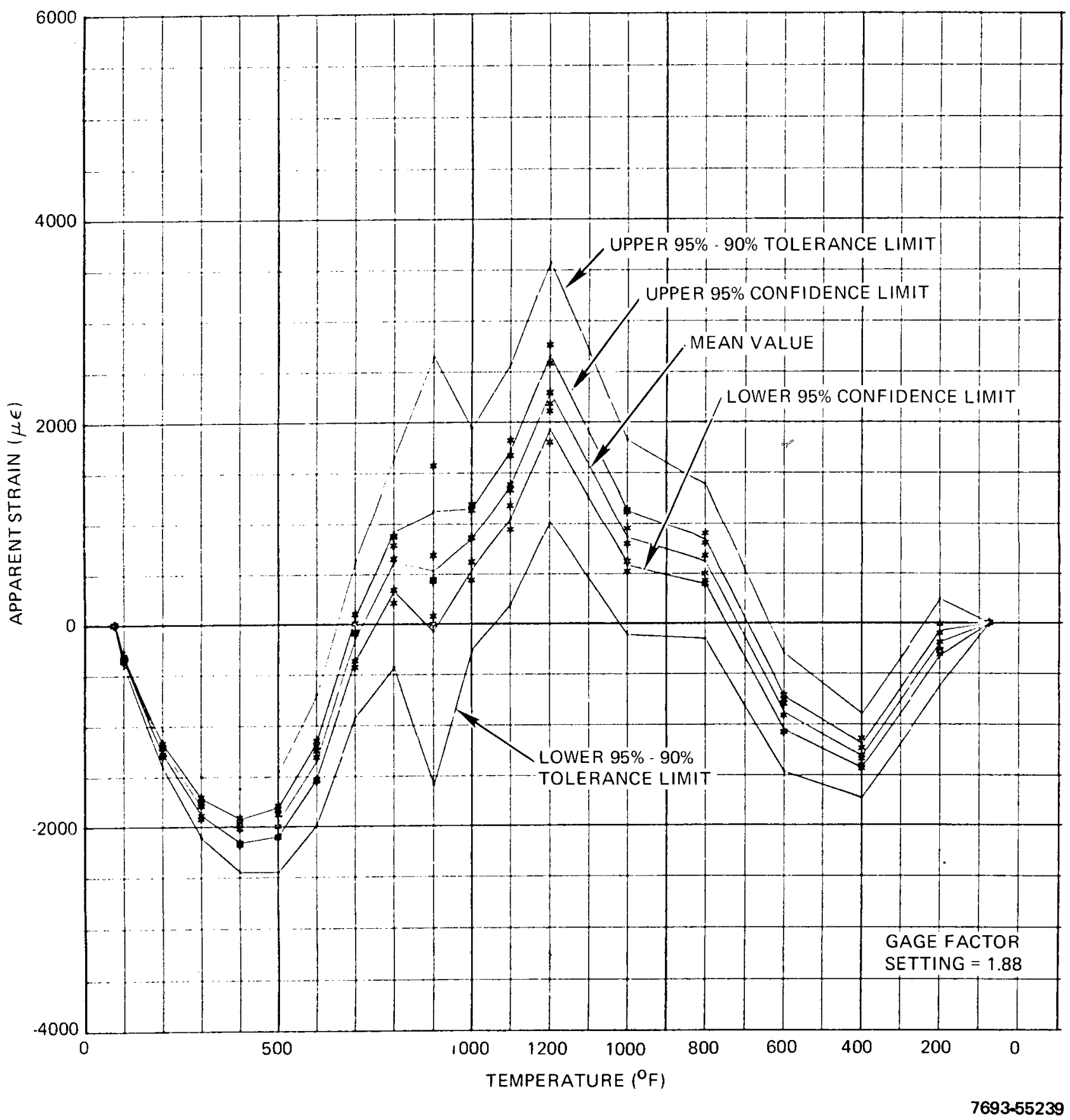

Figure 23. Apparent Strain vs Temperature, with Confidence and Tolerance Limits for Specimens D-21, and 22

6 Gages, Series 1, Cycle 3

LMEC-70-8 


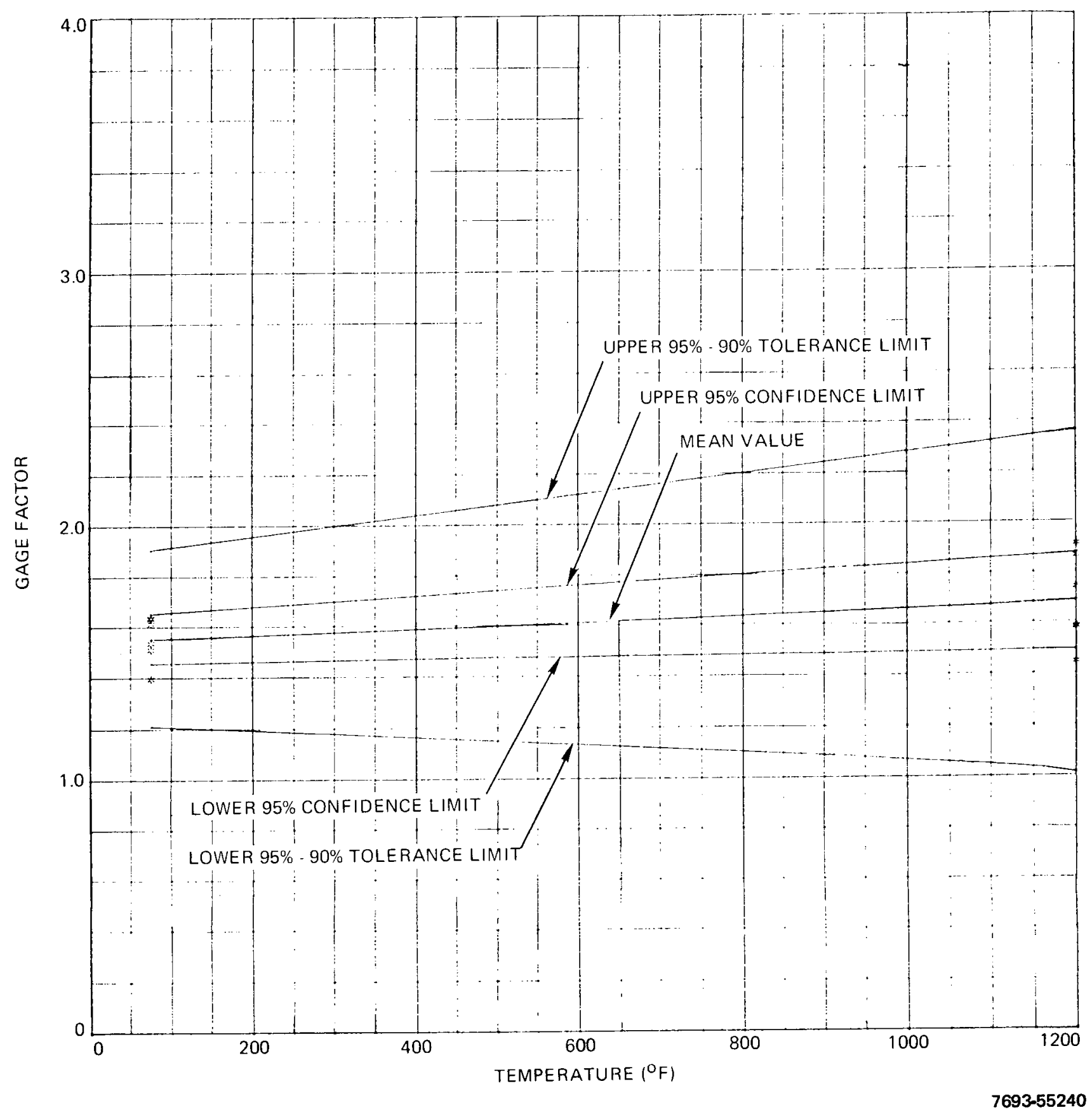

Figure 24. Gage Factor vs Temperature, with Confidence Tolerance Limits for Specimens $D-21$, and -22 6 Gages, Series 1 


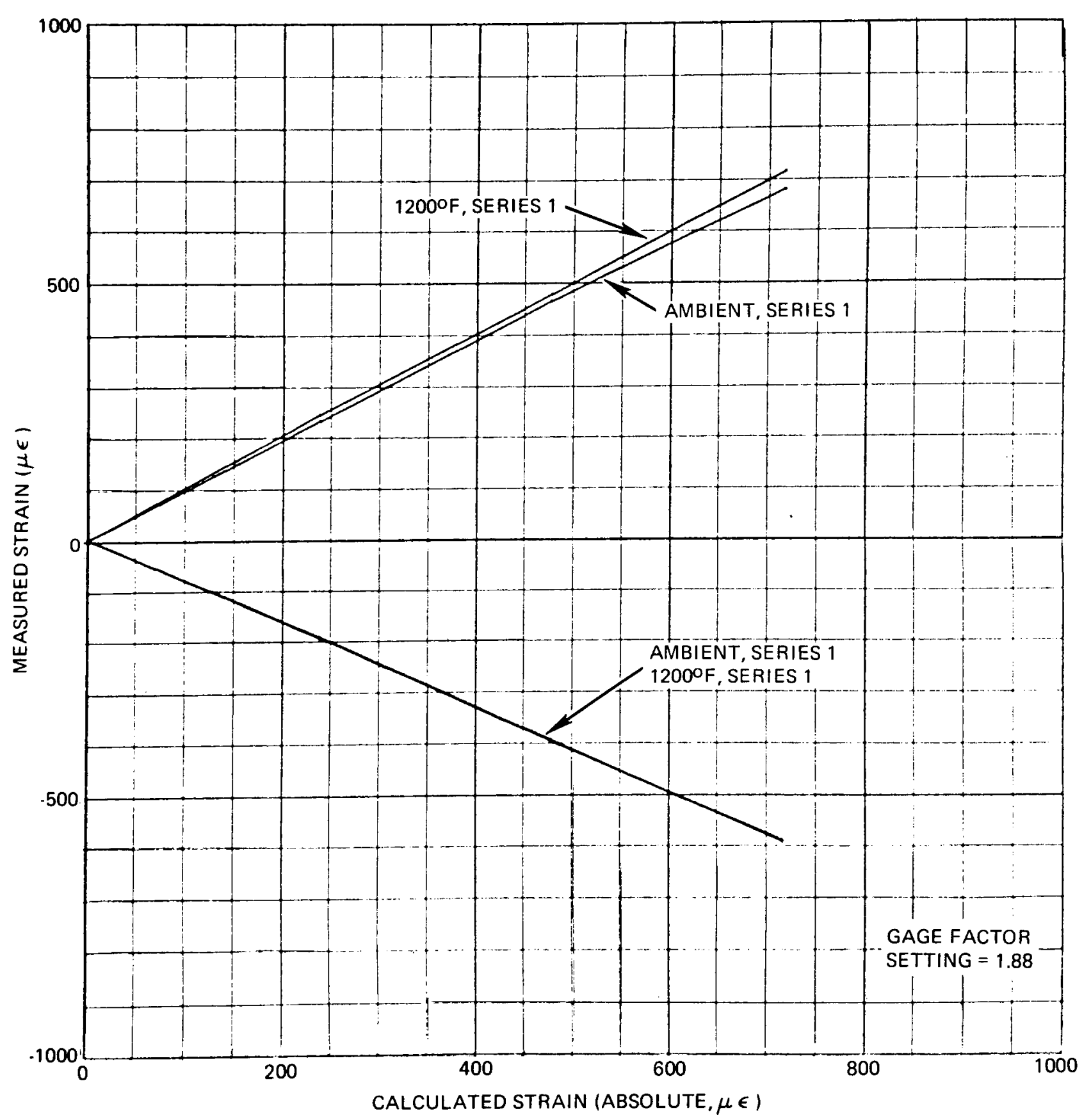

Figure 25. Average Measured Strain vs Calculated Strain for Specimens D-2l and -22 , Series 1

LMEC-70-8 


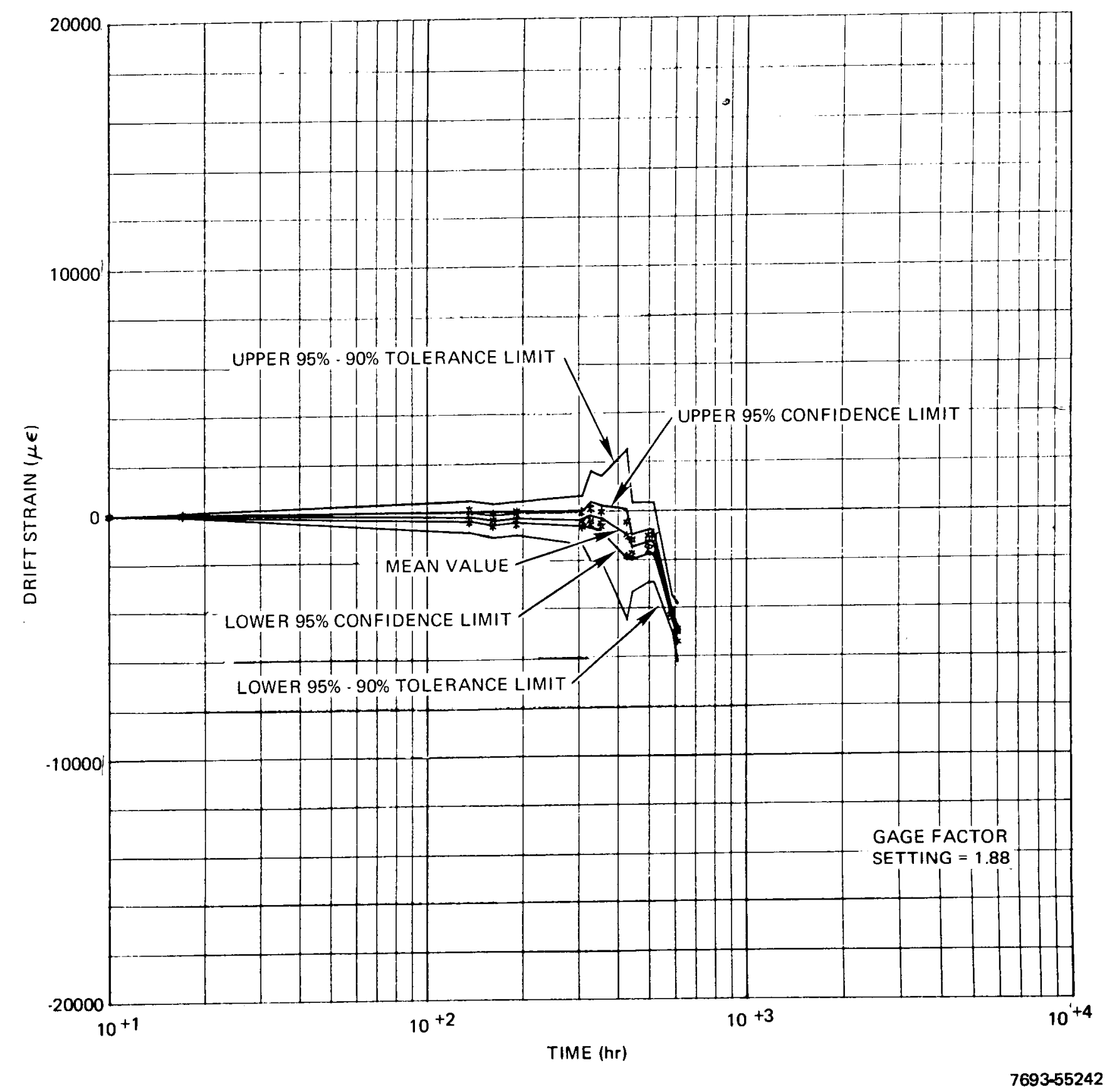

Figure 26. Drift vs Time, $1200^{\circ} \mathrm{F}$, with Confidence and Tolerance Limits for Specimens D-21 and -22 
since no benefit was discerned from use of Hoskins Alloy 875. Care was taken in using fresh carrier tape. Gloves were not used to fabricate the gages because they were considered too cumbersome at that time.

Figures 27 through 29 are plots of apparent strain vs temperature for gages on specimens 29, and 32 through 34, for series 1 through 3 . The apparent strain increases from series to serries. The $1200^{\circ} \mathrm{F}$ confidence and tolerance limits are \pm 293 and $\pm 1313 \mu \epsilon$ for series 1 , and \pm 1073 and $\pm 3798 \mu \epsilon$ for series 3 , indicating an increase in scatter as a result of the effects of the three series of tests.

Figures 30 through 32 are plots of gage factor and average measured strain vs calculated strain for series 1 and 2 . It is evident that the re is little change in gage factor between ambient and $1200^{\circ} \mathrm{F}$, and that there is a slight dip in gage factor at $600^{\circ} \mathrm{F}$. The $1200^{\circ} \mathrm{F}$ confidence and tolerance limits are \pm 0.041 and $\pm 0.185 \mu \epsilon$ (series 1 ), and \pm 0.085 and $\pm 0.345 \mu \epsilon$ (series 2 ), indicating some increase in scatter due to the effects of two series of tests. The difference in mean values between series 1 and 2 gage factors is essentially zero.

The linearity characteristics for both series are considered good, although the measured compressive strains are about $11 \%$ less than the measured tensile strains.

Figure 33 is a plot of the drift characteristics. Note that the drift rate increases slowly for the first $300 \mathrm{hr}$, then more rapidly for a brief period $(290$ to $325 \mathrm{hr}$ ), and then essentially levels out. The average drift rate over $600 \mathrm{hr}$ is approximately $1.5 \mu \epsilon / \mathrm{hr}$, which is considered excellent.

\section{Alco IHX Gages}

Table 2 summarizes the room temperature gage resistance and gage factor, and steady-state apparent strain characteristics for the gages on specimens D-35 through -37, and specimens AT-1 through -6. The apparent strain values are for a temperature of $800^{\circ} \mathrm{F}$, the temperature at which the maximum apparent strains were generally observed, even though the maximum test temperature was $900^{\circ} \mathrm{F}$.

The gage factors of the AT specimens are slightly higher than those of the $D$ specimens, and the apparent strain values of the AT specimens are substantially greater than those for the D specimens.

$$
\text { LMEC - 70-8 }
$$




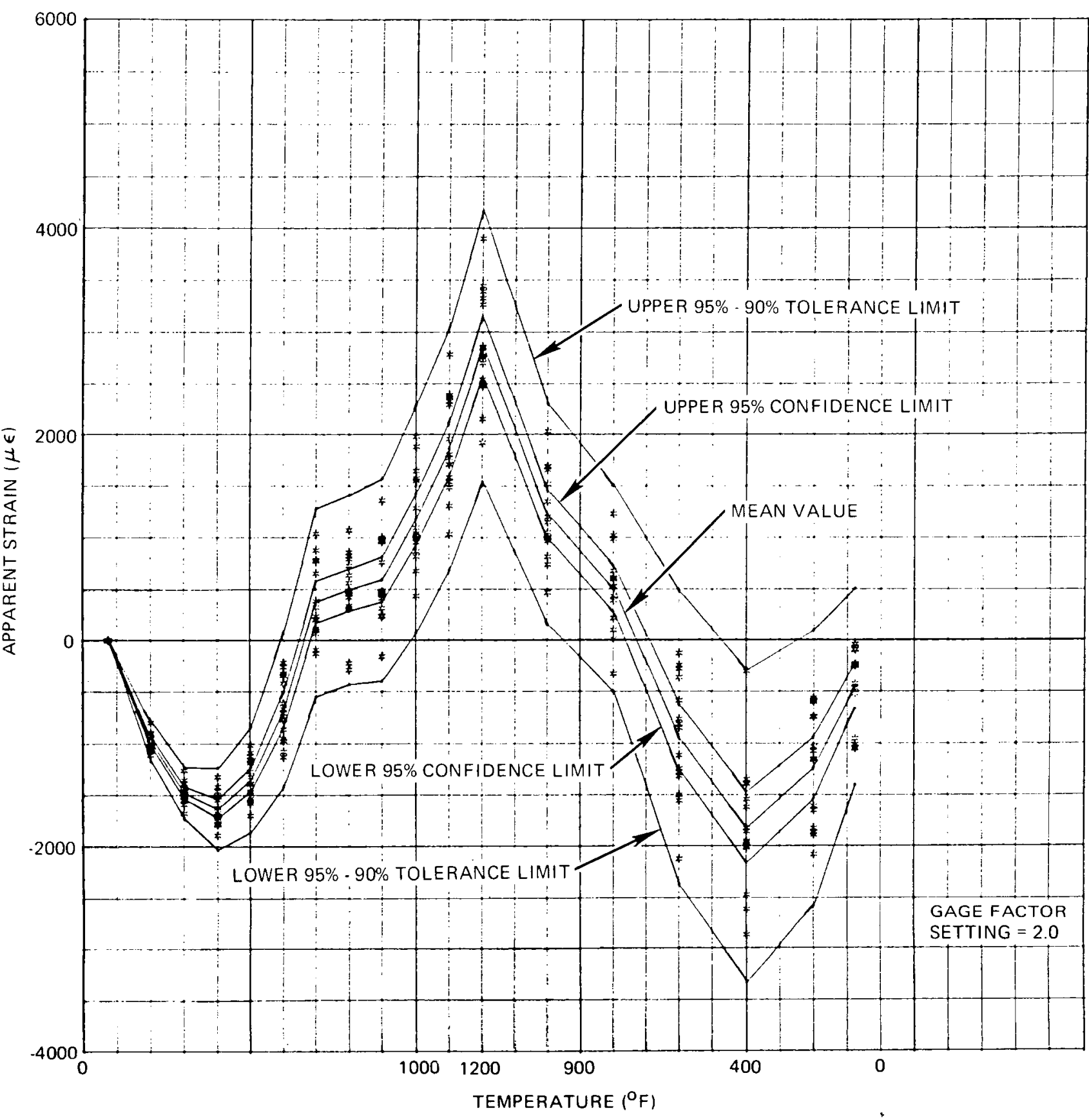

Figure 27. Apparent Strain vs Temperature, with Confidence and Tolerance Limits for Specimens D-29, and -32 through -34, 15 Gages, Series 1, Cycle 1 


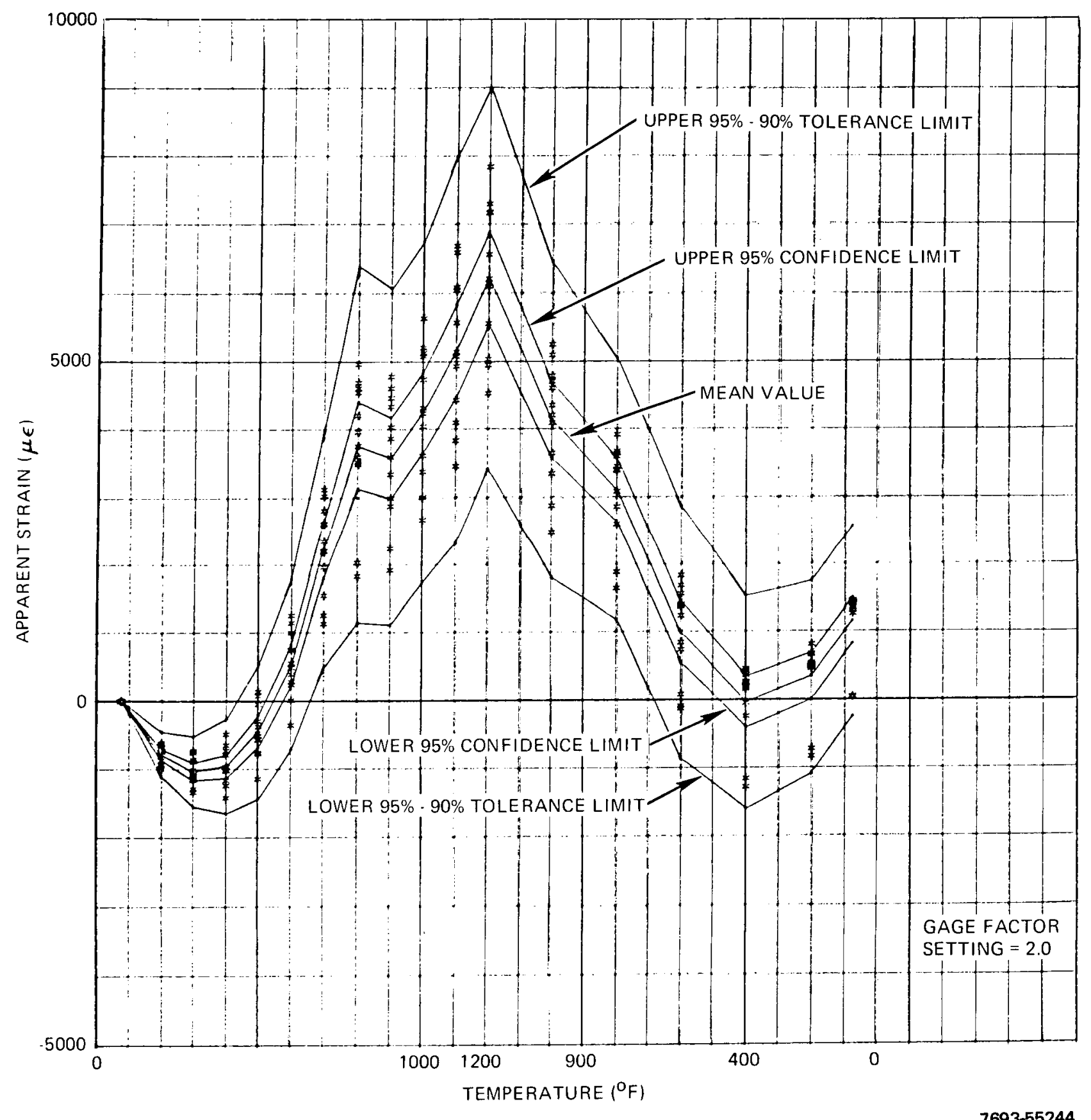

Figure 28. Apparent Strain vs Temperature, with Confidence and Tolerance Limits for Specimens D-29, and -32 through $-34,12$ Gages, Series 2, Cycle 1 


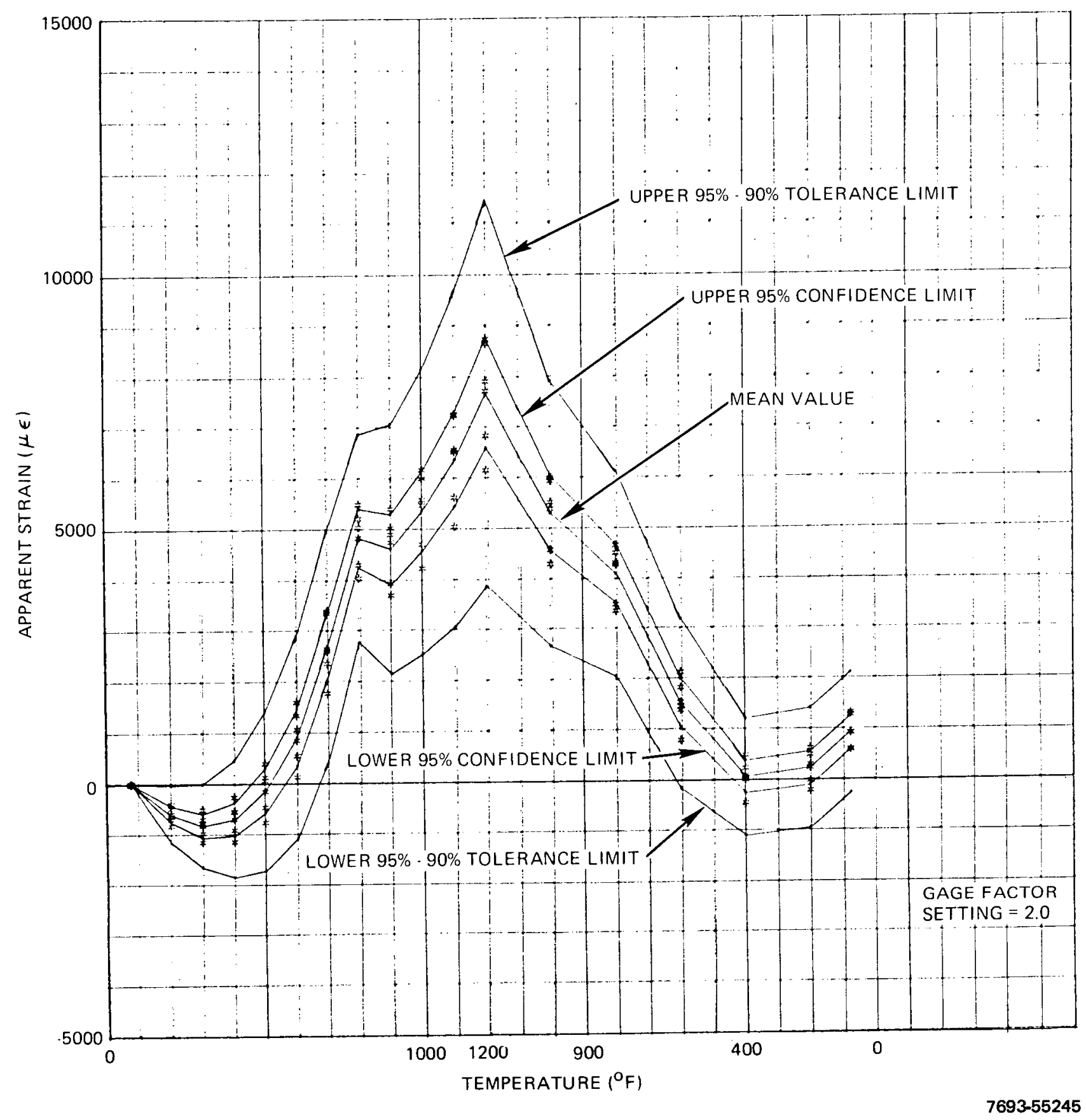

Figure 29. Apparent Strain vs Temperature, with Confidence and Tolerance Limits for Specimens D-29, and -32

through -34 , 6 Gages, Series 3, Cycle 1 


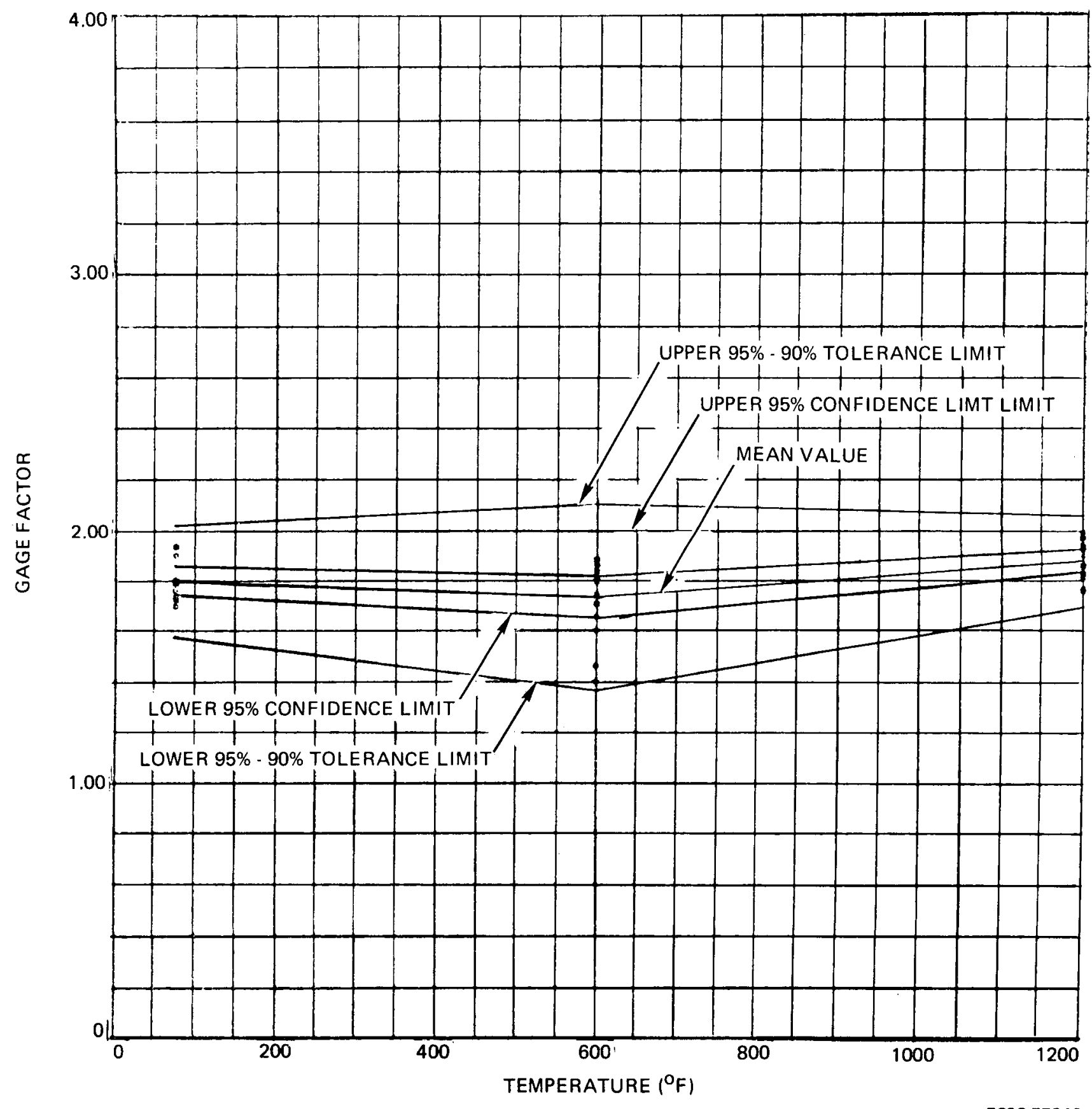

Figure 30. Gage Factor vs Temperature with Confidence and Tolerance Limits for Specimens D-29, and 32 through -34 , 15 Gages, Series 1 


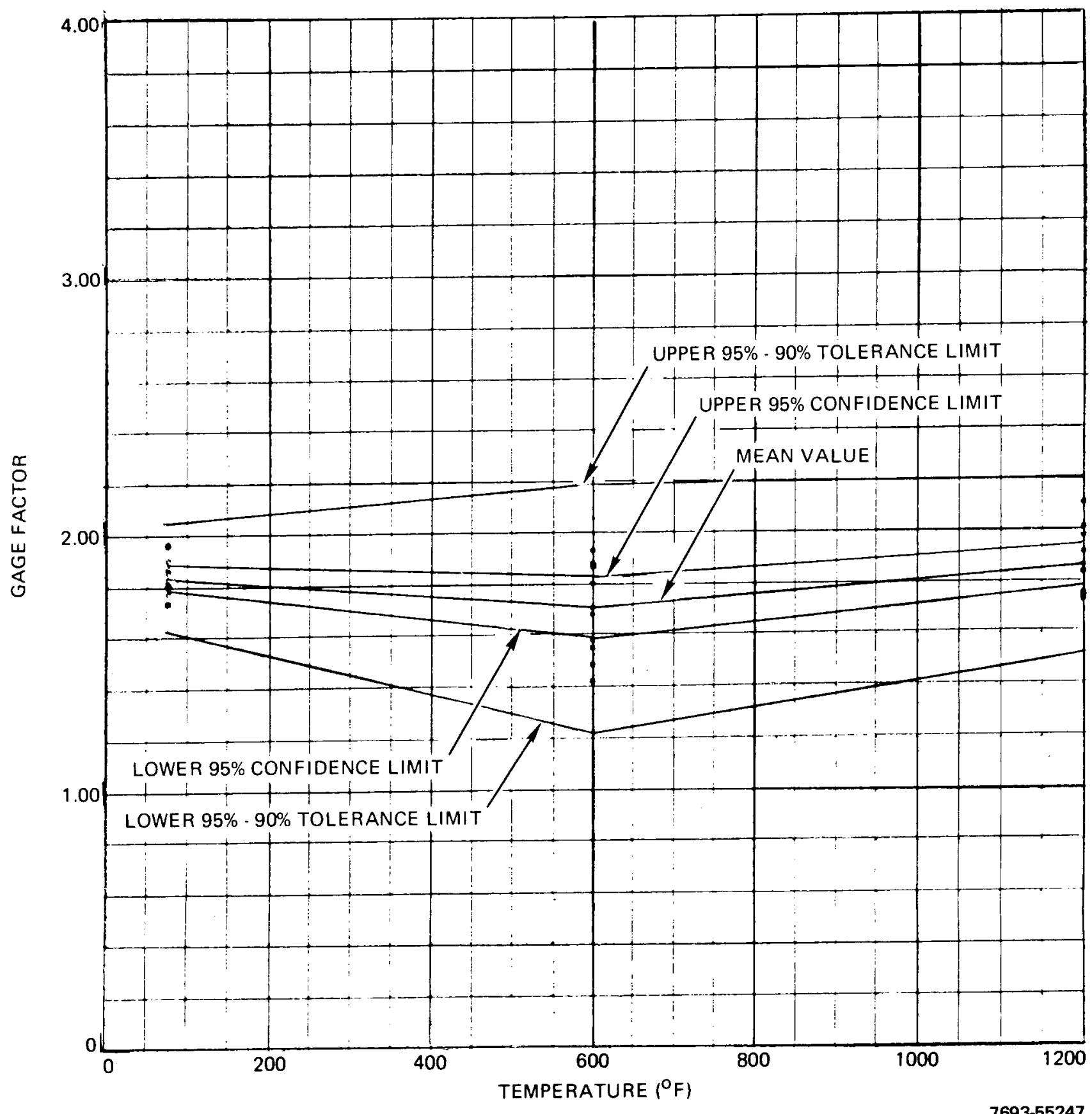

Figure 31. Gage Factor vs Temperature, with Confidence and Tolerance Limits for Specimens D-29, and 32 through $-34,11$ Gages, Series 2 


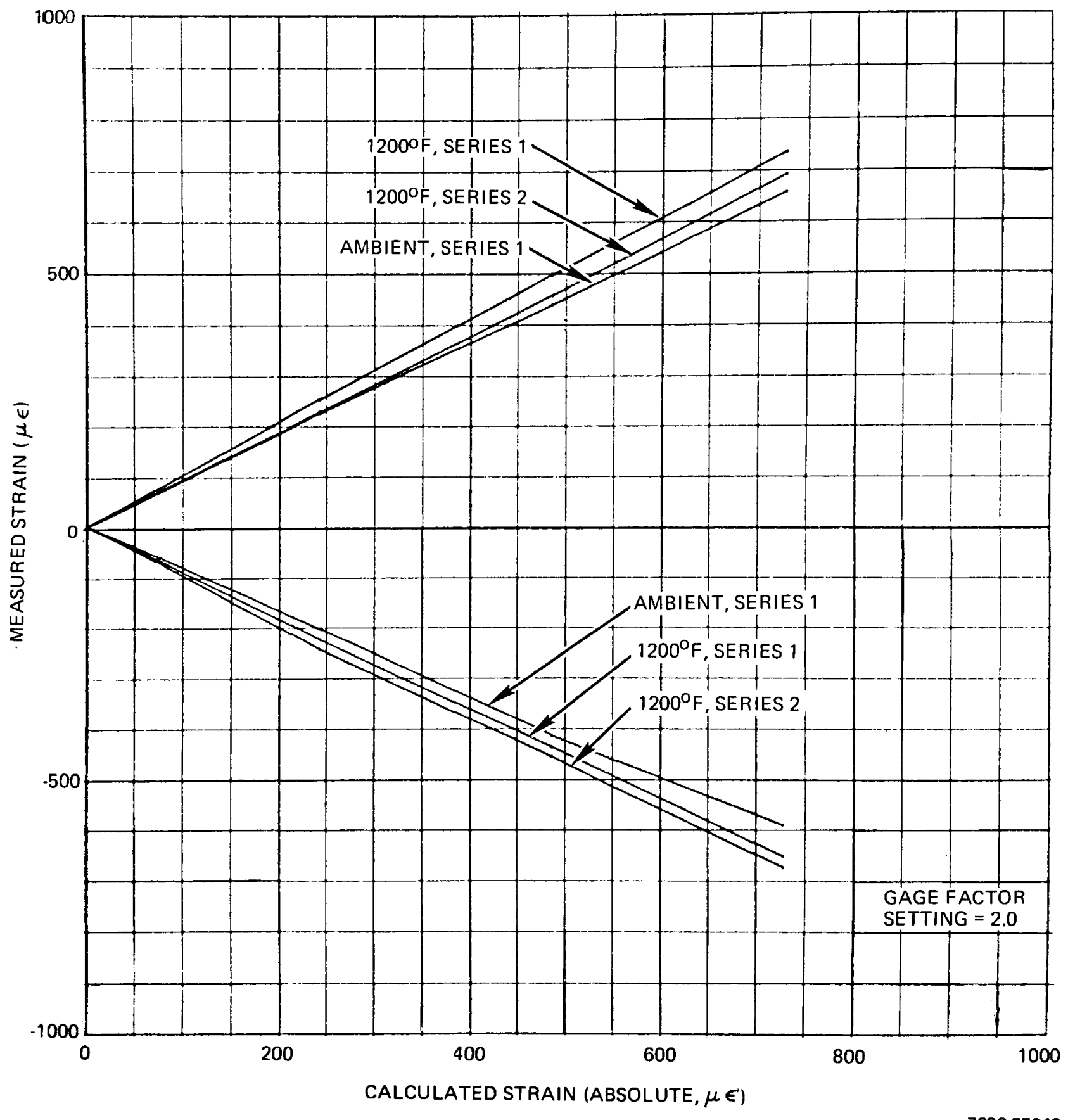

Figure 32. Average Measured Strain vs Calculated Strain for

7693-55248 Specimens D-32 through -34 , Series 1 and 2 


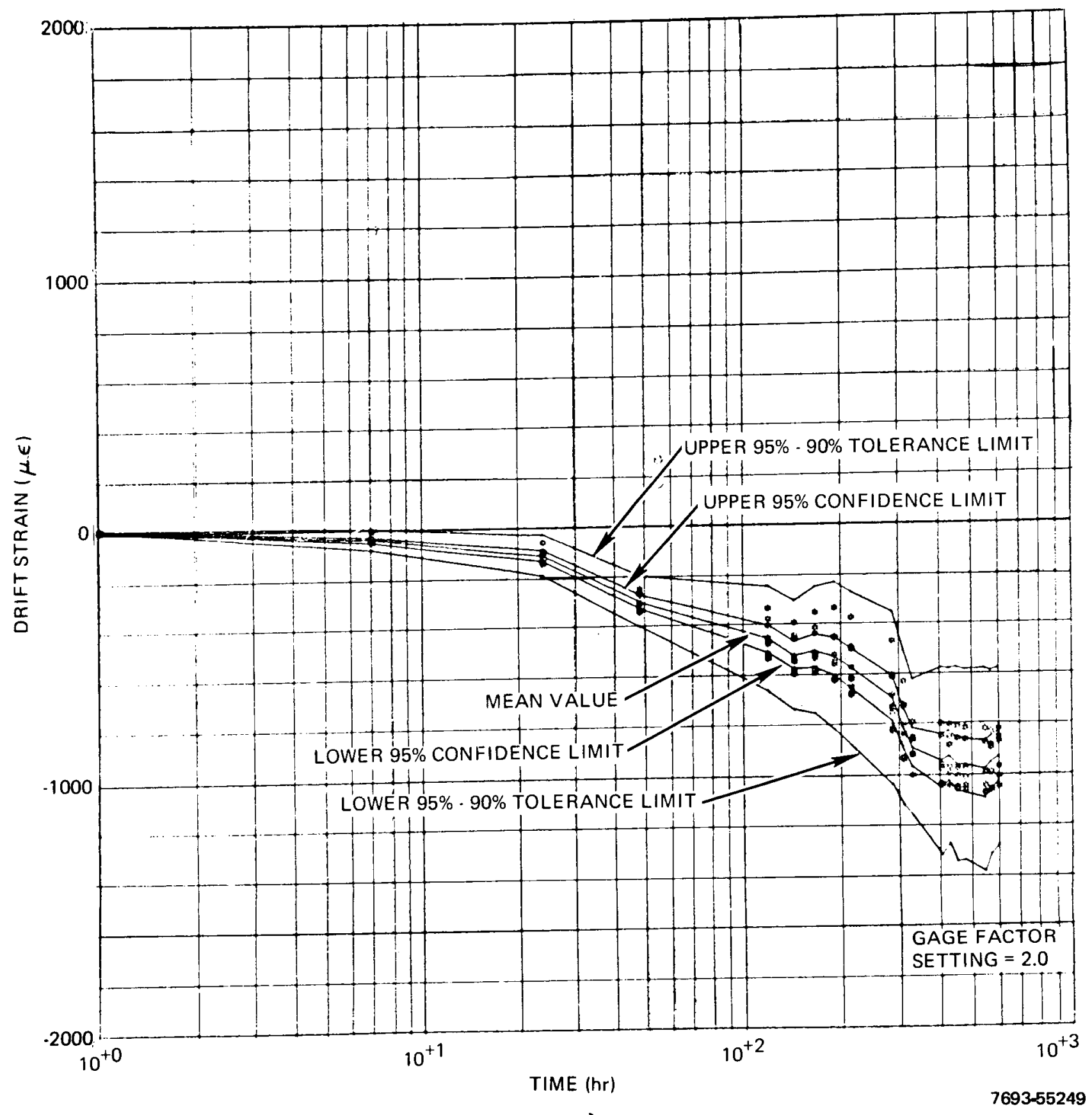

Figure 33. Drift vs Time at $1200^{\circ} \mathrm{F}$, with Confidence and Tolerance Limits for Specimens D-32 through -34

LMEC-70-8 
TABLE 2

SUMMARY OF GAGE CHARACTERISTICS AND PERFORMANCE FOR STANDARD ARMOUR D-PT GAGES CALIBRATED FOR THE ALCO IHX

\begin{tabular}{|c|c|c|c|c|c|c|c|}
\hline \multirow{3}{*}{\multicolumn{2}{|c|}{$\begin{array}{l}\text { Specimen } \\
\text { and } \\
\text { Gage No. }\end{array}$}} & \multicolumn{2}{|c|}{ Room Temperature } & \multicolumn{4}{|c|}{$\begin{array}{c}\text { Steady-State Apparent Strain } \\
\text { at } 800^{\circ} \mathrm{F}(\mu \epsilon)\end{array}$} \\
\hline & & \multirow{2}{*}{$\begin{array}{c}\text { Gage } \\
\text { Resistance } \\
\text { (ohms) }\end{array}$} & \multirow{2}{*}{$\begin{array}{c}\text { Gage } \\
\text { Factor }\end{array}$} & \multicolumn{2}{|c|}{ Series 1} & \multicolumn{2}{|c|}{ Series 2} \\
\hline & & & & Cycle 1 & Cycle $2^{*}$ & Cycle 1 & Cycle 2 \\
\hline \multirow[t]{3}{*}{$D-35$} & 1 & 149 & 1.75 & 980 & 1170 & 1940 & 1280 \\
\hline & 2 & 149 & 1.70 & 780 & 980 & 1790 & 1090 \\
\hline & 3 & 149 & 1.65 & 1210 & 1360 & 2200 & 1550 \\
\hline \multirow[t]{4}{*}{$D-36$} & 1 & 149 & 1.81 & 810 & 670 & 1960 & 1350 \\
\hline & 2 & 144 & 1.78 & 930 & 840 & 2050 & 1460 \\
\hline & 3 & 149 & 1.75 & 1220 & 1050 & 2390 & - \\
\hline & 4 & 149 & 1.65 & 720 & 610 & 1860 & 1270 \\
\hline \multirow[t]{3}{*}{$D-37$} & 1 & 149 & 1.82 & 930 & 990 & 1890 & 1200 \\
\hline & 2 & 148 & 1.80 & 1180 & 1260 & 2100 & 1410 \\
\hline & 3 & 149 & 1.78 & 1075 & 1180 & 1985 & 1315 \\
\hline Mean & Value & 148 & 1.75 & 984 & 1011 & 2019 & 1325 \\
\hline \multirow[t]{2}{*}{$\mathrm{AT}-1$} & 1 & 149 & 1.96 & 3490 & 3140 & 3355 & 3230 \\
\hline & 2 & 150 & 1.94 & 3200 & 2890 & 3130 & 2960 \\
\hline \multirow[t]{2}{*}{$\mathrm{AT}-2$} & 1 & 150 & 1.87 & 3085 & 2820 & 3950 & 2965 \\
\hline & 2 & 149 & 1.88 & 3300 & 3005 & 4075 & 3095 \\
\hline \multirow[t]{2}{*}{$\mathrm{AT}-3$} & 1 & 149 & 1.78 & 2815 & 2750 & 1920 & 2580 \\
\hline & 2 & 151 & 1.83 & 3140 & 3015 & 2210 & 1860 \\
\hline \multirow[t]{2}{*}{$\mathrm{AT}-4$} & 1 & 150 & 1.87 & 3225 & 2910 & 2815 & 3375 \\
\hline & 2 & 151 & 1.86 & 3695 & 3380 & 2330 & 2910 \\
\hline \multirow[t]{2}{*}{$\mathrm{AT}-5$} & 1 & 151 & 1.87 & 3350 & 3090 & 2605 & 3195 \\
\hline & 2 & 151 & 1.79 & 2650 & 2420 & 1960 & 2550 \\
\hline \multirow[t]{2}{*}{$\mathrm{AT}-6$} & 1 & 150 & 1.75 & 3085 & 2775 & 2345 & 2910 \\
\hline & 2 & 150 & 1.83 & 3690 & 3315 & 2855 & 3490 \\
\hline \multicolumn{2}{|c|}{ Mean Value } & 150 & 1.85 & 3227 & 2959 & 2798 & 2926 \\
\hline
\end{tabular}

* Series 1 , cycle 2 began at $350^{\circ} \mathrm{F}$ for specimens D-35 through -37 . 
Referring again to Table 2, the room temperature resistance and gage factor variations are small. Eight of 11 of the D specimens have a room temperature resistance of $149 \mathrm{ohms}$, which is almost identical to the mean value of $148 \mathrm{ohms}$; and for the AT series, the maximum deviation from the mean value of $150 \mathrm{ohms}$ is \pm 1 . With respect to gage factor, the maximum deviation for the $D$ specimens is 0.07 from a mean value of 1.75 , and for the AT series the maximum deviation is 0.11 from the mean value of 1.85 .

As to variations from cycle to cycle, there does not appear to be a precise trend in apparent strain values, except that the variations are small for some gages, but relatively large for others. It is believed that, in part, these variations are a result of imperfections in the wire, and of subtle variations in gage fabrication.

Figures 34 through 36 are plots of apparent strain vs temperature for specimens D-35 through -37 , series 2, cycles 1 through 3 . Note that the tolerance interval decreases as a result of cycling, dropping from $\pm 506 \mu \epsilon$ for cycle 1 to $\pm 407 \mu \epsilon$ for cycle 3 , with a difference of only $\pm 3 \mu \epsilon$ between the second and third cycle, indicating that thermal stabilization was virtually complete after two thermal cycles. At the end of the third cycle, the deviation from the mean value of $1818 \mu \epsilon$, is $\pm 22.4 \%$, in terms of the $95 \%-90 \%$ tolerance limits. The corresponding deviation, in terms of the $95 \%$ confidence limits is only $\pm 5.6 \%$.

Figure 37 is a plot of gage factor vs temperature for the same gages. There is only a slight decrease in gage factor with increasing temperature, with the maximum scatter occurring at $500^{\circ} \mathrm{F}$. At this temperature, the tolerance interval is \pm 0.361 , representing a deviation from the mean value of 1.711 of $21.1 \%$. The deviation in terms of the $95 \%$ confidence limit is $\pm 5.14 \%$.

Figure 38 is a plot of the average measured vs calculated strains for the same gages. As shown, the response is quite linear, the response in compression being slightly lower than that in tension.

Figures 39 through 42 are plots of apparent strain vs temperature for specimens AT -1 through -6 , series 1 and 2 .

At $800^{\circ} \mathrm{F}$, for series 1 , cycles 1 and 2 , the tolerance intervals are \pm 830 , and $\pm 695 \mu \epsilon$, representing deviations from the mean values of 3227 and $2959 \mu \epsilon$,

\section{LMEC - 70-8}




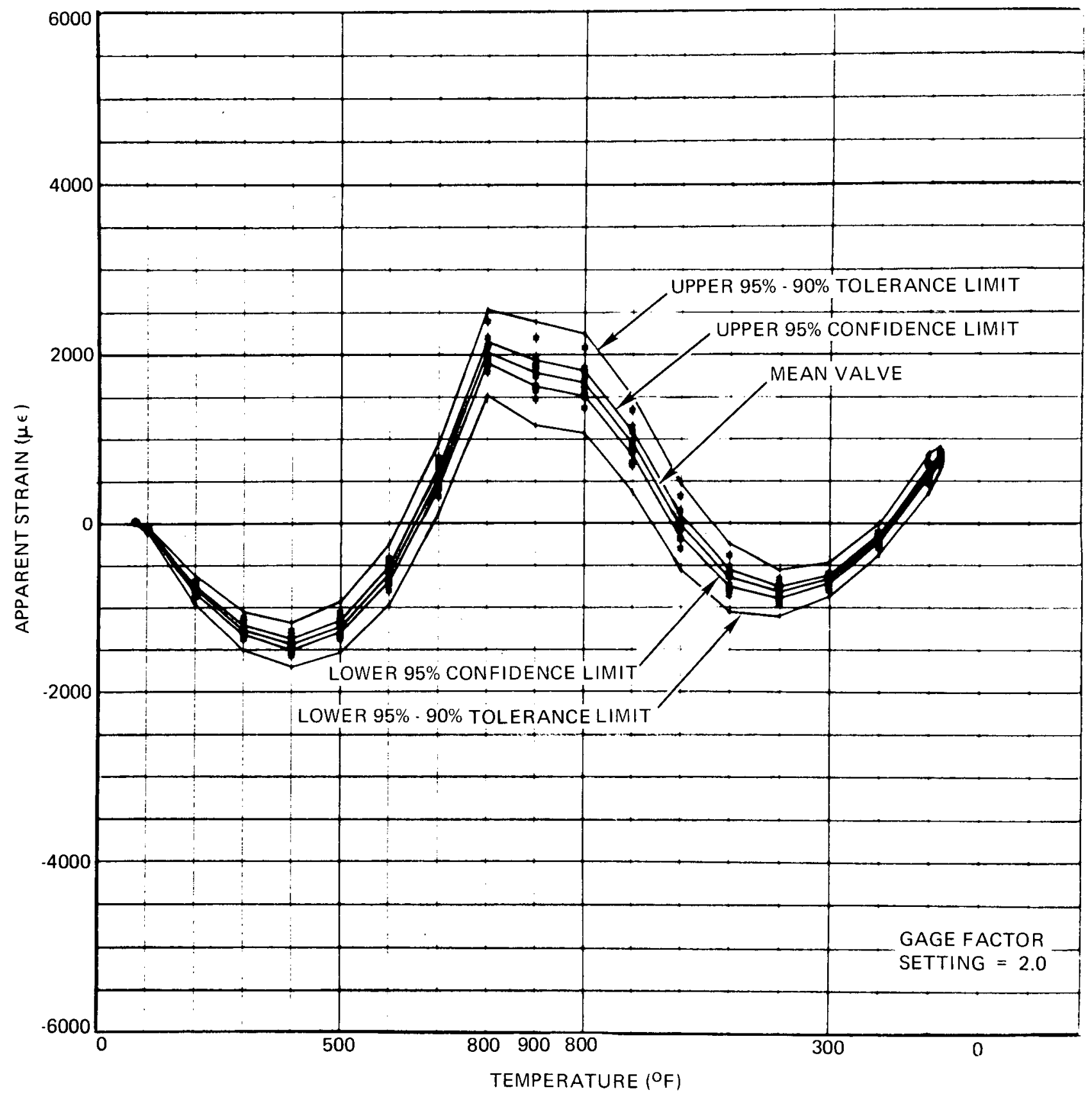

Figure 34. Apparent Strain vs Temperature with Confidence and Tolerance Limits for Specimens D-35 through -37, 10 Gages, Series 2, Cycle 1 


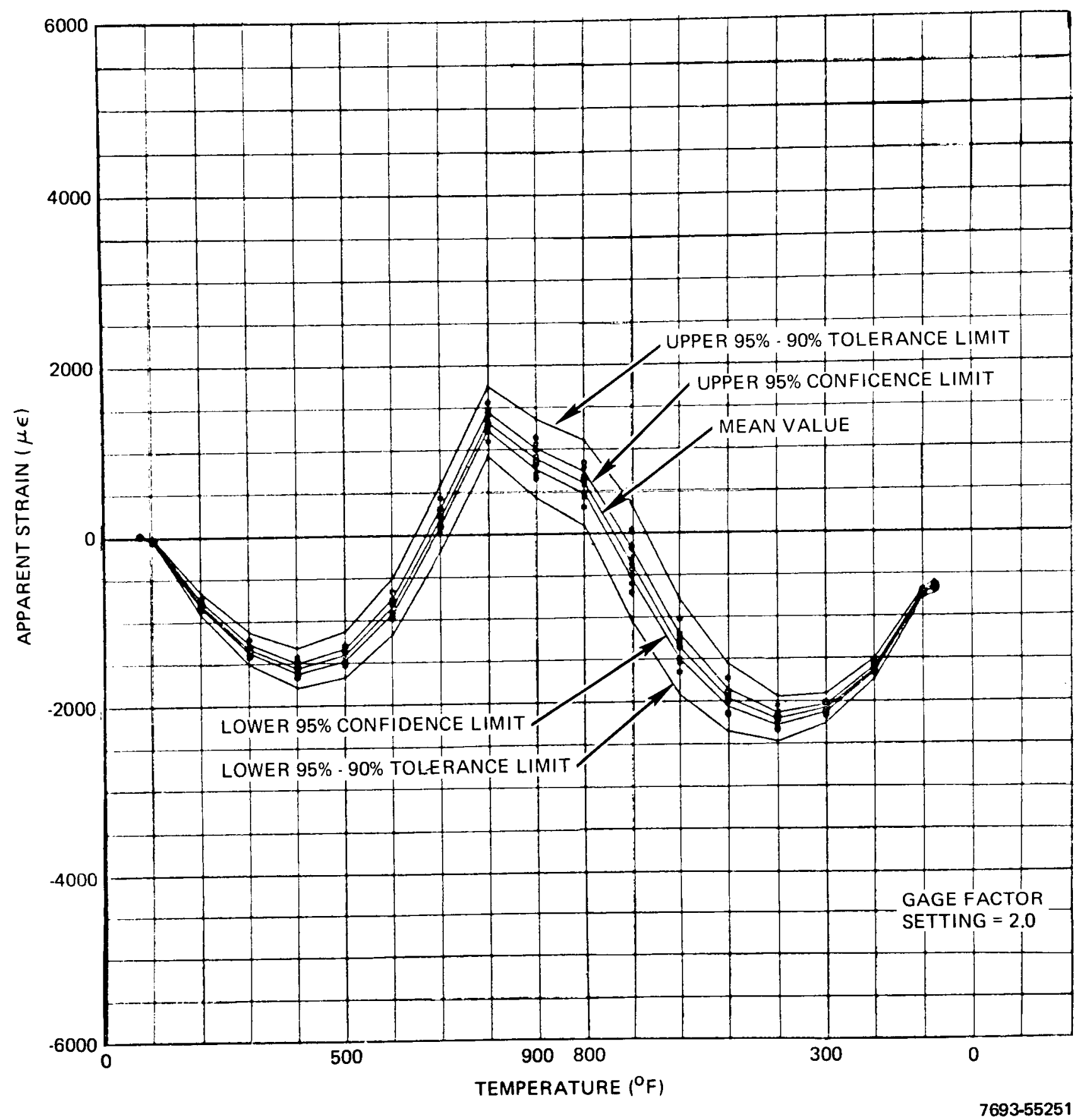

Figure 35. Apparent Strain vs Temperature, with Confidence and Tolerance Limits for Specimens D-35 through - 37, 9 Gages, Series 2, Cycle 2 


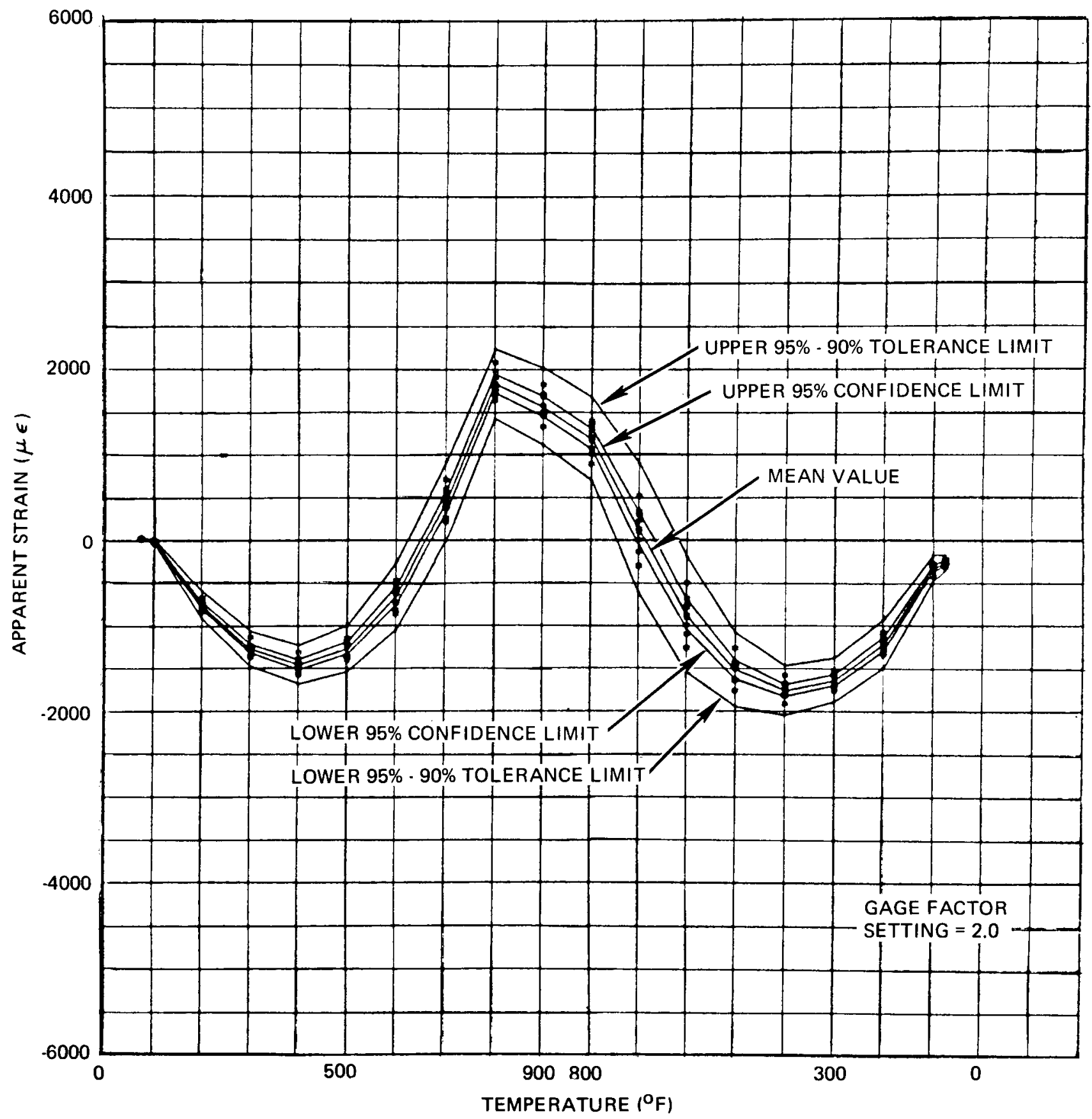

Figure 36. Apparent Strain vs Temperature, with Confidence and Tolerance Limits for Specimens D-35 through -37, 9 Gages, Series 2, Cycle 3 


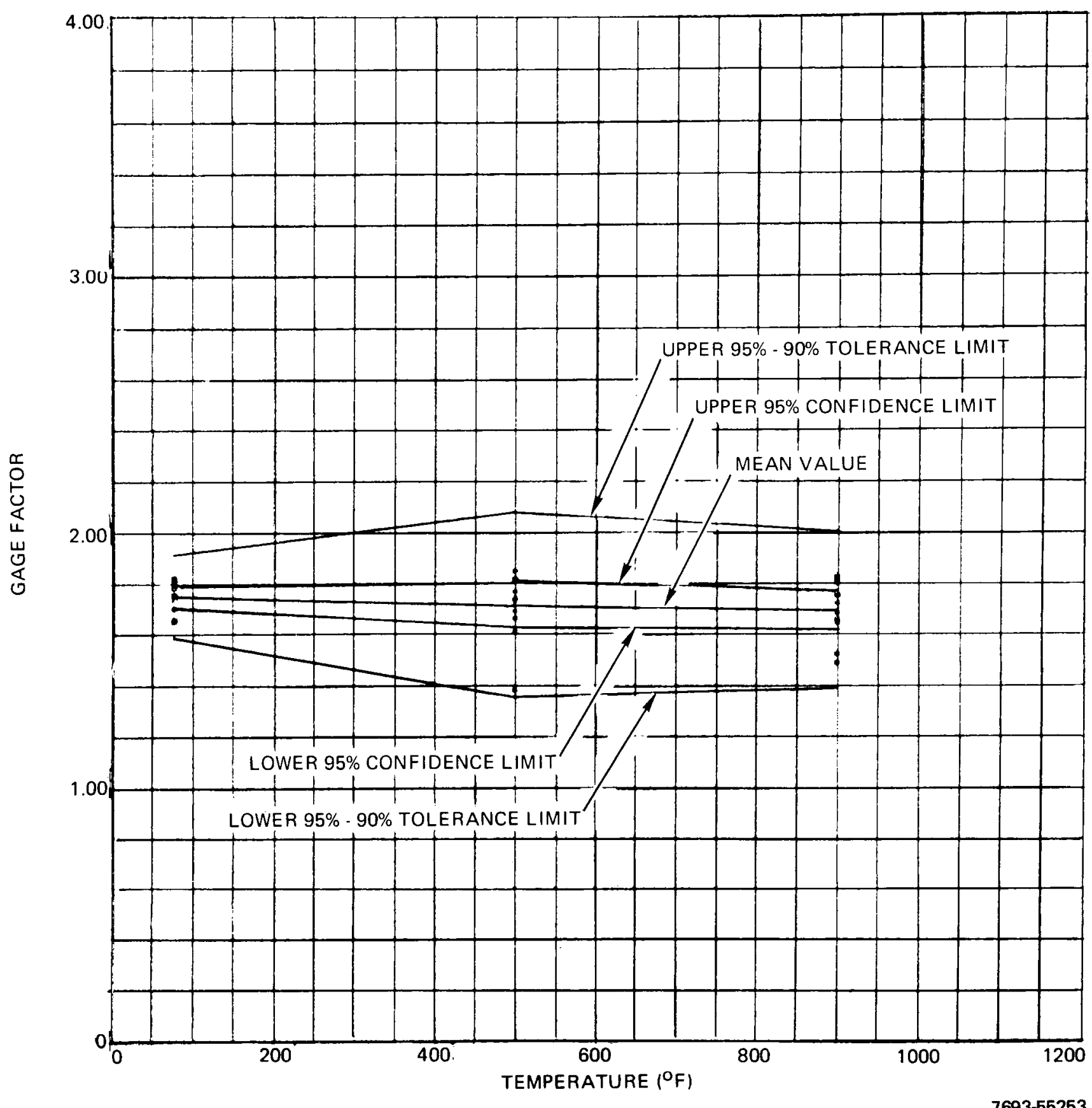

Figure 37. Gage Factor vs Temperature with Confidence and Tolerance Limits for Specimens D-35 through $-37,12$ Gages, Series 1 


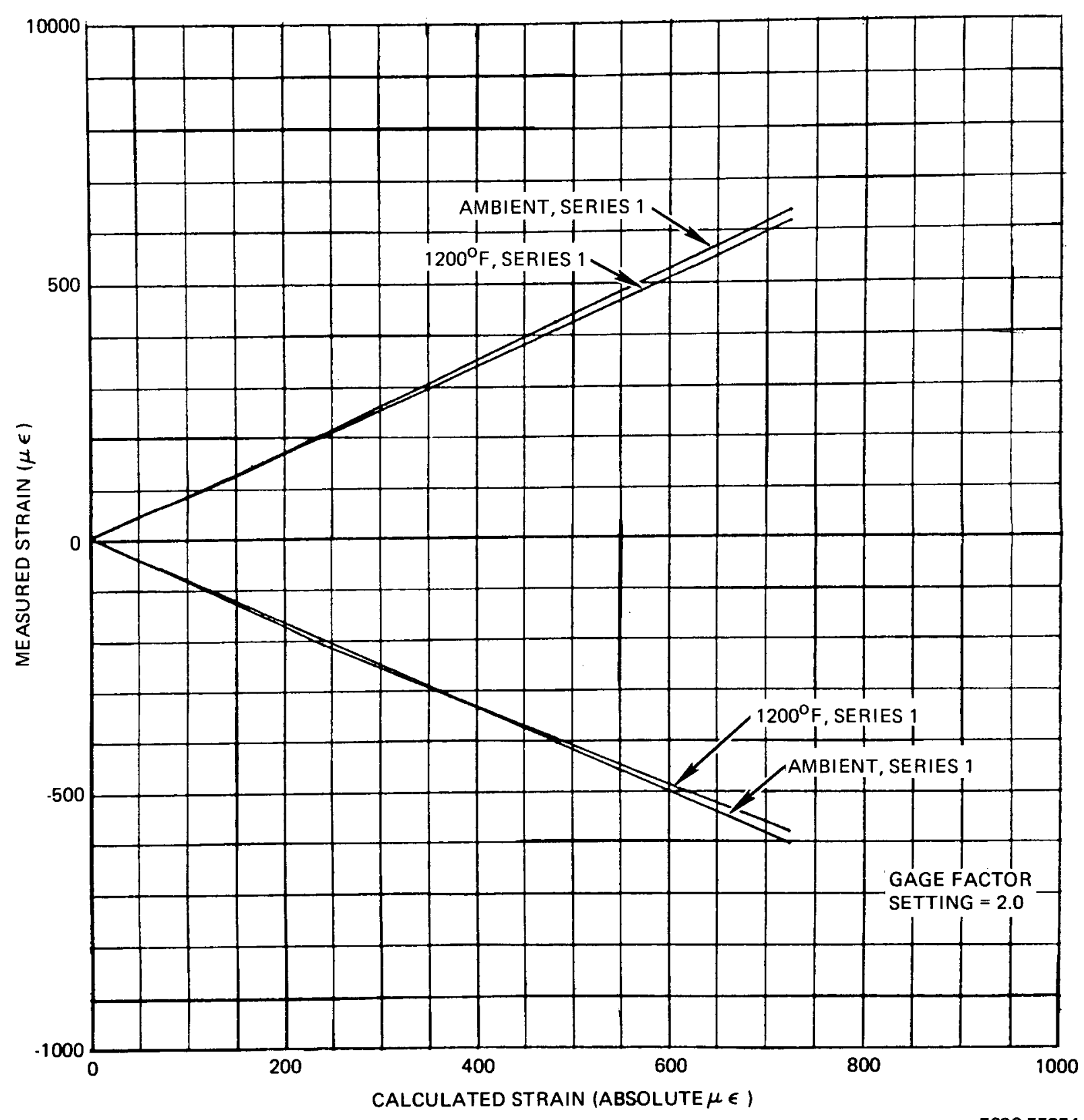

Figure 38. Average Measured Strain vs Calculated Strain for Specimens D-35 through 37, Series 1 


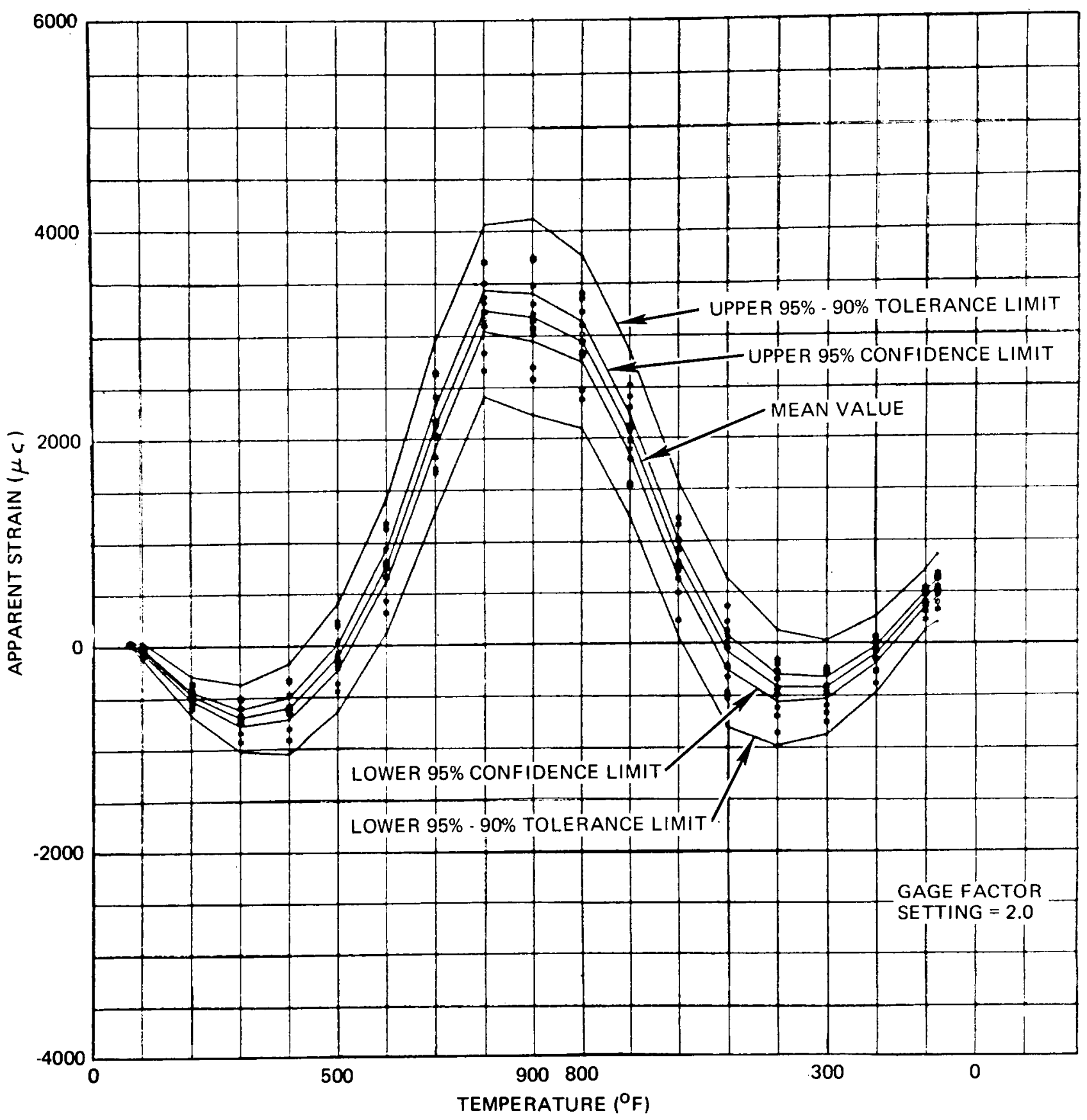

Figure 39. Apparent Strain vs Temperature, with Confidence and Tolerance Limits for Specimens AT-1 through -6, 12 Gages, Series 1, Cycle 1 


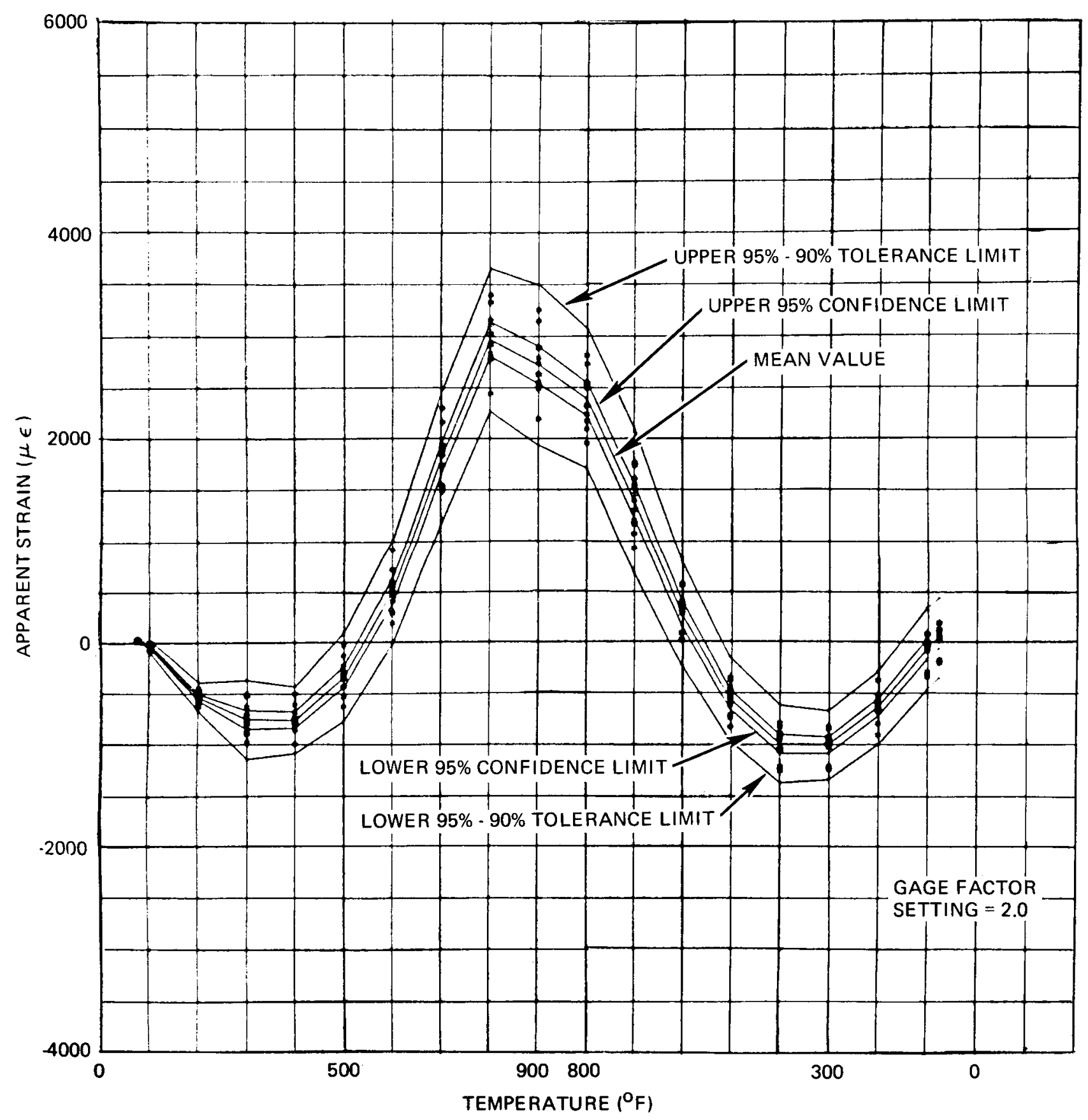

Figure 40. Apparent Strain vs Temperature, with Confidence and Tolerance Limits for Specimens AT- 1 through -6 , 12 Gages, Series 1, Cycle 2

LMEC-70-8 


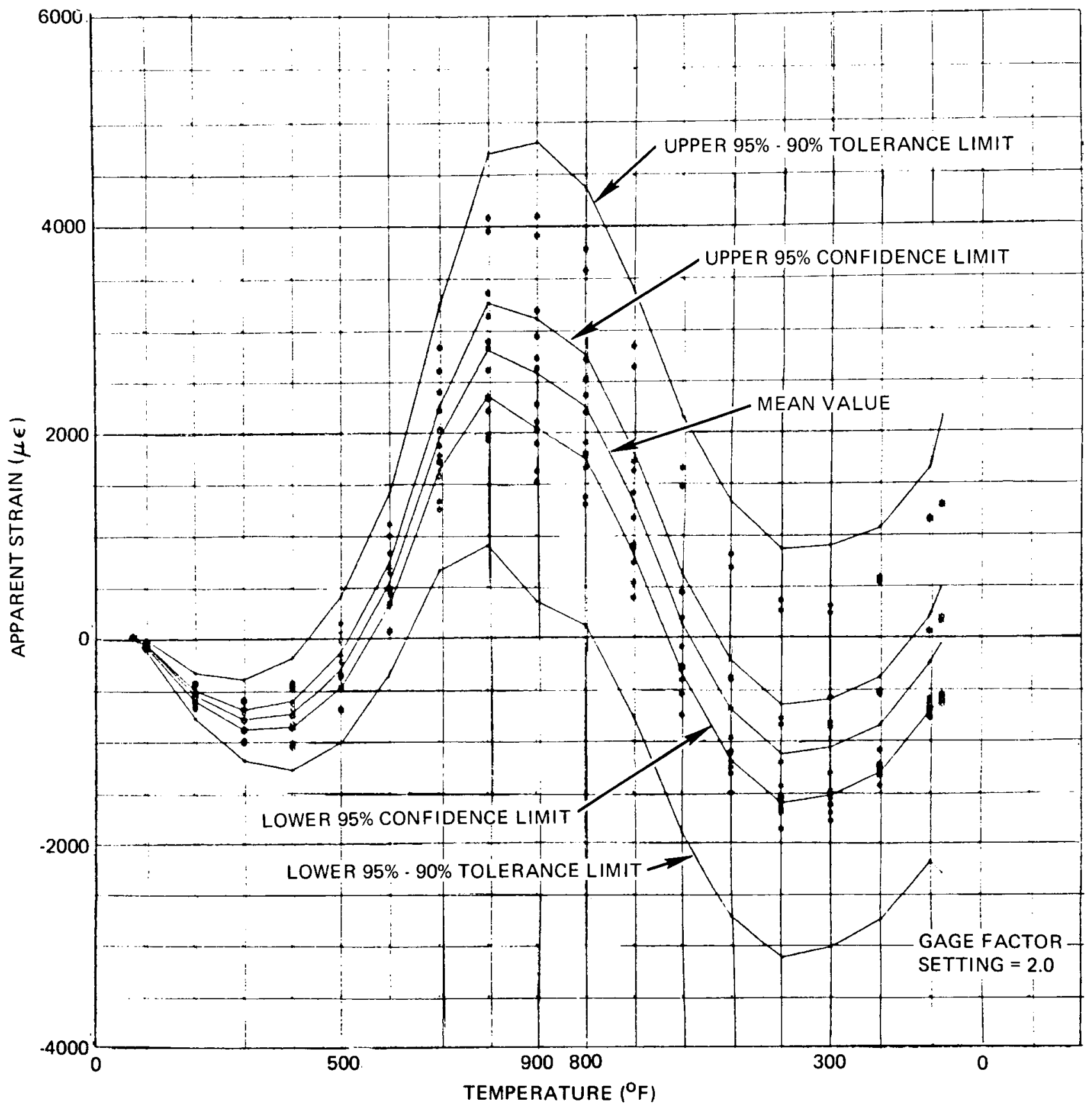

Figure 41. Apparent Strain vs Temperature, with Confidence and Tolerance Limits for Specimens AT-1 through -6, 12 Gages, Series 2, Cycle 1 


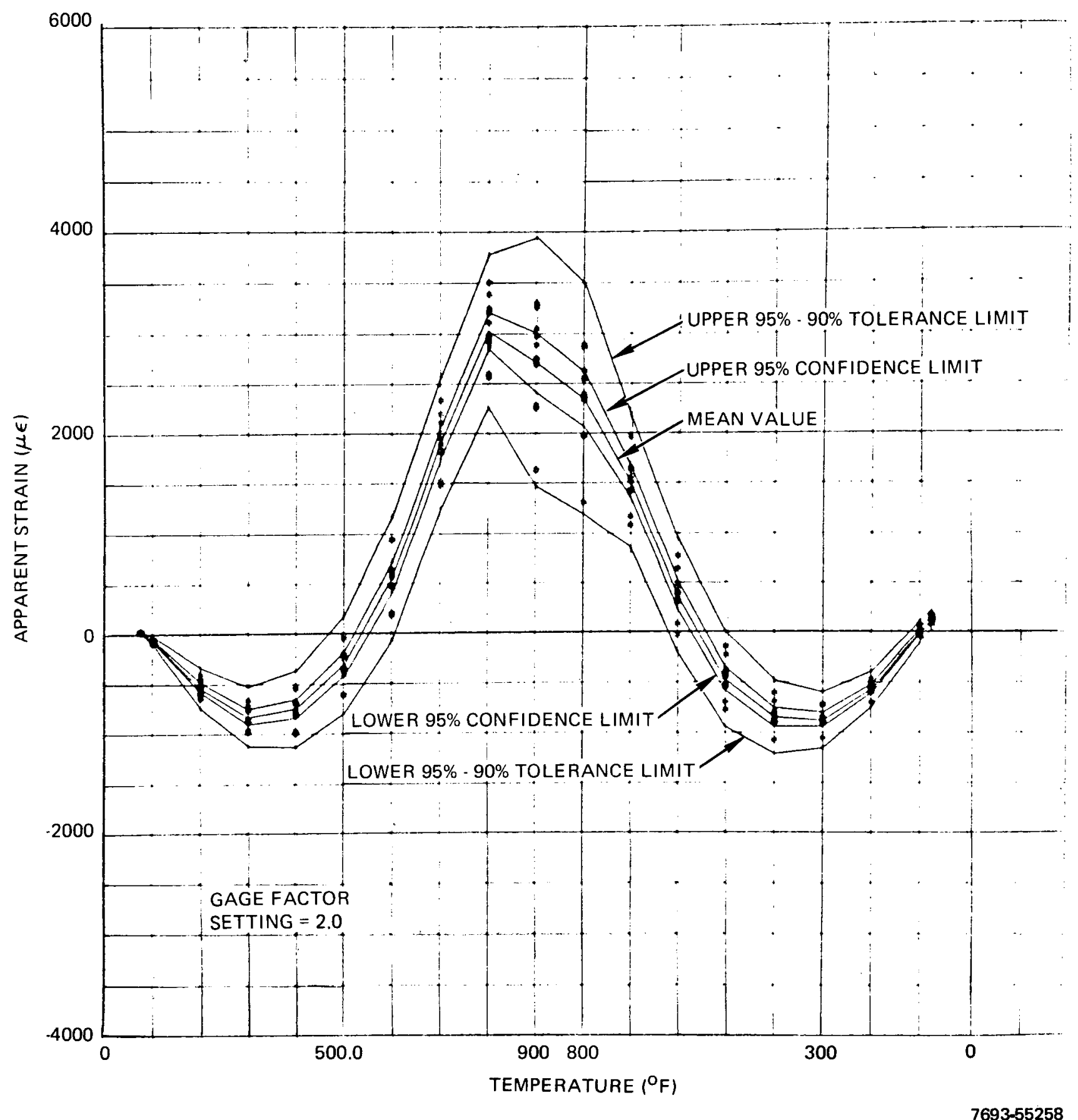

Figure 42. Apparent Strain vs Temperature, with Confidence and Tolerance Limits for Specimens AT-1 through -6, 12 Gages, Series 2, Cycle 2 
of $25.7 \%$, and $23.5 \%$, respectively. The corresponding deviations, in terms of the $95 \%$ confidence limits, are $6.2 \%$, and $5.6 \%$.

At $800^{\circ} \mathrm{F}$, for series 2 , cycles 1 and 2 , the tolerance intervals are \pm 1906 , and $758 \mu \epsilon$, representing deviations from the mean values of 2798 and $3010 \mu \epsilon$ of $68.1 \%$ and $25.2 \%$. The corresponding deviations, in terms of the $95 \%$ confidence limits, are $16.3 \%$ and $6.0 \%$.

The deviation of $68.1 \%$ (series 2, cycle 1) shows the effect of the intervening mechanical load cycles applied during the gage factor portion of the calibration. This effect, however, was essentially eliminated upon completion of the second apparent strain cycle (series 2, cycle 2), as evidenced by the nearly equal percentages of deviation for series 1, cycles 1 and 2, and series 2, cycle 2. This clearly indicates the need for adequate mechanical and thermal stabilization before making strain measurements.

Figures 43 through 45 are plots of gage factor vs temperature for series 1 , cycles 1 through 3. There is a noticeable dip in the curve at $350^{\circ} \mathrm{F}$, which is being investigated; this reduction in gage factor is not evident in the gage factor plots for the D specimens (see Figure 37), since measurements were not taken at the intermediate temperature of $350^{\circ} \mathrm{F}$. To expedite testing, measurements were made at one intermediate temperature on the $D$ specimens.

After the first cycle, the maximum scatter occurs at $350^{\circ} \mathrm{F}$. At $350^{\circ} \mathrm{F}$, for series 1 , cycles 1 through 3 , the gage factor tolerance intervals are \pm 0.133 , \pm 0.159 , and \pm 0.158 , representing deviations from the mean values of 1.665 , 1.667 , and 1.665 , of $8.0 \%, 9.5 \%$, and $9.5 \%$, respectively. The corresponding deviations, in terms of the $95 \%$ confidence limits are $1.9 \%, 2.3 \%$, and $2.3 \%$. From inspection of these mean values and deviations, and Figures 43 through 45, it is evident that there is a small change in gage factors calibration with cycling, and that the gage factor essentially stabilizes after two cycles.

Figure 46 is a plot of the average measured vs calculated strains for the same gages. The response is linear, and the response at $350^{\circ} \mathrm{F}$ is distinctly less than that at ambient, $625^{\circ} \mathrm{F}$, and $900^{\circ} \mathrm{F}$.

\section{B. LMEC ARMOUR D-PLATINUM GAGE FABRICATED WITH 2-MIL-DIAMETER WIRE (D-23)}

As shown in Table 1, gages 1 and 2 sustained five series of evaluation tests before failing, with drift rates of only 2.7 and $2.6 \mu \epsilon / \mathrm{hr}$. These were the lowest

\section{LMEC-70-8}




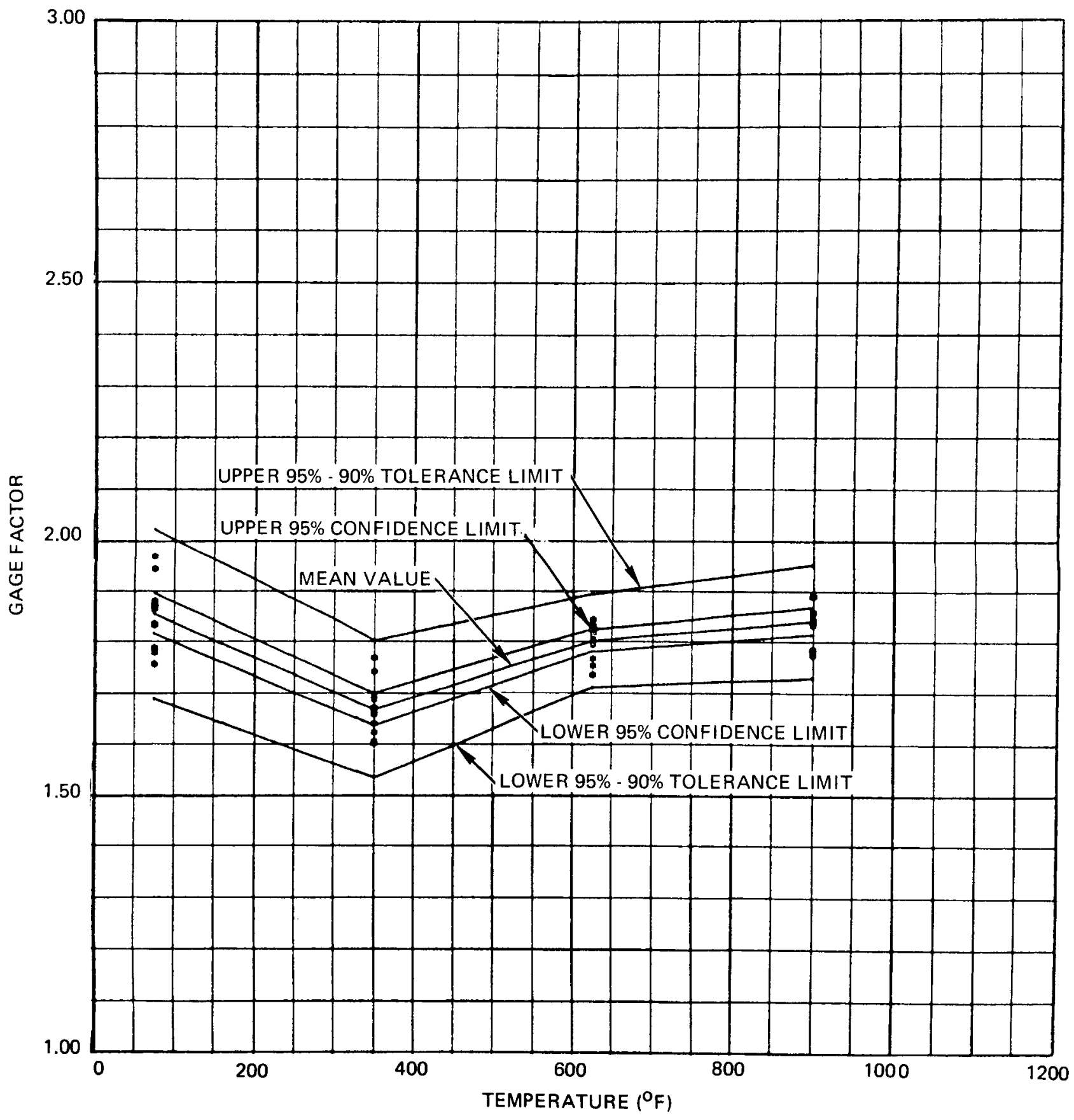

Figure 43. Gage Factor vs Temperature, with Confidence

$7693-55259$ and Tolerance Limits for Specimens AT-1 through -6, 12 Gages, Series 1, Cycle 1 


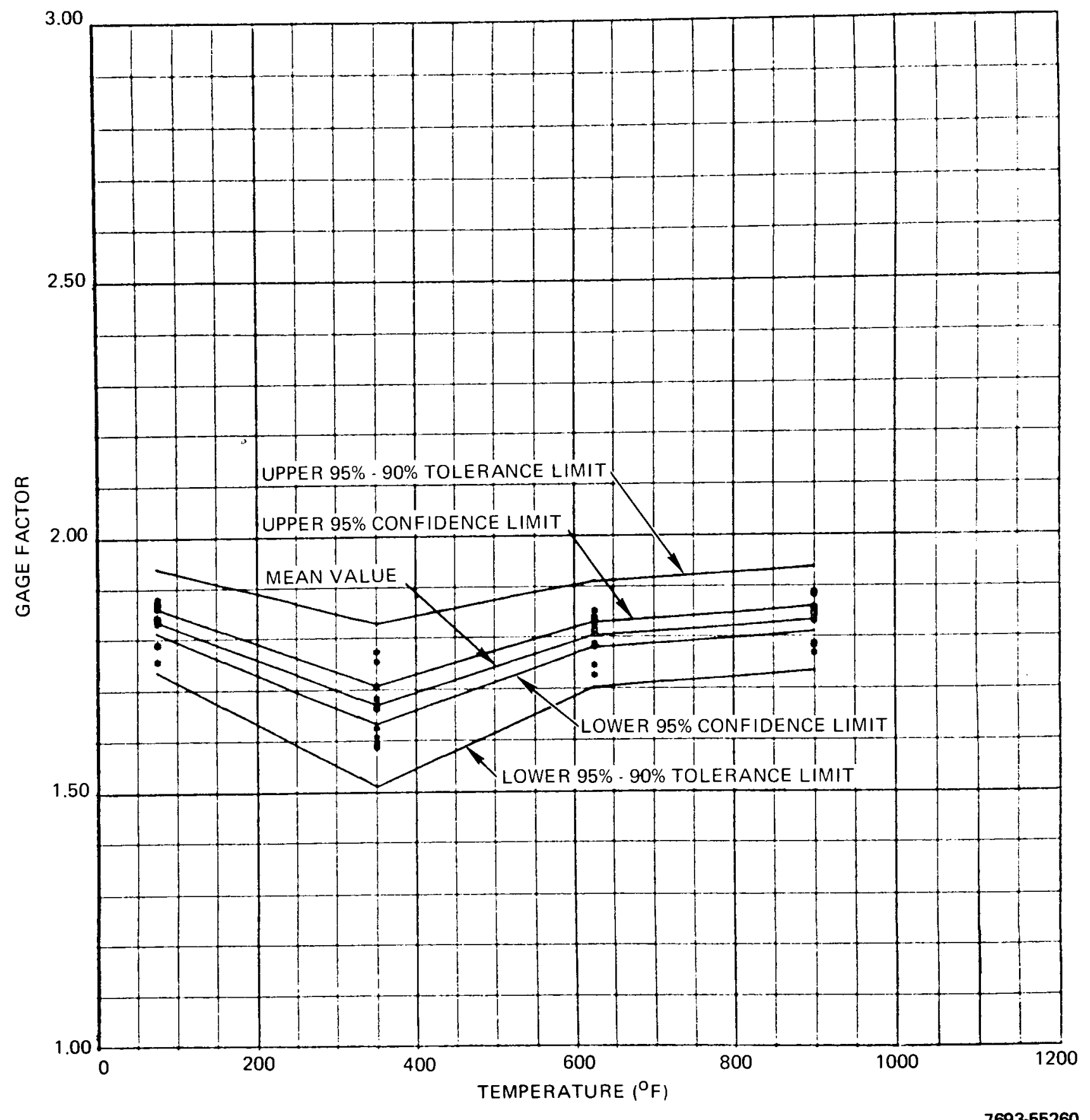

Figure 44. Gage Factor vs Temperature, with Confidence and Tolerance Limits for Specimens AT-1 through -6, 12 Gages, Series 1, Cycle 2 


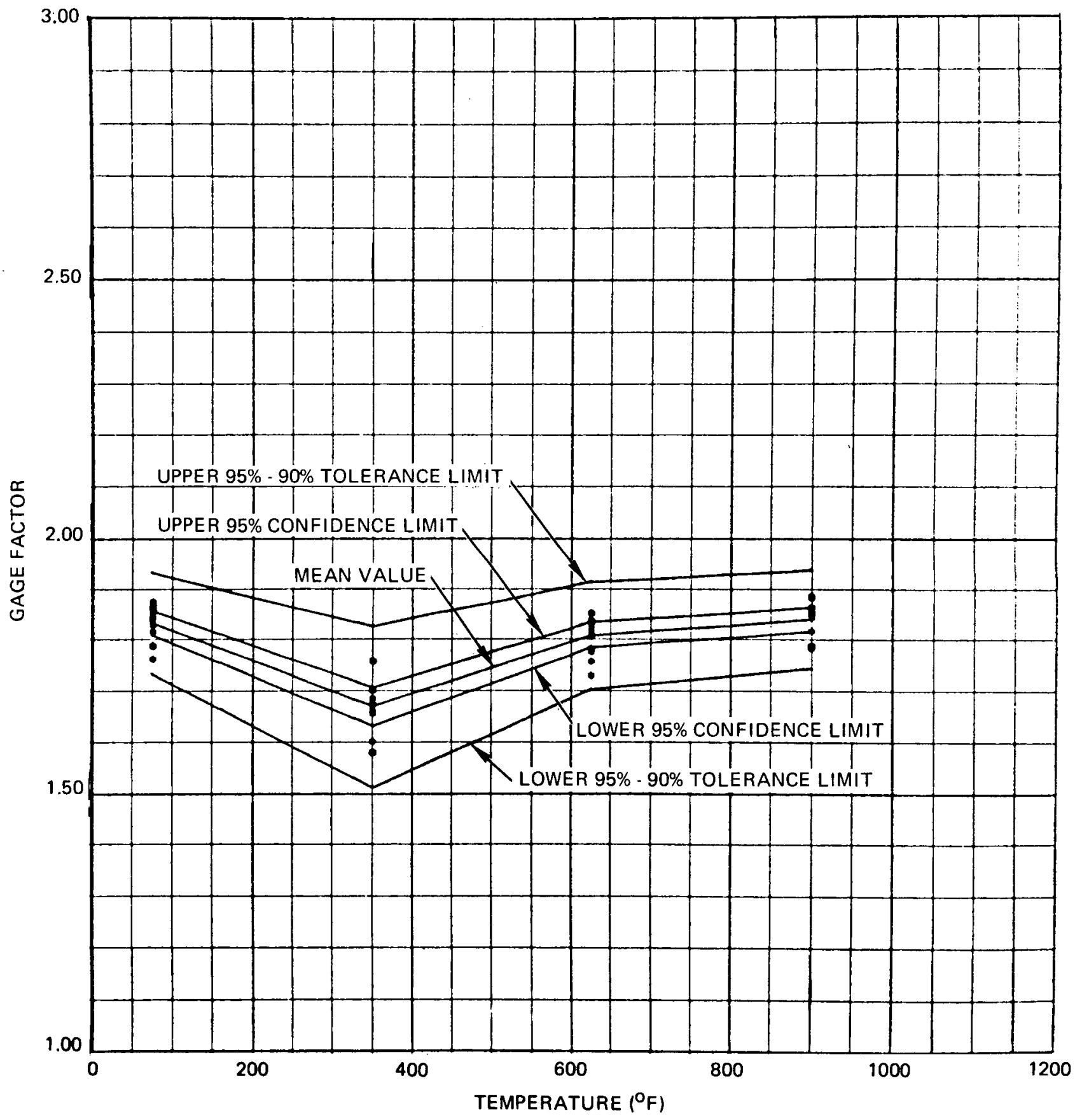

Figure 45. Gage Factor vs Temperature, with Confidence

$7693-55261$ and Tolerance Limits for Specimens AT-1 through -6, 12 Gages, Series 1, Cycle 3 


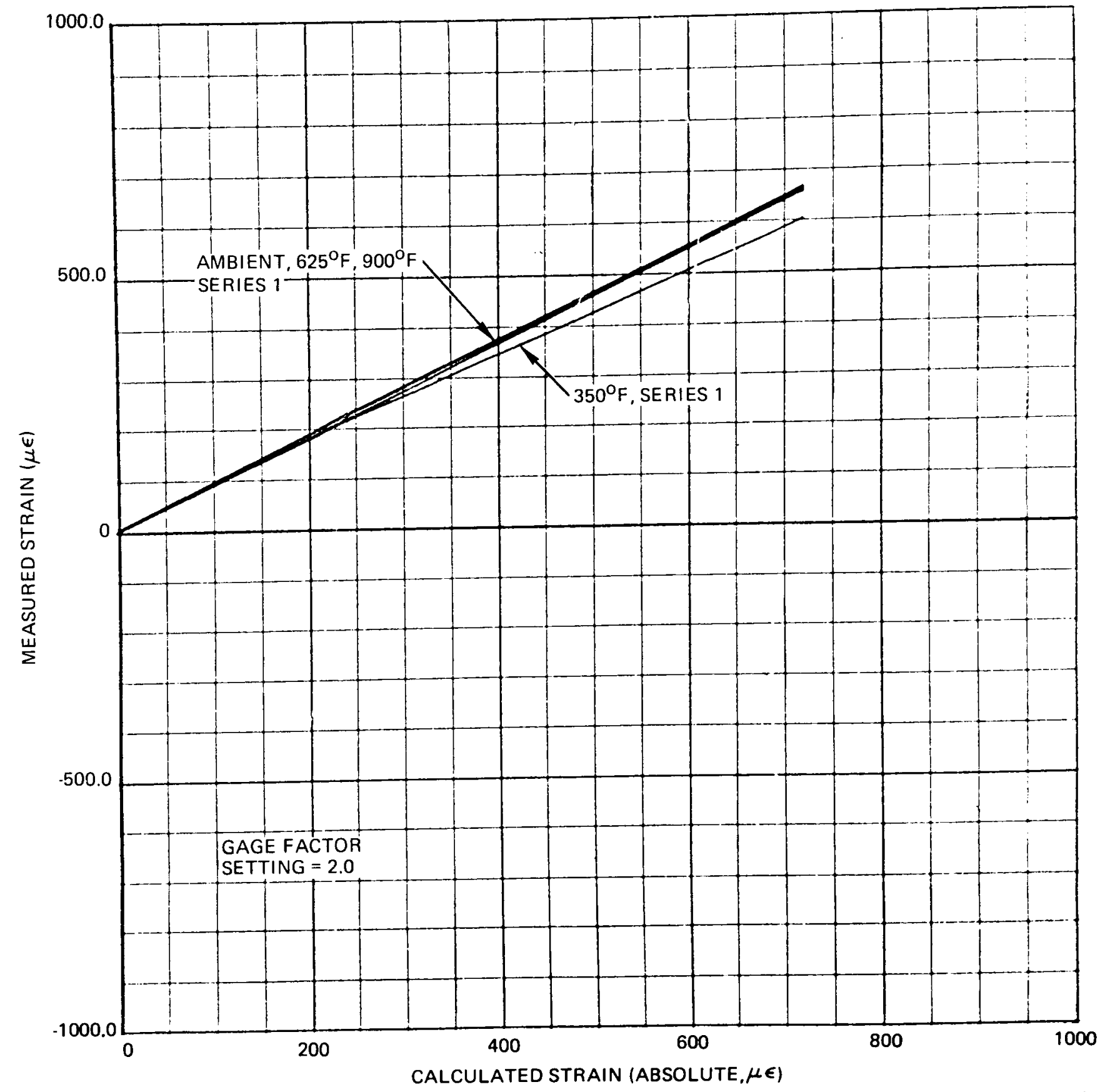

Figure 46. Average Measured Strain vs Calculated Strain for Specimens AT -2 through -5 , Series 1 
overall drift rates observed for any of the gages tested, having a life span-tofailure of at least five series (approximately 1200 to $1500 \mathrm{hr}$ ).

It is believed that the premature failures of gages 3 and 4 were a result of faulty construction or materials and that they should not be attributed to the gage design. Also, in spite of the premature failure of two of four gages on this specimen, none of the other specimens with four Armour D-platinum gages, fabricated from I-mil-diameter wire, had two gages that withstood at least five series of evaluation tests.

The steady-state apparent strain characteristics for gages 1 and 2 for the first series are not quite as good, in terms of uniformity between cycles 2 and 3 , as that for the standard LMEC Armour D-platinum gages, as noted in Table 1. The same statement also applies to gage uniformity for series 2 and 3 ; the transient apparent strain of these gages is larger than that for the standard LMEC Armour D-platinum gage.

Figures 47 through 50 are plots of apparent strain, gage factor, average measured strain vs calculated strain, and drift for specimen D-23. Confidence and tolerance limits are not presented, because the limited number of gages evaluated does not permit a meaningful statistical analysis. Figure 47 clearly shows the change in apparent strain resulting from testing through three series. The change from series 2 to series 3 is substantially less than that from series 1 to series 2; and the maximum positive strain is six to nine times as large as the maximum negative strain. By altering the "turns ratio" between the Armour $D$ and platinum elements, these maximums can be made equal, and thus minimize the absolute value of apparent strain over the entire temperature range.

As is evident in Figure 50, the drift rate changes very slowly in comparison to the changes in drift rate for the Armour D-platinum gages fabricated from 1-mil-diameter wire (see Figure 33). This is attributed to the increased stability resulting from the use of 2-mil-diameter wire.

\section{LMEC ARMOUR D GAGE WITH PLATINUM LEAD TABS (D-25 through -27)}

Referring to Table 1 , it is evident that configuration $C$ (specimen $D-25$ ) was superior to configurations $A$ and $B$ (specimens D-26 and -27) in terms of soak time to failure and thermal shocks. This is believed due to the fragility of the

\section{LMEC - 70-8}




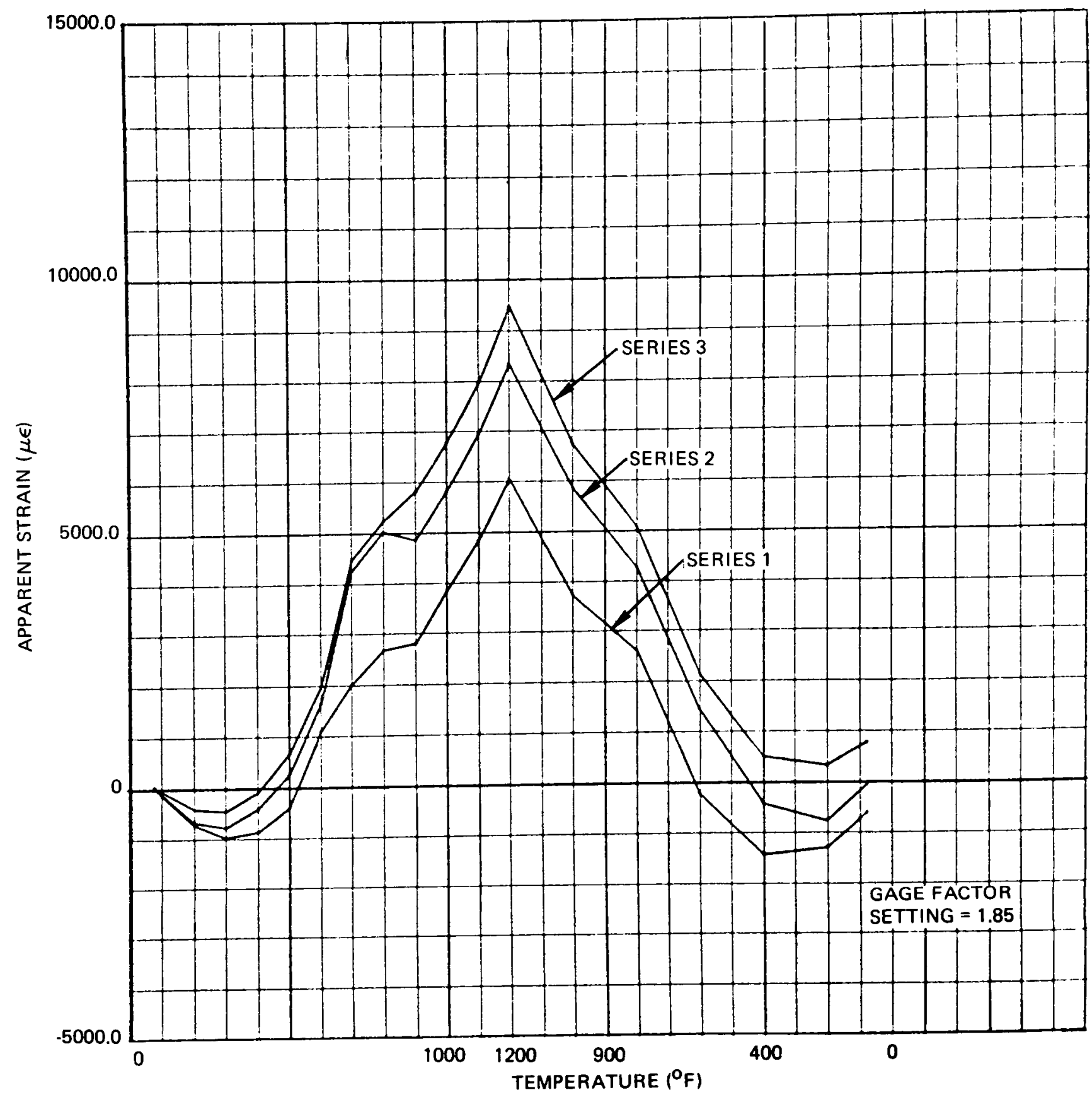

Figure 47. Average Apparent Strain vs Temperature for Specimen D-23, 2 Gages, Series 1 through 3, Cycle 1 


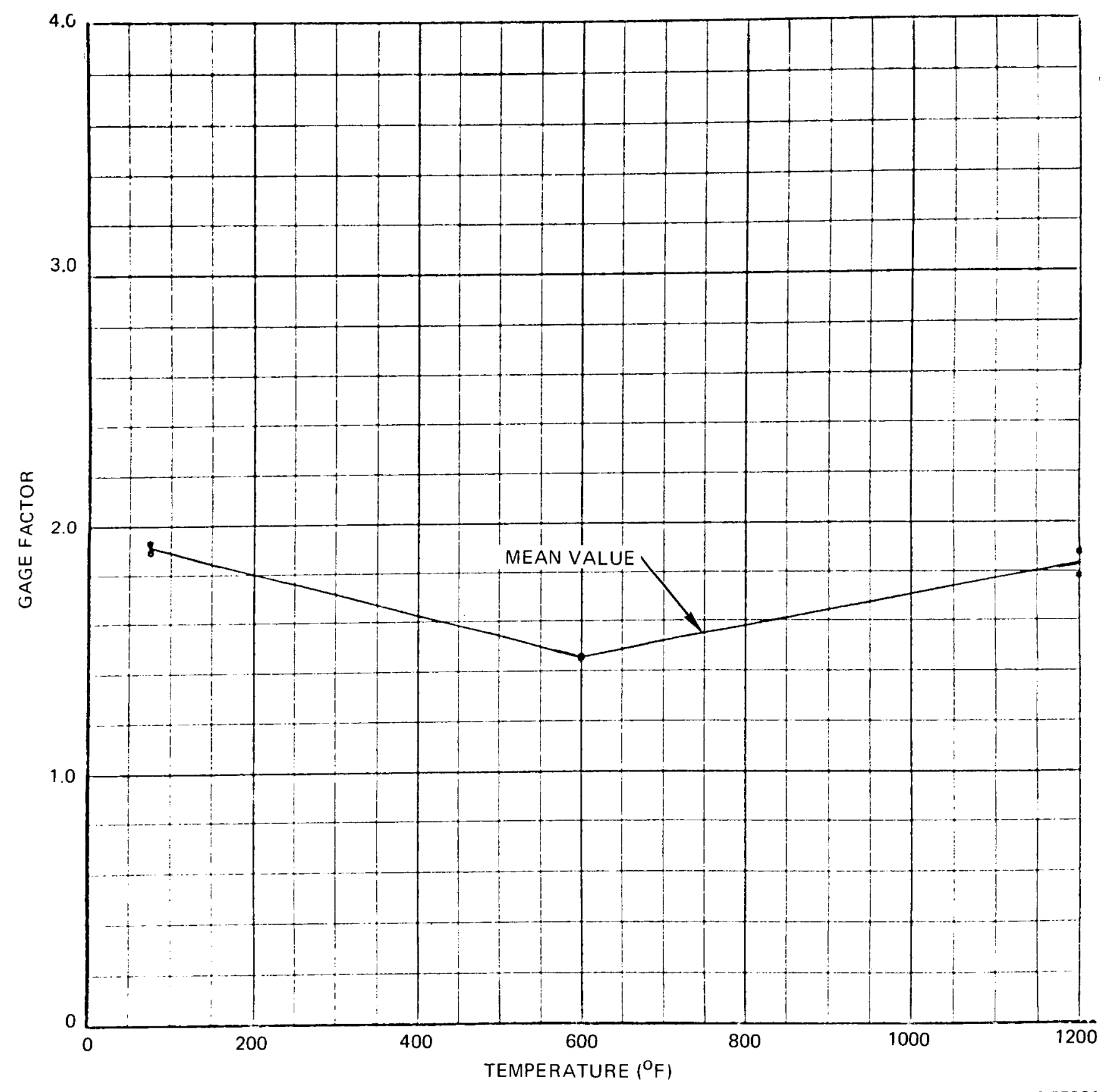

$7693-55264$

Figure 48. Gage Factor vs Temperature for Specimen D-23, 2 Gages, Series 3 


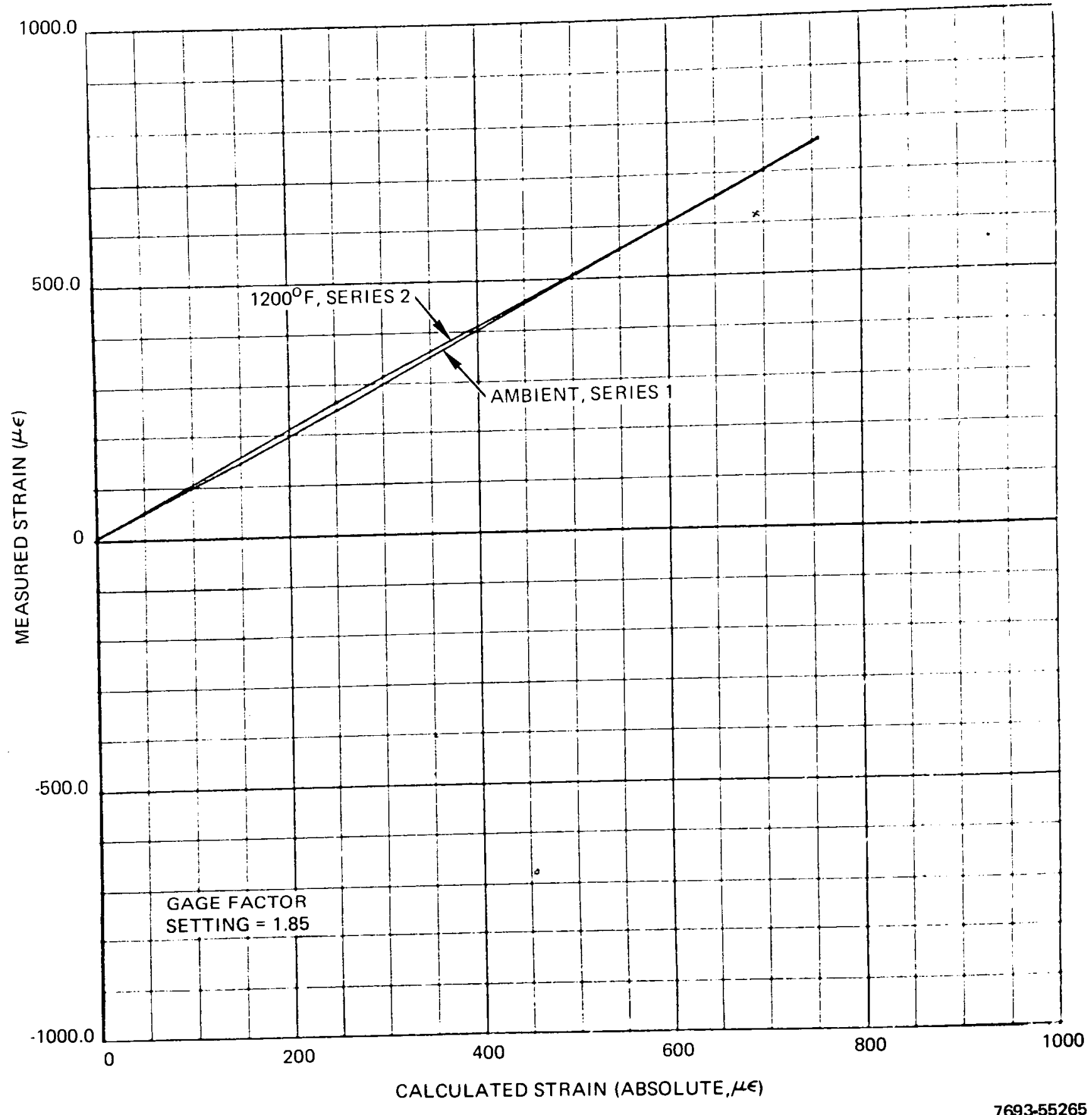

Figure 49. Average Measured Strain vs Calculated Strain, Specimen D-23, Series 1 and 2 


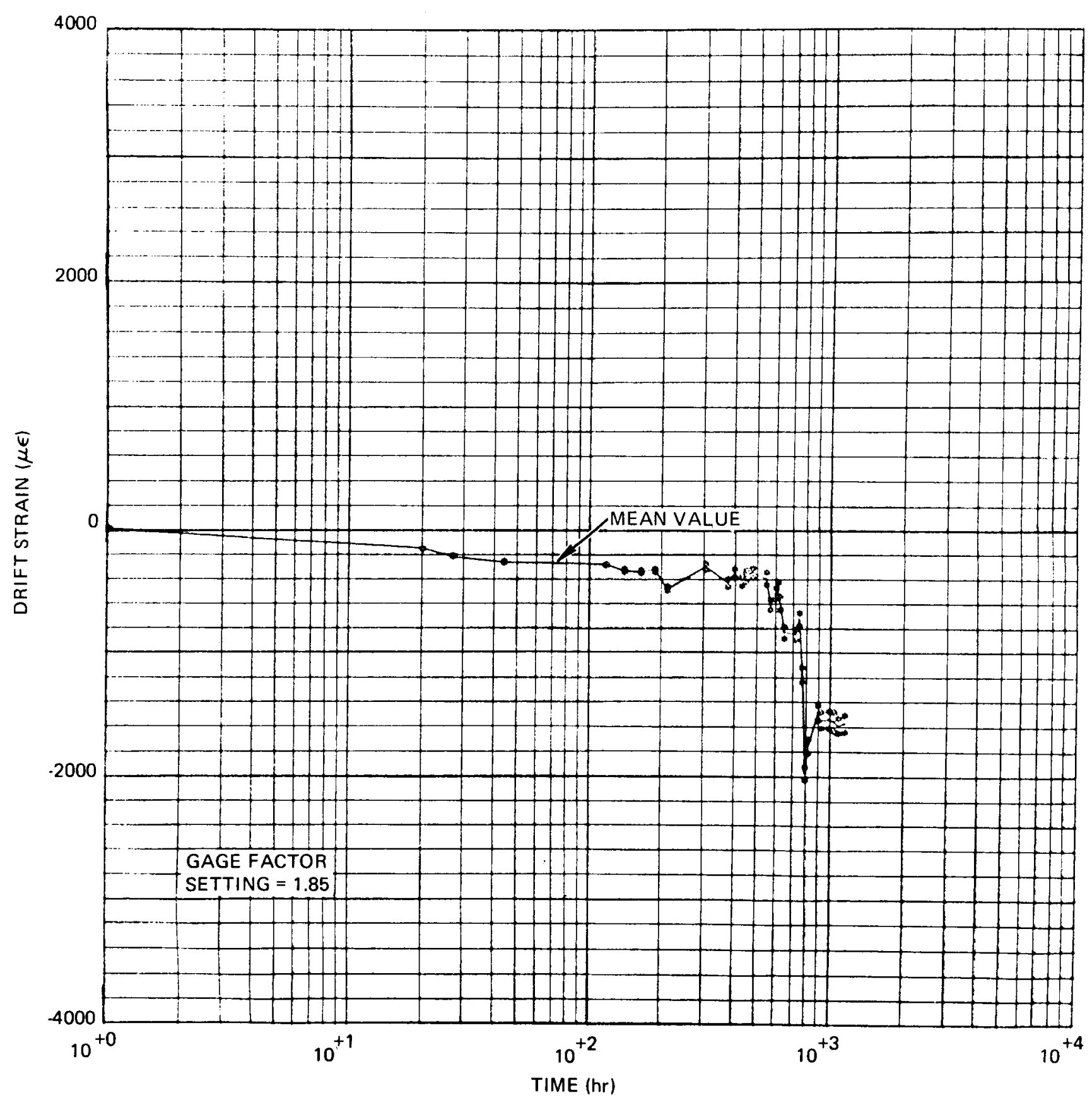

Figure 50. Drift vs Time at $1200^{\circ} \mathrm{F}$ for Specimen D-23 
die-cut platinum elements, or the fragility of the spot-welded joint between the Armour $\mathrm{D}$ wire and the die-cut platinum element. Configuration $\mathrm{C}$ utilizes 1/64- x 0.002-in. platinum ribbon, which proved less susceptible to damage; however, its apparent strain is considerably greater, being approximately five times that for the other configurations. In addition, the repeatability between the second and third cycles of series 1 of configurations $A$ and $B$ is better than that for configuration $C$.

Figures 51 through 54 are plots of apparent strain, gage factor, average measured apparent strain vs calculated strain, and drift characteristics for specimen D-25. Confidence and tolerance limits are not included in these figures because the number of data points obtained were insufficient to permit meaningful statistical analysis. Similarly, the amount of data obtained for specimens D-26 and -27 was insufficient for a graphic presentation.

Figure 51 shows the change in apparent strain resulting from three series of tests. Figure 52 shows the variation in gage factor with temperature in terms of the mean value curve. Although the $1200^{\circ} \mathrm{F}$ value is essentially the same as that for the standard (Group 2) Armour D-platinum gages (see Figures 30 and 31), the corresponding room temperature and $600^{\circ} \mathrm{F}$ values are lower by approximately $10 \%$.

Figure 53 shows a near linear relationship between calculated and measured strain at ambient and $1200^{\circ} \mathrm{F}$. The compressive values again are lower than the tensile values. In this instance they are lower by about $10 \%$.

Figure 54 shows an almost constant positive drift rate for the first $25 \mathrm{hr}$ $(\sim 2 \mu \epsilon / h r)$, after which it becomes negative, with an average drift rate over the first $500 \mathrm{hr}$ of about $0.8 \mu \mathrm{\epsilon} / \mathrm{hr}$, which is considered excellent.

D. LMEC ALL-ARMOUR D GAGE (D-13, - 19, and -20)

Specimen D-13 consisted of two types of all-Armour D gages. Gages 1 and 4 were single-element gages having resistances of 155.2 and 156.4 ohms, respectively.

Gages 2 and 3 were three-element gages, of geometry similar to the standard LMEC Armour D-platinum gage, having resistances of 253.0 and 253.4 ohms, 


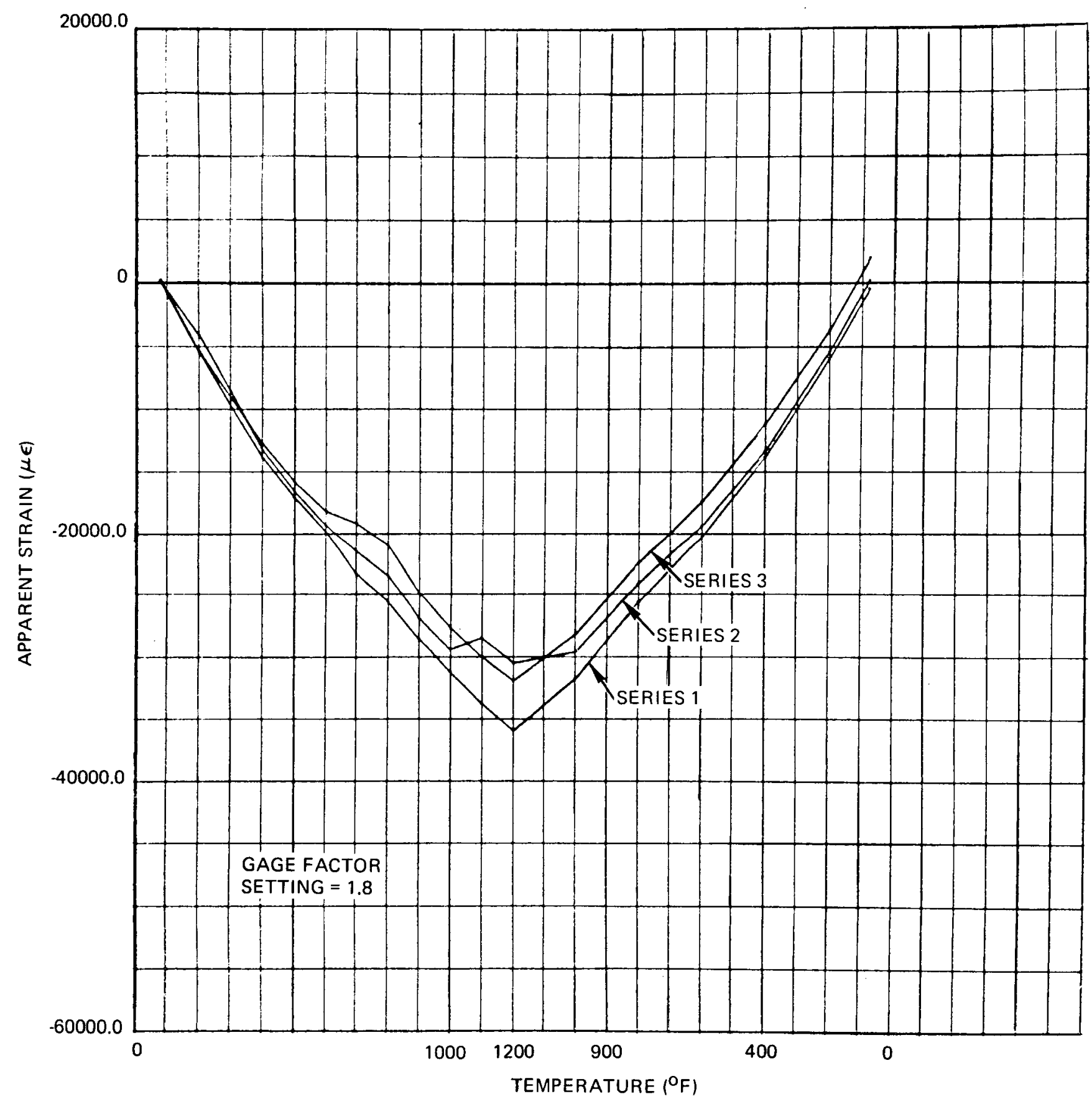

$7693-55267$

Figure 51. Average Apparent Strain vs Temperature for Specimen D-25, 4 Gages, Series 1 through 3, Cycle 1 


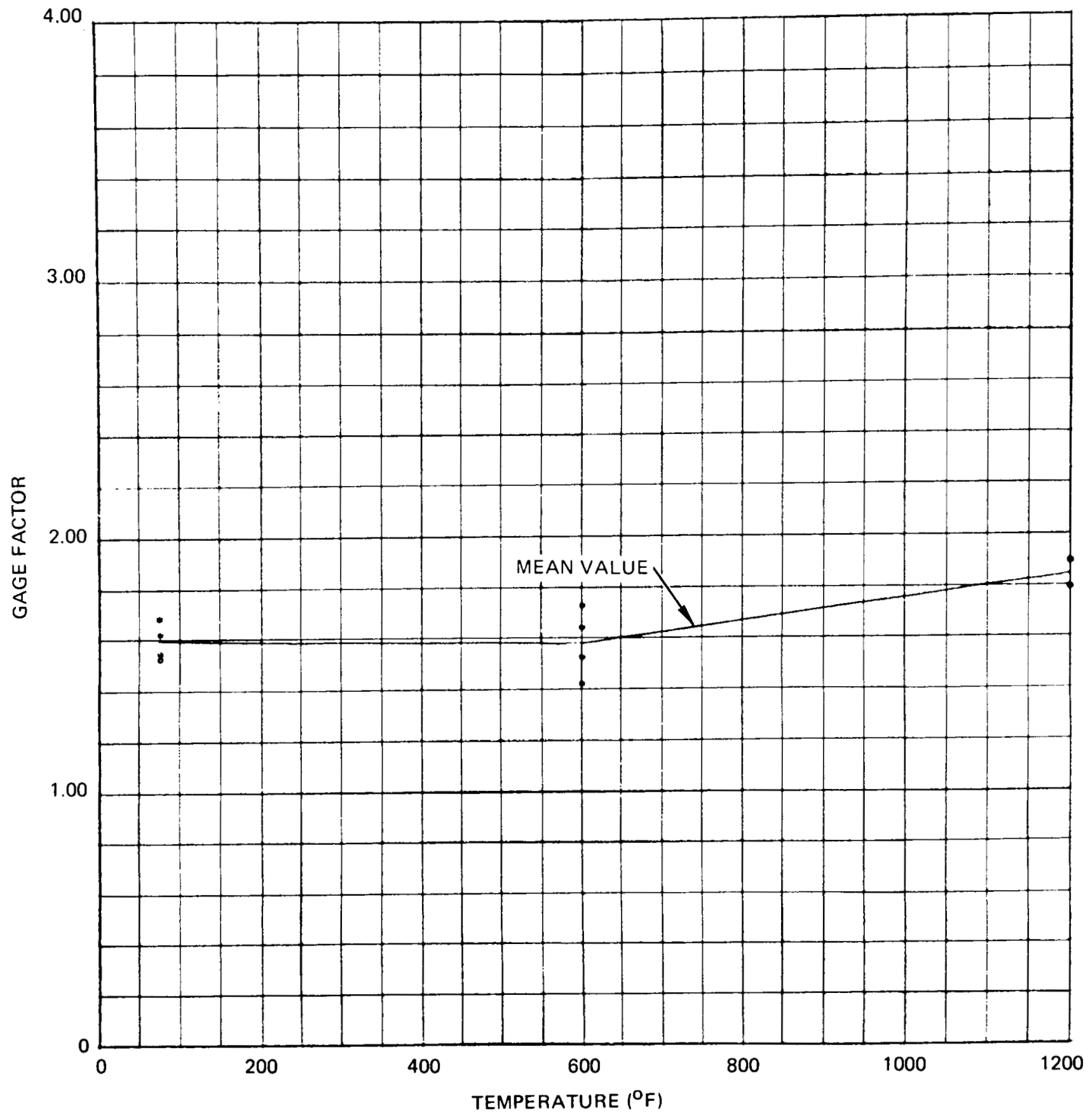

Figure 52. Gage Factor vs Temperature for Specimen D-25, 4 Gages, Series 1 


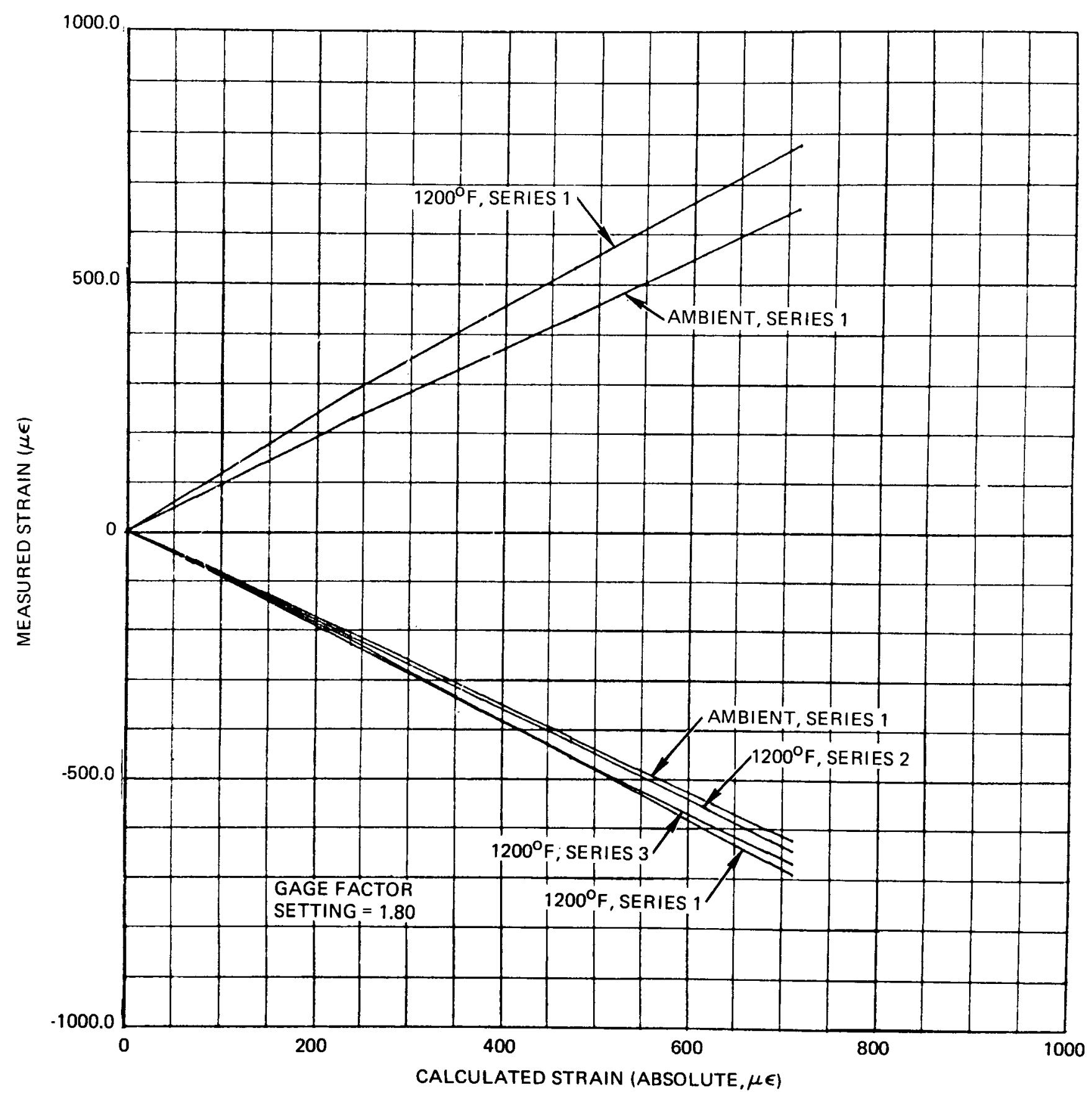

Figure 53. Average Measured Strain vs Calculated Strain, Specimen D-25, Series 1, 2, 3 


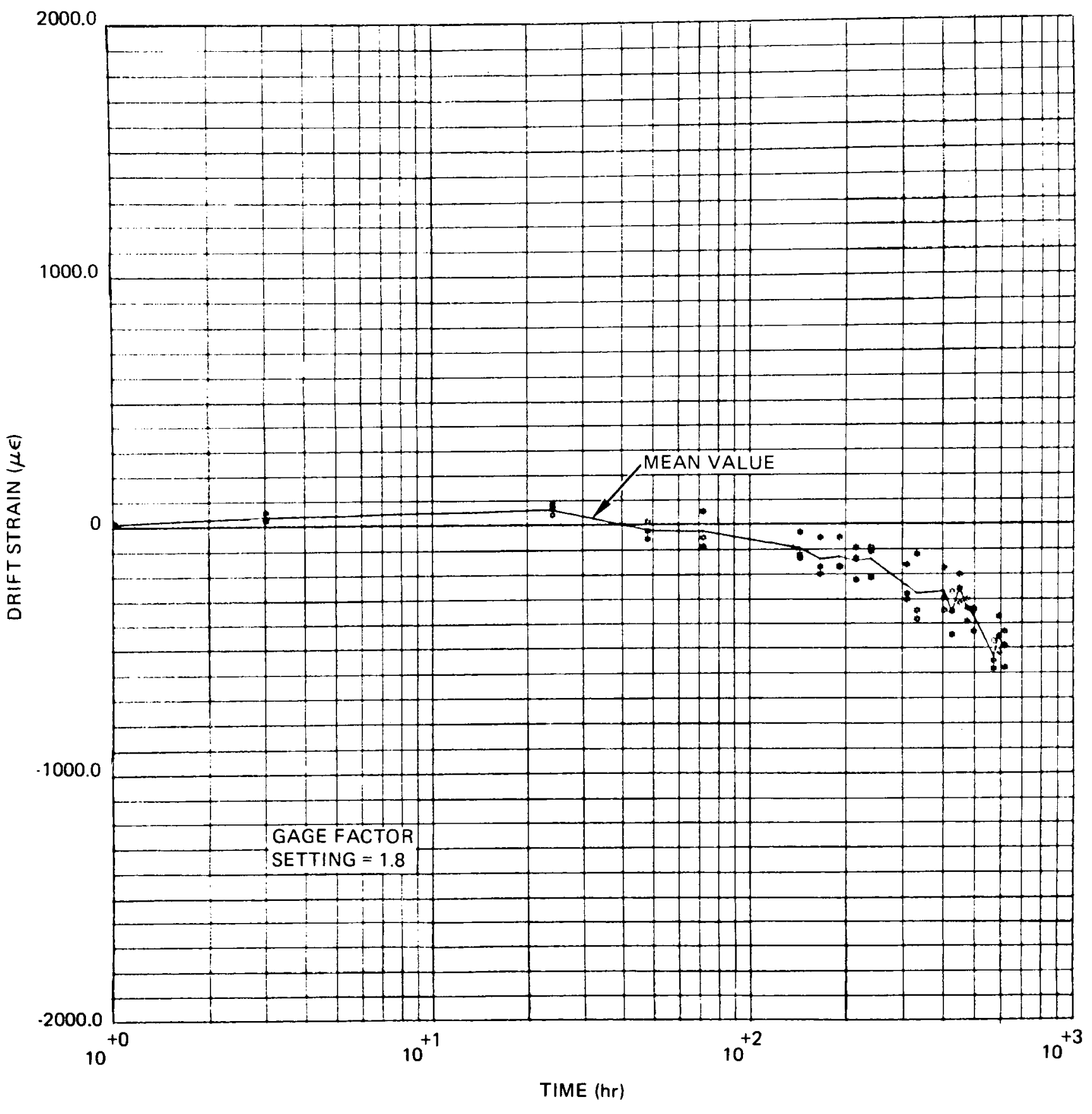

Figure 54. Drift vs Time at $1200^{\circ} \mathrm{F}$ for Specimen D-25

LMEC - 70-8 
respectively. The difference in resistance between gages 2 and 3 and the standard LMEC Armour D-platinum gage, resulted from the substitution of Armour $D$ alloy for the platinum alloy for the two outer elements. The primary purpose of fabricating and evaluating these two gages was to determine whether their steady-state and thermal-shock performance would be superior to the standard LMEC Armour D-platinum gage. Gages 2 and 3 sustained a total of $5408 \mathrm{~h} \mathbf{r}$ of exposure at $1200^{\circ} \mathrm{F}$, and 516 thermal shocks before failure; whereas the best group of gages for the standard LMEC Armour D-platinum gages (D-29) sustained only $2657 \mathrm{hr}$ of similar exposure, and 185 thermal shocks. The large negative apparent strain for these gages stems from the absence of platinum temperaturecompensating elements. In spite of the long life of gages D-13-2 and -13-3, the overall drift rate of these gages to failure was only 3.4 and $3.6 \mu / \mathrm{hr}$.

The reason(s) why gages $D-13-1$ and $-13-4$ did not have lives comparable to those for gages D-13-2 and 13-3 is not known. Since they had fewer joints, it would be expected that they would sustain as much exposure and shock as the latter gages. Had a larger number of samples been tested, this apparent anomaly might not have existed.

Specimens D-19 and -20 had comparable lives and other gage characteristics. Gage D-19-4 sustained $2406 \mathrm{hr}$ of exposure at $1200^{\circ} \mathrm{F}$ before failure, which was second only to the 3903-hr life for specimen D-13-3.

A comparison of the average life of the all-Armour D gages with that of the standard LMEC Armour D-platinum gages shows clearly that the all-Armour D gage is superior. However, this superiority is attained at the expense of a much higher apparent strain.

Figures 55 through 59 are plots of the apparent strain characteristics for three series of tests for specimens D-19 and -20 . Sufficient data were not obtained for specimen D-13 to warrant graphic presentation. The scatter from gage to gage for series 1 is small considering the relatively large magnitude of the apparent strain, which is more than $35,000 \mu \epsilon$. The $1200^{\circ} \mathrm{F}$ confidence limits are $\pm 205, \pm 922$, and $\pm 1505 \mu \epsilon$, for series 1,2 , and 3 ; and the corresponding tolerance limits are $\pm 756, \pm 3264$, and $\pm 5176 \mu \epsilon$. This clearly points up the increase in scatter resulting from three series of testing. 


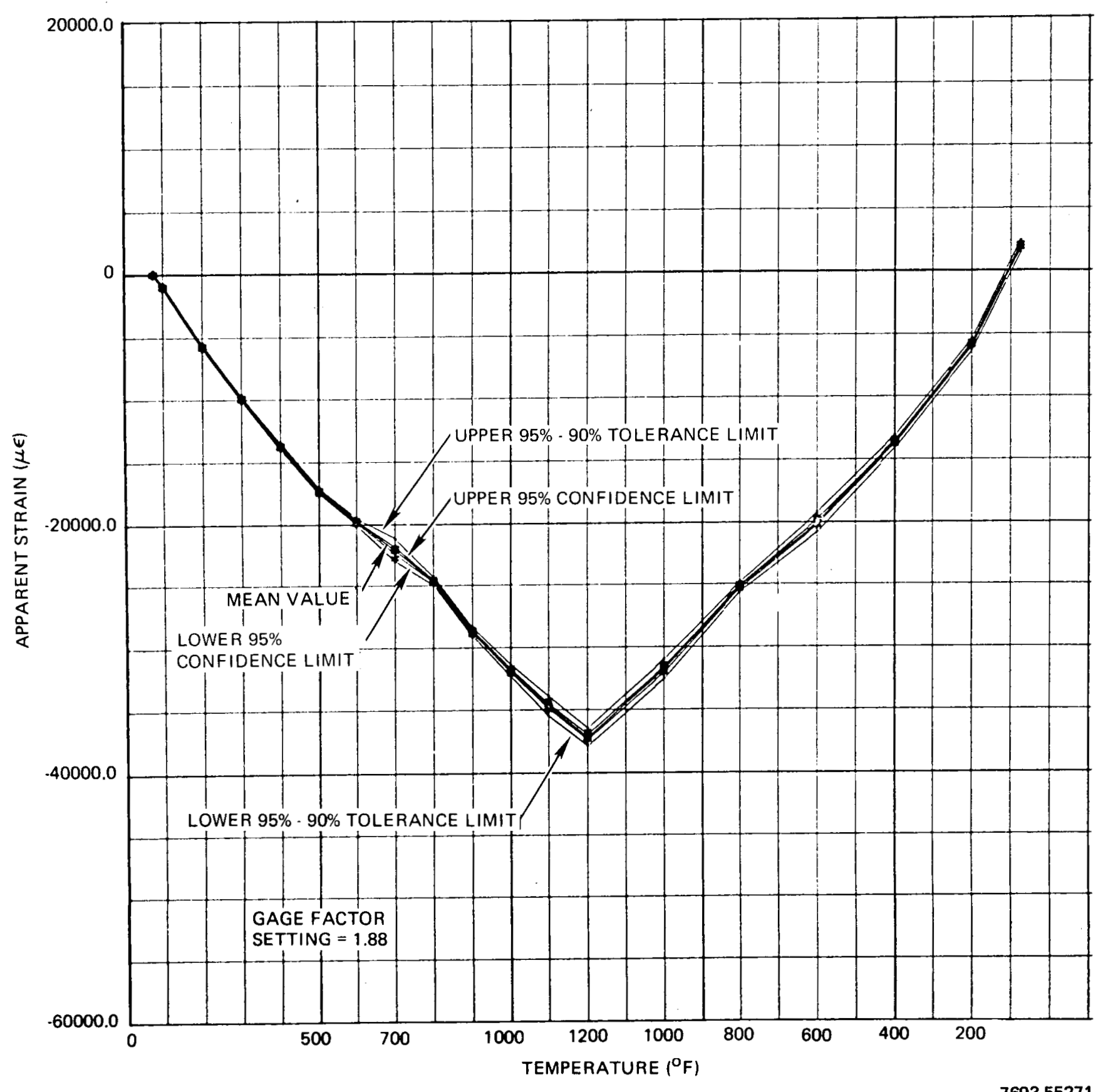

Figure 55. Apparent Strain vs Temperature, with Confidence and Tolerance Limits for Specimens D-19 and -20 , 7 Gages, Series 1, Cycle 2 


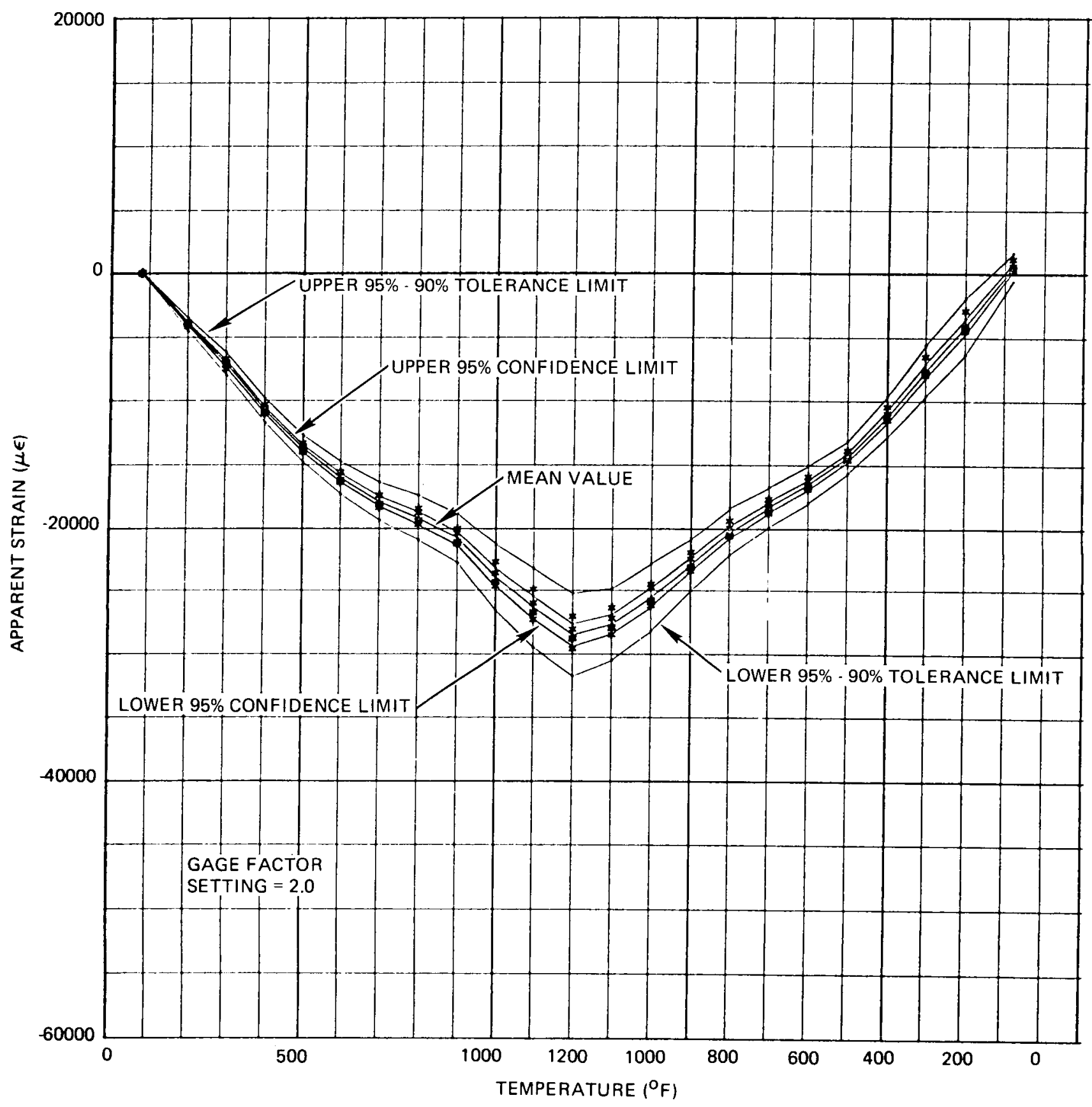

7693-55272

Figure 56. Apparent Strain vs Temperature, with Confidence and Tolerance Limits for All-Armour D Specimens D-19 and -20, 6 Gages, Series 2, Cycle 1 


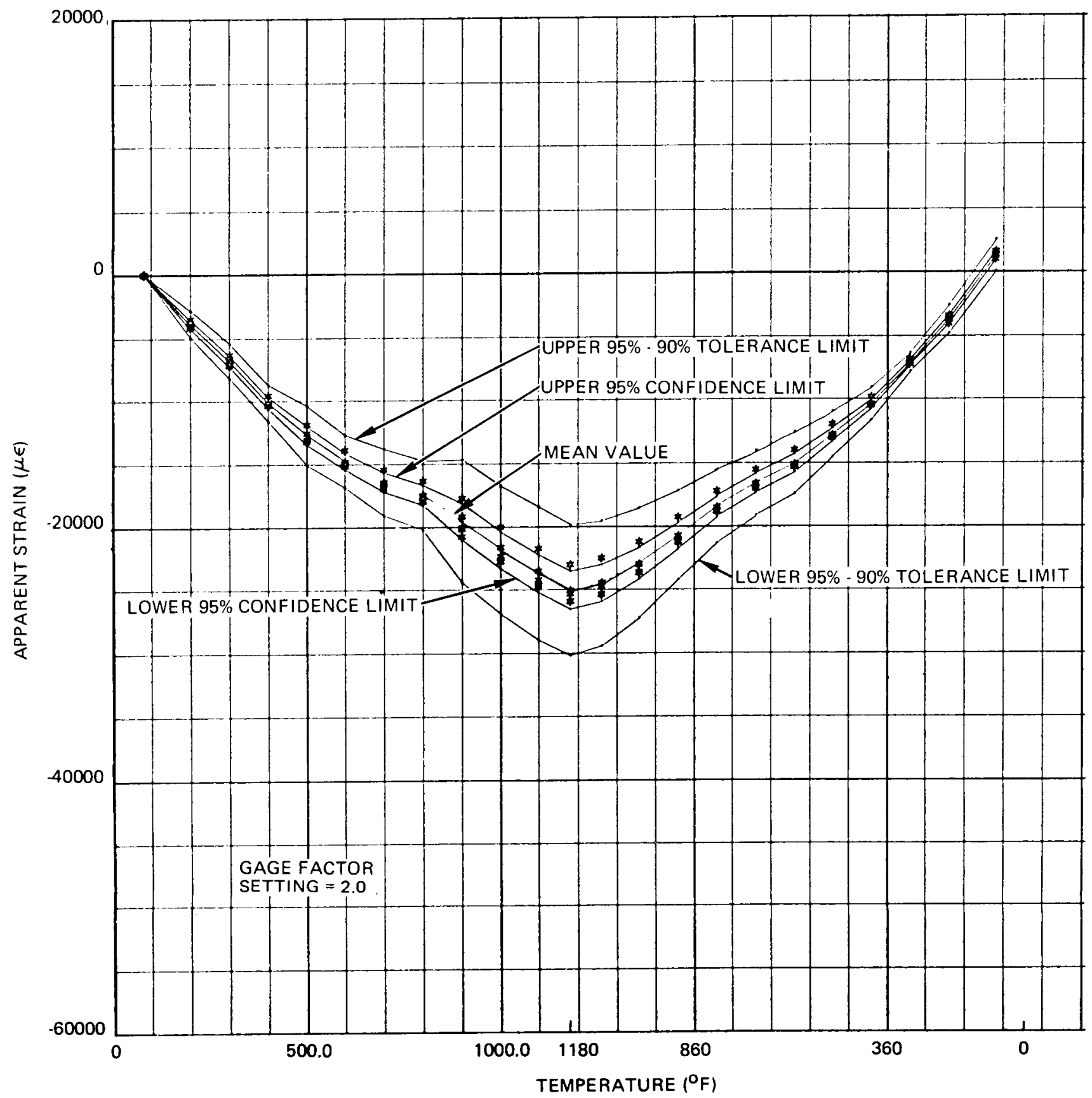

$7693-55273$

Figure 57. Apparent Strain vs Temperature, with Confidence and Tolerance Limits for Specimens D-19 and -20, 5 Gages, Series 3, Cycle 1 
Figures 58 and 59 are plots of gage factor vs temperature and average measured strain vs calculated strain. It is observed that the re is a small increase in gage factor with temperature and that the measured strain response is not as linear as that of the other gages. It is further noted that the strain response in compression is somewhat less than that in tension.

Figure 60 shows the $1200^{\circ} \mathrm{F}$ drift characteristics for a time period exceeding $1000 \mathrm{hr}$. It is evident that the drift rate changes considerably more abruptly than for the composite Armour D-platinum gage. Nevertheless, the average drift rate over the $1000-\mathrm{hr}$ period is still considered satisfactory since it does not exceed $5 \mu \epsilon / \mathrm{hr}$.

E. LMEC CLAD GAGE (D-24, and -30)

Referring to Table 1 , it is noted that these clad gages have gage factors as high as 3.00. This value is substantially higher than that of any of the other Armour $D$ gage types that were evaluated. To date, D-24 has been subjected to $1798 \mathrm{hr}$ at $1200^{\circ} \mathrm{F}$ and 180 thermal shocks, without failure. The overall drift rates for the four gages is between 8.8 and $13.4 \mu \epsilon / \mathrm{hr}$, which is higher than that for most of the standard LMEC Armour D-platinum gages which were evaluated.

Considering the magnitude of the steady-state apparent strain $(>43,765 \mu \epsilon)$, the repeatability between cycles 2 and 3 of series 1 , was better than expected: 51,967 vs $51,035 \mu \epsilon$ for D-24-3. Steady-state apparent strains for the first cycle of the 7 th series of the evaluation are $56,026,63,113,49,764$, and $58,352 \mu \epsilon$ for gages D-24-1 through -24-4, respectively. These compare with 55,770, 49,245, 48,810 , and $43,765 \mu \epsilon$ for cycle 3 of the first series.

For the nickel-clad gages (specimen D-30), the maximum gage life was $589 \mathrm{hr}$ at $1200^{\circ} \mathrm{F}$. There was also less repeatability in apparent strain characteristics than for the platinum-clad gages (specimen D-24).

It was expected that by using a cladding having a positive temperature coefficient of resistivity (TC), it would be possible to compensate for the relatively high negative TC of the Armour D alloy. The end result, however, was a composite having a large positive TC. This was true of both the platinum- and nickel-clad Armour D. 


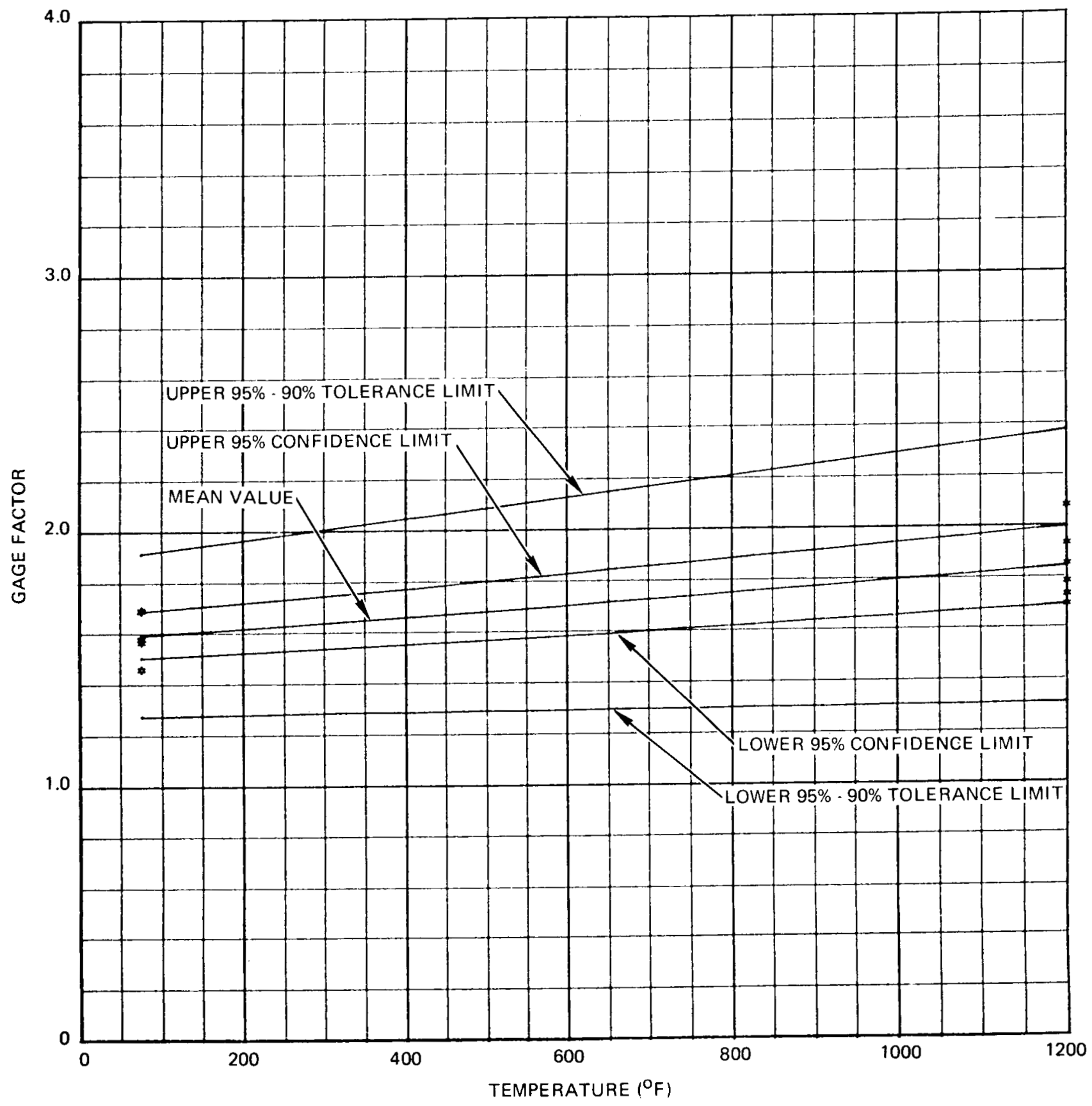

7693-55274

Figure 58. Gage Factor vs Temperature, with Confidence and Tolerance Limits for Specimens D-19 and -20,6 Gages, Series 1 


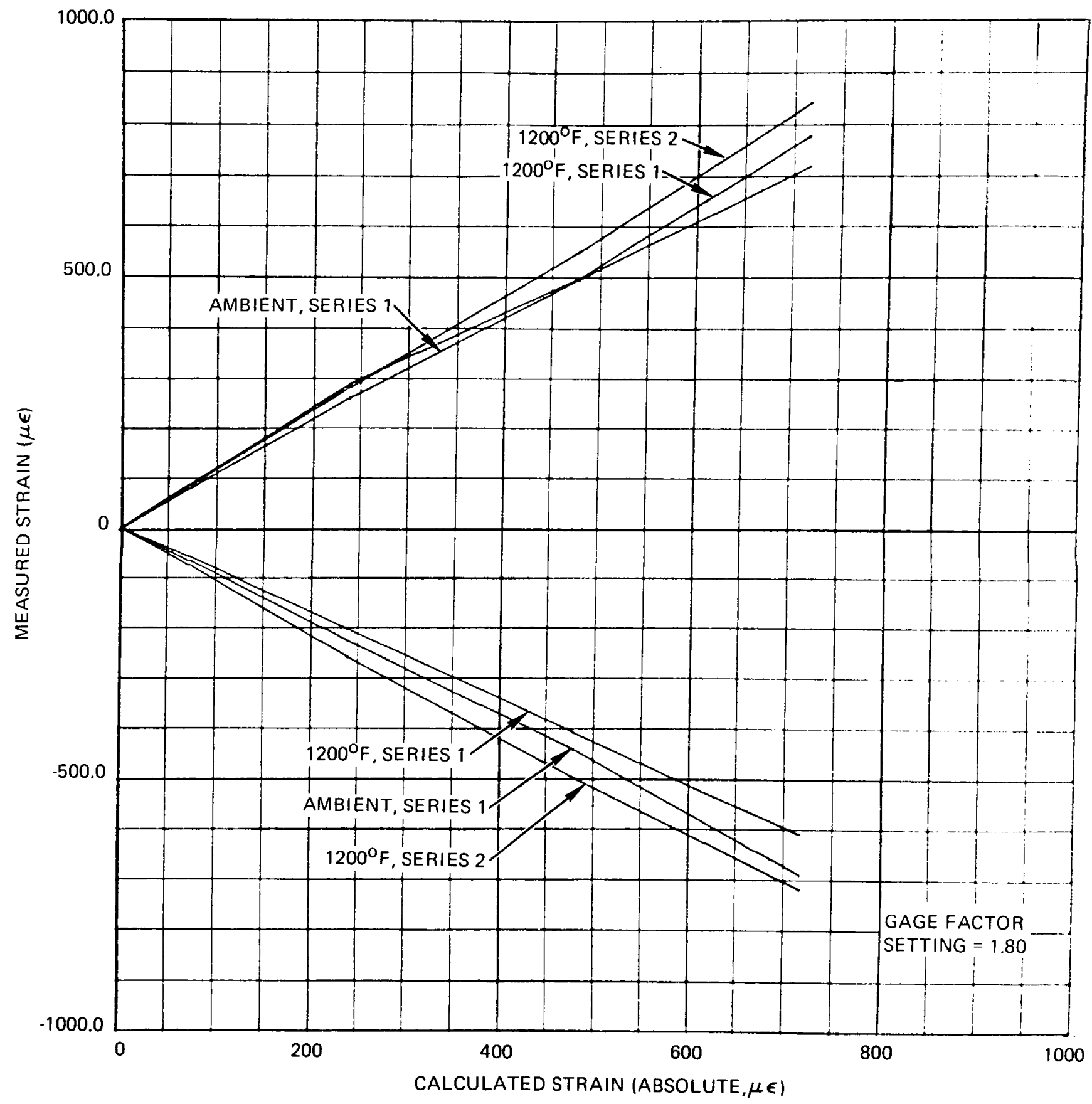

$7693-55275$

Figure 59. Average Measured Strain vs Calculated Strain for Specimens D-19 and -20 , Series 1 and 2 


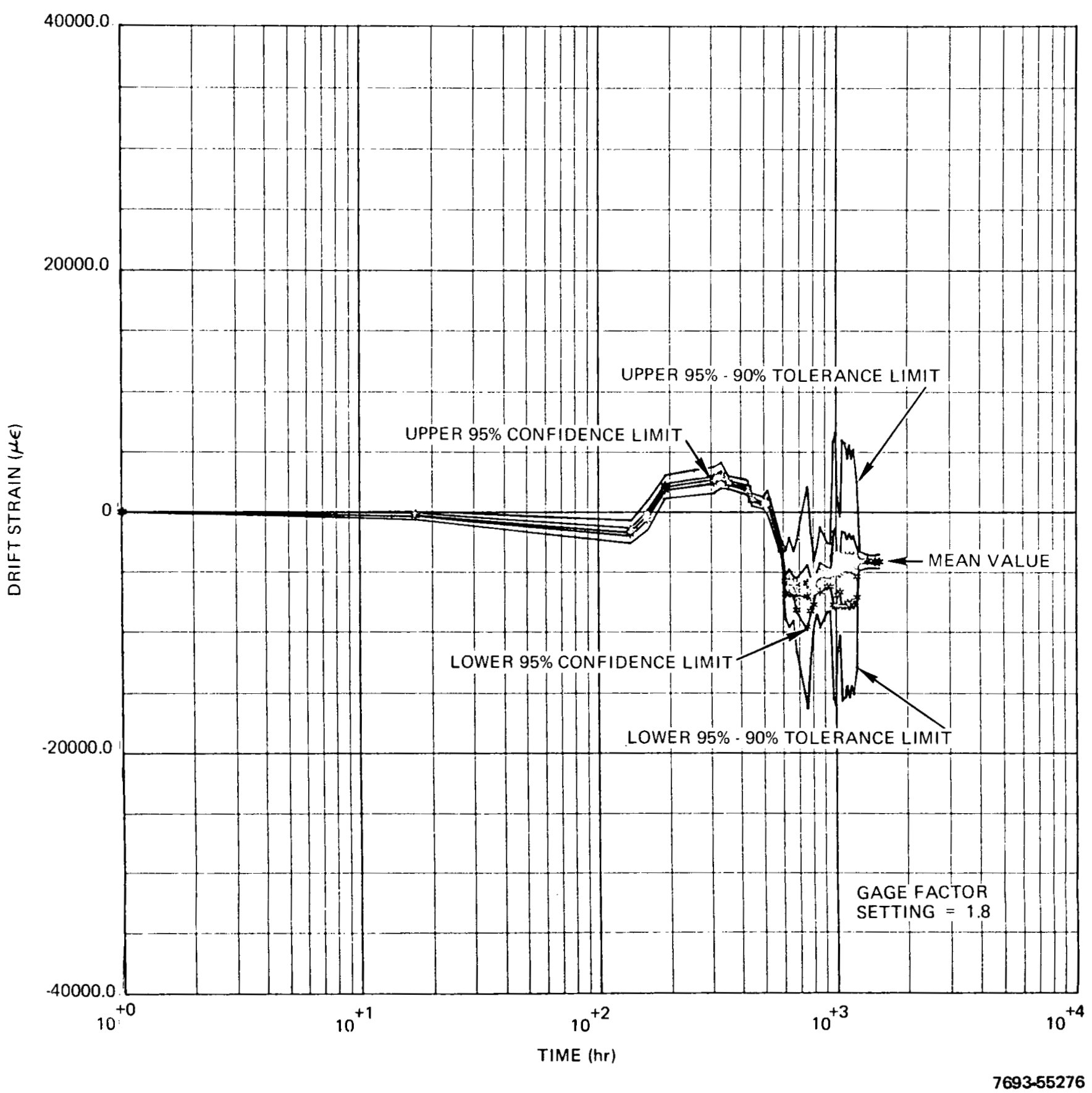

Figure 60. Drift vs Time, $1200^{\circ} \mathrm{F}$, with Confidence and Tolerance Limits for Specimens D- 19 and -20 
It was the primary objective of the pilot development work on clad gages to demonstrate that it was feasible to metallurgically bond thin claddings on Armour $D$ alloy rod and to subsequently draw the clad rod down to strain gage wire size.

As to whether platinum-clad Armour D gages are superior to the LMEC allArmour D gages, it remains to be seen. D-24 will have to be tested until failure or until it has been subjected to $3903 \mathrm{hr}$ of exposure at $1200^{\circ} \mathrm{F}$, which is the total exposure sustained by $D-13-3$ before failure. 


\section{CONCLUSIONS AND RECOMMENDATIONS}

Based on the results obtained during this study, the Armour D-type gages show promise for applications up to $1200^{\circ} \mathrm{F}$, particularly on austenitic stainlesssteel components, because of the closer match in coefficients of thermal expansion than for the platinum-tungsten alloys used in some commercial gages. However, before the full potential of the Armour D alloy can be realized, additional development work now in progress will have to be completed, and the end products of this work carefully evaluated.

The average life of the gages subjected to the full evaluation during this study was approximately $600 \mathrm{hr}$ at $1200^{\circ} \mathrm{F}$. Since $66 \%$ of the tested gages failed during thermal shocking, it is expected that joint design and joint quality (fabrication factors) will play an important role in the development and fabrication of gages having a minimum useful life of at least $1500 \mathrm{hr}$. In addition, the quality of the Armour D alloy will have to be improved; a significant amount of the scatter in gage life and other gage characteristics, within a given gage type, appears to be due to inclusions, microcracks, or other imperfections in the Armour D wire introduced during production of the ingot, or the subsequent working of the ingot into strain gage wire. Unless Armour D wire of consistent quality can be produced (or a feasible nondestructive continuous sampling system developed), it is doubtful that Armour D gages can be produced which are of sufficient longevity and uniformity for the LMFBR Program.

Unfortunately, Armour D alloy $(70 \mathrm{Fe}-20 \mathrm{Cr}-10 \mathrm{Al})$ is difficult to form in certain sizes and conditions, because of the high aluminum content. (Most commercial alloys limit the amount of aluminum to $5 \%$.) If it is not possible to produce Armour D alloy strain gage wire (or foil) of consistent quality, it is recommended that Armour B alloy (67.5 Fe - $25 \mathrm{Cr}-7.5 \mathrm{Al}$ ) be considered because of its lower aluminum content, and the fact that it still has a negative TC. Most commercial alloys suitable as strain gage materials have a positive $\mathrm{TC}$, including the $\mathrm{Fe}-\mathrm{Cr}-\mathrm{Al}$ alloys with up to $5 \% \mathrm{Al}$. Only by utilization of two materials having opposite TC's can temperature compensation be achieved.

The joints for the gages fabricated for this study were made by spotwelding, which may not necessarily produce the most reliable and consistently uniform joint. It is recommended therefore that consideration be given to other joining processes such as laser-ultrasonic-, or electron-beam welding.

\section{LMEC-70-8}


On the basis of the information obtained for gages D-13-2, -13-3, and the gages on specimen D-29, it is concluded that platinum shortens gage life, since gages $D-13-2$ and $-13-3$ are of the same geometry and have the same number of spot-weld joints as the gages on specimen D-29. It is recommended that consideration be given to finding a stronger and more fatigue-resistant material than platinum for the compensating element.

On the basis of the information obtained for specimen D-23, it appears that gage longevity can be significantly increased by using 2-mil-diameter wire rather than 1-mil-diameter wire. It is recommended that further consideration be given to gages of this type.

On the basis of the information obtained to date for the clad gages, the platinum-clad gage is superior to the nickel-clad. Although the evaluation of the former gage is no longer in progress, it appears that this concept deserves further study because of its unusual performance; in terms of longevity, it is one of the best of the gages evaluated. In particular, it is recommended that an effort be made to reduce the magnitude of positive apparent strain by establishing the optimum cladding thickness. Time did not permit this during the pilot effort.

Although the results for the gages with the die-cut platinum elements, which served as temperature-compensating elements and as lead tabs, were not particularly promising, the concept is believed sufficiently attractive to justify further study. The poor performance of these gages (specimens D-26 and -27 ) appears to be due to the fragility of the die-cut elements or to the joint between the element and the Armour D wire.

If an improved Armour B or Armour D alloy is manufactured with consistent and predictable properties, the all-Armour gages (D-13, -19, and -20) should have considerable promise. This would be true in spite of their large apparent strain, since a companion dummy gage, or a half-bridge gage, could then be used to accurately null out the apparent strain for many applications.

Finally, since there is no feasible way of precalibrating each gage; the characteristics (apparent strain vs temperature, gage factor vs temperature, and drift vs time) must be determined on the basis of statistical sampling techniques. The $95 \%$ confidence limits and 95\%-90\% tolerance limits for the gages 
evaluated in this study, including the calibration gages ( $D-35$ through -37 , and AT-1 through -6), indicate gage variations which are larger than permissible for accurate strain measurements on LMFBR components. This is evident from mere inspection of the confidence and tolerance limits and percent deviations for apparent strain, gage factor, and drift; a detailed error analysis is unnecessary. Whether the accuracy of the LMEC gage is good enough for other applications, only the user can decide. In arriving at this decision, the user will have to answer such questions as: Is there a better gage or better technique available? Can the strain (or stress) be calculated more accurately than it can be measured? Will having strain data, which at best is only qualitative or semiquantitative, be better than having no data whatever; and, if so, is the need urgent enough, in terms of cost and project schedule, to justify obtaining it? 